\title{
What we do and do not know about the menstrual cycle or, questions scientists could be asking
}

Sioban D. Harlow

Sara A. Ephross

Follow this and additional works at: https://knowledgecommons.popcouncil.org/departments_sbsr-rh

Part of the Demography, Population, and Ecology Commons, Family, Life Course, and Society Commons, International Public Health Commons, and the Women's Health Commons How does access to this work benefit you? Let us know!

\section{Recommended Citation}

Harlow, Sioban D. and Sara A. Ephross. 1995. "What we do and do not know about the menstrual cycle or, questions scientists could be asking," Robert $\mathrm{H}$. Ebert Program on Critical Issues in Reproductive Health Publication Series. New York: Population Council. 


\section{What We Do \\ and Do Not Know \\ about the Menstrual Cycle; or, \\ Questions Scientists \\ Could be Asking}

by Sioban D. Harlow, PhD

with the assistance of

Sara A. Ephross

\footnotetext{
A report prepared for the Population Council The Robert H. Ebert Program on Critical Issues in Reproductive Health and Population
} 
Copyright May 1995

The Robert H. Ebert Program on Critical Issues in Reproductive Health and Population

The Population Council

One Dag Hammarskjold Plaza

New York, NY 10017

(212) 339-0500

Fax: (212) 755-6052

E-mail: pubinfo@popcouncil.org

Cover and text printed on recycled paper in the USA 


\section{Acknowledgments}

The author would like to thank Donna Baird, Joseph Goldzieher, and Maryfran Sowers for their comments on the manuscript, and Jean Olszewski for her help in preparing the manuscript.

The Population Council is grateful for the support of the Rockefeller Foundation and the John D. and Catherine T. MacArthur Foundation for production of this publication. We would also like to thank Alice Tufel for her professional copyediting. 


\section{PREFACE}

This review piece was commissioned by the Population Council as part of its series published under The Robert H. Ebert Program on Critical Issues in Reproductive Health and Population. The purpose of these publications is to present new, interesting, and innovative thinking on neglected and underrepresented topics.

We believe this paper is one of these important pieces of work that presents a perspective not previously considered and whose ideas may be integrated into a broader conceptualization of women's health. Our goal in presenting it is to expand the boundaries of the discussion on women's health.

The objective of the paper is to consider from a public health perspective the types of questions we might be asking about the relationship between menstrual function and women's health and to evaluate to what extent these questions have, or have not, been addressed by the scientific community. 


\section{TABLE OF CONTENTS}

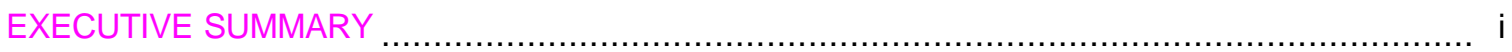

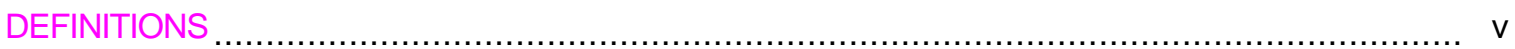

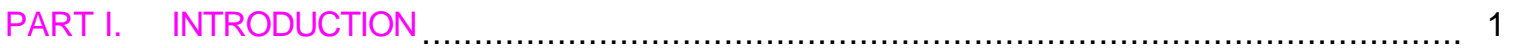

PART II. THE NATURE OF VARIATION IN MENSTRUAL CYCLES FROM MENARCHE TO MENOPAUSE

Menstrual Cycle Length, Duration of Bleeding, and Amount of Flow



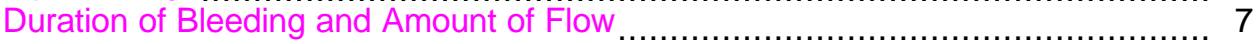

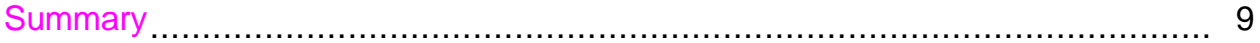

Variability in the Ovarian Cycle: Ovulation, the Follicular and Luteal Phases, and

Periods of Follicular Suppression ....................................................... 9

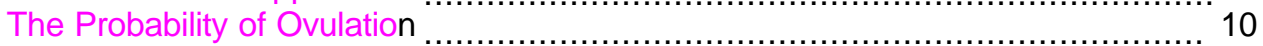

Variability in the Length of the Follicular and Luteal Phases........................... 11

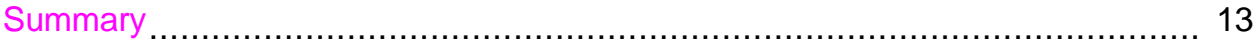

Variability in the Endocrine Cycle: Production, Secretion, and Metabolism of

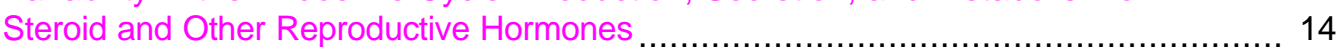

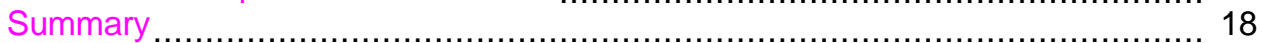

PART III. BEYOND AGING: OTHER HOST AND ENVIRONMENTAL FACTORS THAT

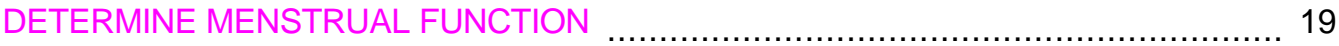

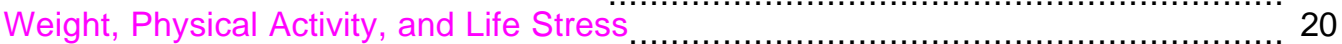

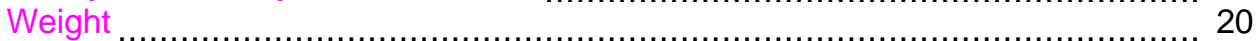

Physical Activity

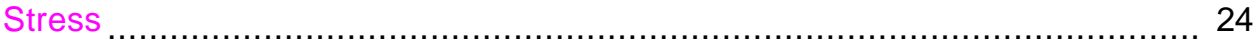

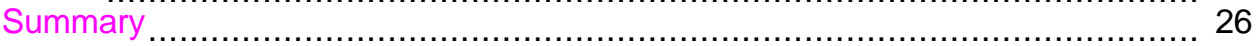

Additional Host and Environmental Factors that May be Important Determinants of

Menstrual Function $\quad 27$

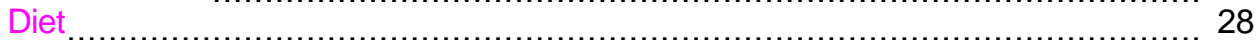

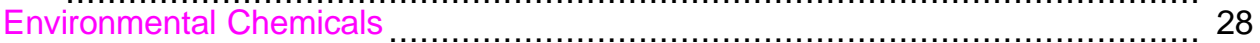

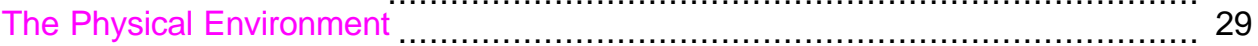



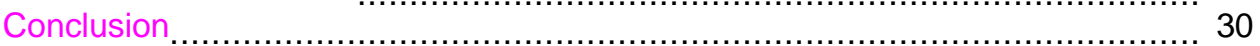

The Importance of Considering Environmental Impacts on Menstrual Endpoints

Other than Ovulation and Cycle Length ......................................................... 31

PART IV. POPULATION PREVALENCE OF MENSTRUAL DYSFUNCTION _........................ 32

Functional Ovulatory Disorders: Anovulation and Luteal Phase Defects ....................... 33

Menstrual Cycle Length Disorders: Amenorrhea and Oligomenorrhea .......................... 34

Bleeding Disorders: Menorraghia and Dysfunctional Uterine Bleeding ......................... 35

Menstrual Cramps: Dysmenorrhea ............................................................ 36

Summary 
PART V. MENSTRUAL CYCLING, PHYSIOLOGIC FUNCTION, AND WOMEN'S LONGTERM HEALTH STATUS 38

Changes in Physiologic Function During the Menstrual Cycle

Immune Function



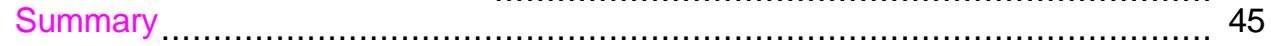

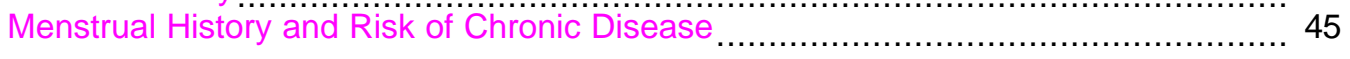

PART VI. DEFINING A RESEARCH AGENDA FOR THE MENSTRUAL CYCLE ..................... 49

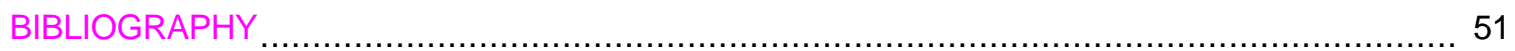

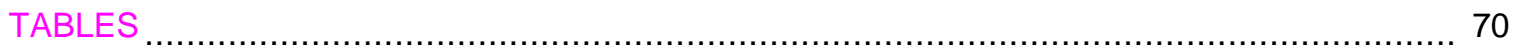




\section{EXECUTIVE SUMMARY}

Periodic bleeding - either its presence or its absence-is an integral part of a woman's experience throughout much of her reproductive life. In addition to the concern provoked by unexplained alterations in bleeding patterns, considerable morbidity is directly attributable to menstrual disturbances. In the United States, among women 25-54 years of age, 2.9 million office visits are made annually for disorders of menstruation. Abnormal bleeding is one of three leading indications for hysterectomy, the most common nonobstetric major surgery for U.S. women. Alterations in menstrual bleeding patterns may also signal potential fertility problems. In addition to these relatively obvious and familiar connections between menstruation and women's health, evidence continues to accumulate which suggests that the endogenous hormonal environment plays a critical role throughout a woman's life in determining her long-term risk of developing chronic diseases such as osteoporosis, cancer, and cardiovascular disease. This report reviews our current knowledge about the menstrual cycle and its relation to women's physical health and considers what new questions we ought to be asking about menstruation.

What is the nature of variation in menstrual cycle characteristics, such as cycle length, amount of bleeding, probability of ovulation, and hormone profiles, across the reproductive life span? Four classic studies provide useful information about changes in population mean cycle length and in population variance from menarche to menopause (for example, the change in average cycle length in a population for women of different ages). These studies describe gross changes in bleeding patterns a woman might expect as she approaches menopause. However, none of these studies provide a detailed picture of menstrual function, nor do they describe the more subtle changes that occur between the ages of 20 and 40 . Age stratified population averages tell us little about variability in cycle length as it is experienced by individual women. Considerably fewer data are available on population distributions of the duration or amount of menstrual bleeding. Currently available data on menstrual cycle length and blood loss lack the detail necessary to enable women and clinicians to anticipate the specific bleeding changes women are likely to experience at different life stages, to differentiate potentially pathological alterations from short-term aberrations, and to identify bleeding patterns that may be risk factors for infertility or for the development of chronic disease.

Data on the probability of ovulation come principally from four relatively small studies that provide estimates of the average per-cycle probability of ovulation at different ages. These studies leave many questions about the process of ovarian maturation and senescence unanswered. Descriptions of within-woman changes in the probability of anovulation over the life course are scarce and data on pattern differentials by region or by other population subgroups are virtually 
nonexistent. Only about five articles provide data on variability in length of the follicular and/or luteal phase. To the extent that population variability in hormone production has been examined, studies have exclusively focused on whether estrogen production was sufficient to achieve ovulation and/or whether progesterone production was sufficient for the retention of pregnancy. Obtaining more detailed and quantitative data on population variability in hormonal patterns will be critical to developing a better understanding of how a woman's endogenous hormonal environment influences her risk of menstrual dysfunction, infertility, and chronic disease. Currently, we know very little about what constitutes meaningful variation in hormone profiles.

In addition to these shortcomings in basic descriptive information on menstrual function, literature on factors that alter or perturb the menstrual cycle is sparse. Marked geographic differences have been reported in the timing of reproductive maturation and, to a lesser extent, senescence. Information on other menstrual parameters is more limited, but provocative data do exist on regional differences in bleeding characteristics. Nonetheless, our knowledge about determinants of variability in menstrual function is largely confined to data measuring the effect of three risk factors (weight, physical activity, and stress) on three menstrual parameters (menstrual cycle length, the probability of ovulation, and adequacy of luteal function). Extremes of weight have been clinically associated with anovulation and amenorrhea, with both absolute weight and change in weight appearing to influence menstrual function. Women athletes have a higher frequency of amenorrhea, anovulation, and luteal phase defects than nonathletes. Recreational exercise can also increase mean menstrual cycle length and the probability of anovulation. Although psychological stress is generally considered a major determinant of menstrual dysfunction, scientific investigation of the association between stress and menstrual function is actually quite limited and consists mainly of studies of the effect of major life changes, of catastrophic events, and of girls leaving home on the probability of amenorrhea.

Additional studies should be undertaken to assess the effect of physical activity and energy expenditure on menstrual function in cultures where women typically are occupied in nonaerobic but energy-intensive tasks such as farming. Similarly, further investigation of the effects of specific stressors and of cumulative life stress on menstrual function is needed. Considerably more attention should be given to other factors that may influence menstrual function, including diet, common environmental chemicals such as pesticides, and diverse aspects of the physical and social environment.

Moving from questions of normal function to the problem of menstrual dysfunction, descriptive and etiologic studies of menstrual disturbances are noticeably lacking, despite a considerable literature on medical and surgical treatment of menstrual disorders. For the more commonly evaluated dysfunctions of anovulation, amenorrhea, and luteal phase defects, research deficiencies 
are primarily etiological. Research needs for abnormal bleeding and dysmenorrhea range from basic issues such as the development of appropriate classification systems and of operational definitions to the overriding need to identify etiologic risk factors.

Finally, considerable data indicate that hormones play an important role both in normal physiologic function and in the development of chronic disease such as breast, endometrial, and ovarian cancer, cardiovascular disease, and osteoporosis. However, mechanisms relating menstrual function to women's long-term health profile are not well understood. Studies of hormonal risk factors for chronic disease have generally used relatively crude markers of endocrine functionfor example, age at menarche, age at menopause, and pregnancy-related variables such as parity or age at first birth. Few studies have examined the role of menstrual history per se or the effect of the endocrine environment on physiologic risk factors for chronic disease. The menstrual cycle appears to modulate several aspects of women's physiology, including heart rate, pulse transit time and blood pressure, energy metabolism, and various aspects of immune function. The physiologic impact of menstrual cyclicity has not been rigorously evaluated.

Based on this review, the need for a comprehensive program of menstrual cycle research is evident. Given our lack of knowledge about fundamental aspects of normal menstrual function and about linkages between the menstrual cycle and other physiologic systems, the importance of conducting basic research before proposing widespread treatment programs cannot be underestimated. Although the National Institutes of Health $(\mathrm{NIH})$ have begun several research initiatives focused on menopause and the health effects associated with the ending of reproductive life, considerably more focus needs to be given to the menstrual cycle itself, as its influence extends over 30 to 40 years of a woman's life. Specific recommendations for research program priorities include the following:

1. More population-based studies of the natural variability in menstrual cycle characteristics across the reproductive life course need to be conducted in ethnically, culturally, and socially diverse populations, with attention to a wider range of host and environmental factors that may influence this variability.

2. Epidemiologic studies should be conducted of age-specific incidence and prevalence of menstrual dysfunction, coupled with case-control studies, to examine etiologic risk factors.

3. Basic research on changes in physiologic function across the menstrual cycle should be undertaken for most physiologic parameters, with a priority focus on cyclic changes in immune function, metabolism, and cardiovascular function.

4. Systematic investigation is needed of the relationship between menstrual cycle characteristics and risk of chronic disease, including evaluation of hormone profiles and physiologic risk factors in premenopausal women. 


\section{DEFINITIONS}

The term "menstrual cycle" refers to a physiologic process that encompasses at least three distinct cyclic phenomena: (1) the growth and shedding of the endometrium, which results in periodic vaginal bleeding; (2) the growth, maturation, and involution of ovarian follicles, which results in the production of ovarian hormones and in ovulation; and (3) the systemic change in production and secretion of reproductive hormones. The term is also used to refer to the global phenomenon that encompasses all three of these cycles. This report uses the following terms to facilitate conceptual distinctions among the different cyclic phenomena.

- Menstrual cycle is used to refer both to the global physiologic phenomenon and to cyclic endometrial bleeding.

- Ovarian cycle is used to refer to cyclic ovarian activity, including folliculogenesis, ovulation, and luteal activity.

- Endocrine cycle is used to refer to the cyclic systemic fluctuations in reproductive hormones, including gonadotropin-releasing hormone $(\mathrm{GnRH})$, the gonadotropins (luteinizing hormone $[\mathrm{LH}]$ and follicle-stimulating hormone $[\mathrm{FSH}])$, and the estrogen and progesterone hormones produced by the ovary.

- Menstrual cycle length is the number of days from the start of one menstrual bleeding period to the start of the next bleeding period.

- Duration of bleeding is the number of days from the start of menstrual bleeding until the start of the next bleed-free interval. 


\section{PART I. INTRODUCTION}

In 1991, a report in the Lancet (Badwe et al., 1991) confirmed previous findings (Hrushesky et al., 1989; Ratajczak et al., 1988) that the timing of surgery during the menstrual cycle influenced breast cancer survival. Women with node-positive premenopausal breast cancer who had surgery during the luteal phase (after ovulation, when progesterone is present) were found to have up to 30 percent better survival than similar women who had surgery in the late follicular phase (before ovulation, when estrogen levels are highest and progesterone is absent) (Badwe et al., 1991; Senie et al., 1991). Although not all reports are consistent (see, for example, Low et al., 1991; Goldhirsch et al., 1991), a meta-analysis indicates that the timing of breast surgery is relevant to survival (Gregory et al., 1992). The number of potentially unnecessary deaths has been estimated to be 600 per year in England alone (Badwe et al., 1991).

This finding provides a provocative illustration of the potential physiologic significance of the menstrual cycle to women's health. Here, cyclic change in the internal endocrine environment appears to alter a woman's natural resistance to carcinogenic growth and metastatic spread. Given extant data on the influence of estrogen on immunologic function and cellular growth, it cannot be argued that elucidation of the relationship between timing of surgery and breast cancer survival was dependent upon a new and important scientific discovery. Rather, someone needed to begin asking more penetrating questions about the medical implications of women's cyclic physiology.

Whether the problem lies in a trivialization of menstrual morbidity or in a failure to recognize the impact of women's reproductive biology on nonreproductive disease processes, scientific investigation of the menstrual cycle has been limited and disjointed. Until recently, the possibility that menstrual function could influence various disease processes seldom penetrated scientific paradigms for research on women. All too often, the menstrual cycle is viewed solely as a mechanism to achieve pregnancy. Recent initiatives within the National Institutes of Health to describe the natural history of menopause and concurrent changes in metabolism, immune function, and cardiovascular function indicate that new paradigms of women's health are emerging. However, such efforts focus primarily on the cessation of menstruation.

Recognizing the relevance of menstrual function to women's physiology is not the same as assuming that women's health is wholly determined by their reproductive hormones. Certainly, medical science has also erred in its tendency to accept that certain diseases-for example, premenstrual syndrome-are wholly caused by hormonal imbalances. Nonetheless, the continued failure to perceive and investigate linkages between menstruation and women's health carries a great cost.

Periodic bleeding, whether in its presence or absence, is an integral part of a woman's 
experience throughout much of her reproductive life. In addition to the concern provoked by unexplained alterations in bleeding patterns, considerable morbidity is directly attributable to menstrual disturbances. In the United States, among women 25-54 years of age, 2.9 million office visits are made annually for disorders of menstruation, of which 1.9 million are for heavy bleeding, menorraghia, or dysfunctional uterine bleeding (National Ambulatory Care Survey, 1985, unpublished data). Among women 35-44 years of age, the annual visit rate for abnormal bleeding is 7.2 visits per 100 women. Abnormal bleeding is also one of three leading indications for hysterectomy, the most common nonobstetric major surgery for U.S. women, totaling over 500,000 operations annually (Graves, 1992; Bernstein et al., 1992). A recent study in India has shown that menstrual disturbances also appear to be a common complaint in nonindustrialized countries, although such problems are often not brought to medical attention (Bang et al., 1989). As a primary marker of ovarian function, menstruation is also an important signpost of a woman's reproductive health. Altered ovarian function, including anovulation and luteal phase defects, is a major cause of female infertility, and alterations in menstrual bleeding patterns may signal potential fertility problems. Despite this considerable clinical morbidity, neither the nature of normal variability in menstrual function nor the etiology of menstrual dysfunction are well understood.

Separate from these relatively obvious and familiar connections between menstruation and a woman's health, the menstrual cycle also defines and reflects a woman's internal endocrine environment. Evidence continues to accumulate which suggests that this endogenous hormonal environment plays a critical role throughout a woman's life in determining her long-term risk of developing chronic diseases such as osteoporosis, cancer, and cardiovascular disease (Sherman et al., 1982; La Vecchia et al., 1985; Olsson et al., 1983; Parazzini et al., 1989; Gao et al., 1987; Sowers et al., 1990, Barrett-Connor and Bush, 1991). However, limited data are available on how the hormonal environment differs from woman to woman, and mechanisms that relate hormonal variation to a woman's disease risk are not well defined. One important area requiring further investigation is the role of the menstrual cycle in modulating normal physiologic function. For example, systematic fluctuations in lymphocyte counts across the menstrual cycle have been demonstrated (Mathur et al., 1979) and a woman's risk of developing a Candida infection appears to differ in the follicular and luteal phases (Kalo-Klein and Witkin, 1989). Yet, even though a vast literature exists about the in vitro effects of estrogen and progesterone on immune function, changes in immune response across the menstrual cycle have never been systematically evaluated. Ultimately, evaluation of the health consequences of hormonal contraception and hormone replacement therapy (HRT) and identification of "optimal" treatment regimens will require a better understanding of the complex relationship between menstrual function, women's physiology, and women's disease risk. 
The objectives of this report are to review our current knowledge about the menstrual cycle and its relation to women's physical health, to consider what new questions we ought to be asking, and to develop recommendations for a program of epidemiologic research on menstruation. Although the focus is on the endogenous menstrual cycle, the importance of linking research about the endogenous endocrine environment with research on the health implications of pharmacologic interventions is discussed. The report is organized into six major sections. Following this Introduction, Part II describes what we know about biologic variability in menstrual bleeding patterns and ovarian activity across the reproductive life course. Part II is followed by a review of the literature on host and environmental factors that perturb menstrual function, and proposals for new avenues for etiologic research. The next section, Part IV, considers menstrual morbidity, focusing specifically on problems in defining menstrual dysfunction. Part $\mathrm{V}$ addresses the relationship between menstrual cycling, the endocrine environment, and women's physiology. Implications for women's long-term health and for epidemiologic studies of women's health are also considered. The final section proposes a research agenda.

The strategy of this report is not to provide a detailed compendium of the scientific literature. Rather, the aim is to outline the dimensions (or limitations) of our knowledge and, thereby, to inspire a vision of a comprehensive research program on the menstrual cycle. 


\section{PART II. THE NATURE OF VARIATION IN MENSTRUAL CYCLES FROM MENARCHE TO MENOPAUSE}

The medical textbook image of the 28-day menstrual cycle is an idealized model of the hormonal changes that occur during an ovulatory menstrual cycle. The majority of women, however, neither consistently experience 28-day cycles nor ovulate precisely on day 14 , and most women experience numerous changes in their menstrual cycle patterns during their reproductive life span. In order to gain a better understanding of menstrual function and dysfunction, we must first understand how women's cycles depart from this idealized medical model. Since most biologic systems exhibit some amount of noise, it is important to differentiate this biologic noise from variation attributable to perturbation of the system. As is shown here, however, the way in which these two distinct sources of variability influence length of the menstrual cycle, follicular phase and luteal phase, duration of menstrual bleeding, or level of hormone production is not well described.

Consider, for example, what is known about variation in the length of the menstrual cycle. We know something about the frequency with which a cycle of 24 , or 32 , or 29 days will occur within a population of women and about changes in the frequency of very long and very short cycles that occur after menarche and before menopause. However, few quantitative data are available to explain how cycle length or bleeding duration varies from cycle to cycle within a woman over time, or how that pattern of variation may differ from woman to woman, or how these patterns change as women age. Similarly, some data are available about the range of variability in length of the follicular and luteal phases and about how luteal phase length is related to reproductive function. However, descriptions of changes in phase length from cycle to cycle within a woman as she ages are scant. The variability in patterns of hormone production, metabolism, and excretion remain virtually unexplored.

\section{Menstrual Cycle Length, Duration of Bleeding, and Amount of Flow Cycle Length}

Information on the length and variability of the menstrual cycle throughout a woman's reproductive life comes predominantly from the seminal works of Matsumoto et al. (1962), Treloar et al. (1967), Chiazze et al. (1968), and Vollman (1977), who investigated menstrual bleeding patterns among white U.S. (Treloar), U.S. and Canadian (Chiazze), Swiss (Vollman), and Japanese (Matsumoto et al.) women. Participants in these studies kept menstrual diaries for varying lengths of time; both the Treloar and Vollman studies include records of bleeding patterns throughout a woman's reproductive life. More recently, the World Health Organization (WHO) has published data from a series of studies that followed women for short periods of time but included women from both 
industrialized and nonindustrialized countries (WHO, 1981, 1983, 1986). A scattering of other small studies provide data on menstrual function in, for example, adolescent Swiss (Flug et al., 1984) and Nigerian (Thomas et al., 1990) girls, and in young adult Mexican women (Alvarado et al., 1988). For the most part these studies corroborate previous findings on age-related variation in menstrual cycle length. With few exceptions, they are not sufficiently detailed to enable evaluation of regional differences in menstrual cycle characteristics. (See Part III of this report.)

The large-scale prospective studies summarized data on menstrual cycle length across the reproductive life span by describing the distribution of cycle lengths within each age strata in what is essentially a series of cross-sectional analyses (see Table 1). The picture is fairly consistent across studies. Population variability in menstrual cycle length is greatest immediately after menarche and shortly before menopause, with the menarcheal and menopausal transitions lasting two to five years. Both periods are characterized by an increased frequency of both very long and very short cycles, as well as by an increased range of cycle lengths. For example, in the Treloar et al. (1967) data, during the first year of menstruation, cycle lengths span 65 days-ranging from 18 to 83 days-when 95 percent of all cycles are considered. By the fifth year post-menarche this range drops to 19 days. Two years before the onset of menopause this range once again increases to 65 days. Cycle length from age 20 to age 40 exhibits considerably less variability, although the observed population mean cycle length gradually shortens by two to three days over the course of these two decades.

These classic studies have provided extensive and useful information about changes in population mean cycle length and in population variance from menarche to menopause. In other words, these data tell us what the average cycle length would be in a population of women of a given age. They also provide information about the type of gross changes in bleeding patterns a woman might expect as she approaches menopause. However, they do not provide a very detailed picture of menstrual function. The more subtle changes that occur between the ages of 20 and 40 are not well described and the significance of the gradual shortening of population mean cycle length for an individual woman is unclear. The same cross-sectional data would be generated if each woman's cycle length gradually changed with age or if each woman's cycle length abruptly changed over a relatively short period and different women experienced this change at slightly different ages. Findings from one study suggest that the abrupt-change scenario may be a more accurate description of the experience of individual women, as a sudden increase in long menstrual cycles was observed in women at the start of perimenopause (Metcalf, 1979, 1983). A more precise understanding of the subtler changes occurring during these decades may give a better insight into age-related changes in fertility and help women predict their expected time of menopause. 
An allied problem is that prior analyses have focused solely on population-averaged changes; menstrual cycle length variations from cycle to cycle within a woman are not addressed. To understand this point, consider the following simple example. Suppose we have two "populations" of three women each. We have observed the length of three consecutive menstrual cycles in each woman, as shown below. In population A, each woman maintains a stable cycle length over time. In population $B$, cycle length varies within each woman over time.

\begin{tabular}{|c|c|c|c|c|c|c|}
\hline \multicolumn{7}{|c|}{$\begin{array}{c}\text { Menstrual cycle lengths for three consecutive cycles } \\
\text { in two hypothetical populations }\end{array}$} \\
\hline & \multicolumn{6}{|c|}{ Number of days per cycle, for three consecutive cycles } \\
\hline & \multicolumn{3}{|c|}{ Population A } & \multicolumn{3}{|c|}{ Population B } \\
\hline Variable & 1 & 2 & 3 & 1 & 2 & 3 \\
\hline Woman \#1 & 20 & 20 & 20 & 20 & 30 & 40 \\
\hline Woman \#2 & 30 & 30 & 30 & 40 & 20 & 30 \\
\hline Woman \#3 & 40 & 40 & 40 & 30 & 40 & 20 \\
\hline Ponulation mean & 20 & 20 & 20 & 20 & 20 & 30 \\
\hline Population median & $\frac{30}{30}$ & $\frac{30}{30}$ & $\frac{30}{30}$ & $\begin{array}{l}30 \\
30\end{array}$ & $\frac{30}{30}$ & $\frac{30}{30}$ \\
\hline Population variance & 67 & 67 & 67 & 67 & 67 & 67 \\
\hline
\end{tabular}

The population mean, median, and variance describe the distribution of cycle lengths in each population at each of the three time points. In the example shown above, the population statistics are the same in both groups of women despite the fact that the experiences of the individual women are very different. Age-stratified population averages tell us nothing about variability in cycle length as it is experienced by individual women. The classic studies discussed above provide excellent descriptions of the average menstrual experience of a population; however, they provide very little information about the dynamics of menstrual cycling within individual women.

In fact, virtually no information exists on how cycle length varies from one cycle to the next in individual women. If, for example, a woman had a 48-day menstrual cycle this month, what is the probability that next time her cycle would be 23 days, or 29 days, or 48 days again? Would that probability be the same when she is 45 years old as it was when she was 35 , or 25 years old? Data from the only two studies (Matsumoto et al., 1962; Harlow and Zeger, 1991) that provide quantitative estimates of such probabilities are summarized in Tables 2 and 3 . Both studies show that, regardless of the length of the previous cycle, most cycles will fall in the midrange of cycle lengths (approximately 26-34 days). Very long cycles and very short cycles do tend to recur, but the probability of such recurrence is low. Given the existence of age-related changes in menstrual cycle length and variability, one might expect that age-related changes in transition probabilities also occur, although available data do not permit us to evaluate such age effects. Better 
descriptions of the dynamics of menstrual cycling would not only be useful clinically in evaluating menstrual morbidity, but may also be important in identifying subgroups at risk of developing chronic disease.

Finally, the classic studies provide only a limited understanding of menstrual function because descriptions that solely examine changes in the mean and spread about the mean can never fully explain the phenomenon of menstrual variability (Harlow and Zeger, 1991). Harlow and Zeger (1991) have argued that the distribution of cycle lengths comprises two salient features: an approximately symmetric unimodal part and a very long right tail. Part of the problem with the current medical model of a 28-day menstrual cycle is that it is not clear how to extend this model to incorporate the phenomenon of very long cycles or amenorrhea (that is, cycles that fall in the tail of the distribution). Both Treloar et al. (1967) and Vollman (1977) noted that in the years approaching menopause, they observed an increased frequency of both very long and very short cycles. Exercise and certain stressors have also been shown to increase the number of observations in the right tail and shift the mode in the symmetric part of the distribution to the left (Bernstein et al., 1987; Bullen et al., 1985; Dale et al., 1979; Harlow and Matanoski, 1991). These two changes occurring simultaneously may leave the mean unchanged. Similarly, a change in the mean could reflect either a true shift in the modal value or an increased probability of having cycles in the tail of the distribution. Further analysis of the shape of the population distribution of menstrual cycle lengths and of changes in the shape of this distribution over age could provide us with a better understanding of ovarian biology and, therefore, help us develop clearer definitions of menstrual abnormality. At the very least, a medical model of ovarian function should portray ovarian activity for the entire range of menstrual cycle lengths (see Variability in the Ovarian Cycle).

\section{Duration of Bleeding and Amount of Flow}

Despite the shortcomings of information on menstrual cycle length, considerably more data are available about cycle length than exist about population distributions of the duration or amount of menstrual bleeding. Among the large population-based studies cited above, only Matsumoto et al. (1962) reported on length of the bleeding episode and subjective amount of flow (that is, a woman's perception of her flow as scanty, moderate, or profuse). In this study, duration of bleeding after ovulatory cycles ranges from two to twelve days, with 80 percent of bleeds lasting from three to six days ( mode $=5$, mean $=4.6$, standard deviation $[S D]=1.3$ ) and the heaviest flow usually reported on the second day. Long menstrual periods (more than eight days) were associated with ovarian dysfunction, being more common in anovulatory cycles and in cycles with an inadequate luteal phase.

The most comprehensive information on actual blood loss comes from a population-based 
study conducted in Sweden (Hallberg et al., 1966) (see Table 4). Mean volume of blood loss per bleeding episode was 43.4 milliliters, with blood loss ranging from 10 to 84 milliliters in 80 percent of the episodes. Among women who considered their bleeding to be normal, mean blood loss was somewhat lower (38.5 milliliters), while the mean for women with subjectively normal blood loss who also had adequate iron levels was 10 milliliters lower (33.2 milliliters). After comparing data from women with and without adequate iron levels and from women who did and did not consider their menstruation to be "abnormal," these investigators defined the upper limit of normal blood loss to be 80 milliliters.

As is true for menstrual cycle length, bleed characteristics apparently vary during the reproductive life course, with the greatest extremes occurring during the menarcheal and menopausal transitions. Women over the age of 35 appear to bleed about half a day less than women aged 20-24 (Matsumoto et al., 1962), to experience fewer bleeds longer than seven days (Collett et al., 1954), and to subjectively report lighter flow (Matsumoto et al., 1962). After menarche, and presumably before menopause, menstrual periods are more frequently extremely long or extremely short (WHO, 1986). In terms of actual blood flow, 15-year-old girls bled 1-2 milliliters less and 50-year-old women bled about 6 milliliters more than women aged 20-45 (Hallberg et al., 1966). Women approaching menopause were more likely to experience very heavy bleeding (90th percentile=133 milliliters in women aged 50) than were younger women (for example, 90 th percentile $=86-88$ milliliters for women aged 30-45). Although the general boundaries of normal blood flow are identified by these few extant studies, no detailed picture of expected changes in blood flow over the reproductive life span, or of bleeding changes from menstruation to menstruation within a woman, is provided.

The absence of data that characterize bleeding changes as women approach and pass through the menopause is of particular concern given the high rate of medical visits for abnormal bleeding and the prevalence of hysterectomies after age 35. Given the importance of learning more about patterns of blood loss, the fact that subjective reports of amount of blood flow are only moderately correlated with measured blood volume presents an important methodologic and public health problem. Although mean blood loss for women who report heavy bleeding is greater than mean loss for women who report light or moderate bleeding, many women who experience considerable blood loss do not report excessive bleeding (Hallberg et al., 1966; Fraser et al., 1984, 1985). Hallberg et al. found that 37 percent of women with more than 80 milliliters of blood loss reported their bleeding as moderate. Conversely, 14 percent of those who lost less than 20 milliliters of blood considered their bleeding to be heavy. These data suggest that, although on average women have some idea of how their blood flow compares on a scale of light to heavy bleeding, at the individual level women have no real criterion on which to grade the severity of their 
own blood loss. Perceptions of blood loss are likely to depend on a woman's own previous experience and self-report appears to be both fairly accurate in describing relative changes within the individual and predictive of ovulation (Campbell and Gray, 1993). However, the high degree of misclassification of actual blood loss by subjective report indicates that self-reports are not sufficient for clinical diagnosis of pathological conditions such as menorraghia (Fraser et al., 1984). Obviously, better clinical and research tools for the measurement of menstrual blood loss are needed. However, the fact that no common popular conception exists about how much bleeding constitutes "too much" suggests that public education campaigns are also needed in order to create a better awareness of what constitutes menstrual dysfunction in the community. Objective criteria will need to be developed by which women can self-rate their daily blood loss in order to gain a better appreciation of the qualitative and quantitative changes that they will experience over their reproductive life span.

\section{Summary}

Available data on population distributions of menstrual cycle length and blood loss, though useful, lack the detail necessary to enable women and clinicians to anticipate the specific bleeding changes women are likely to experience at different life stages, to differentiate potentially pathological alterations from short-term aberrations, and to identify bleeding patterns that may be risk factors for infertility or for the development of chronic disease. Our ability to more clearly define menstrual dysfunction and to relate menstrual function to fertility or long-term risk of chronic disease will require more precise information on these patterns of variation and the dynamics of menstrual cycling.

\section{Variability in the Ovarian Cycle: Ovulation, the Follicular and Luteal Phases, and Periods of Follicular Suppression}

Descriptions of the ovarian cycle are generally oriented toward the critical event of ovulation, with the ovarian cycle depicted as a two-phase phenomenon-the follicular phase corresponding to the pre-ovulatory period of gonadotropin-dependent follicular growth, and the luteal phase corresponding to the post-ovulatory follicular luteinization and regression. Investigations into the population variability in ovarian function thus focus on these three phenomena: the probability of ovulation, the length of the follicular phase, and the length of the luteal phase.

\section{The Probability of Ovulation}

Data on population distributions of the probability of ovulation come principally from four studies. In their longitudinal studies, Vollman (1977) and Matsumoto et al. (1962) both obtained 
basal body temperatures (BBTs) on subsamples of women. Doring (1969) charted BBTs and Metcalf (1983) assayed urine for pregnanediol (a metabolite of progesterone) in age-stratified samples of German women and New Zealand women of European descent, respectively. Table 5 summarizes these data on the probability of ovulation by age and menstrual cycle length.

As can be seen from the table, anovulation is associated with menstrual cycle length: short and long cycles are 10-30 percent more likely to be anovulatory than are cycles of about 25-35 days. Given this association, it is not surprising that the probability of anovulation is greatest during the postmenarcheal and premenopausal years, when long and short cycles are also more common. From about age 25 to 39, the years of relative stability in menstrual function, approximately 2-7 percent of cycles are anovulatory. In contrast, 50-60 percent of cycles in 10-14-year-old girls and about 34 percent of cycles in women over age 50 are anovulatory.

In fact, much of the age-related change in the probability of ovulation appears to be directly associated with the corresponding age-related variability in menstrual cycle length. Among women approaching menopause, an increased frequency of anovulation was apparent only in those women who had also experienced the onset of episodes of oligomenorrhea (an increased frequency of cycles longer than 35 days). Among women aged 40-55, 95 percent of those with no recent change in menstrual cycle length ovulated consistently, compared with only 34 percent of those who reported a recent history of oligomenorrhea (Metcalf, 1979). However, the data also indicate that age has an independent influence (Metcalf, 1983), as the probability of anovulation differs between adolescents and older women for any given range of cycle lengths. A more precise understanding of how the coupling of ovarian and endometrial function changes with age may provide important insights as to why the frequency of menorraghia (heavy or prolonged bleeding) increases in older women. As was true for menstrual characteristics, simple population estimates of the average per-cycle probability of ovulation leave many questions about the process of ovarian maturation and senescence unanswered. Descriptions of within-woman changes in the probability of anovulation over the life course are scarce, as are data on how these patterns may differ by region or by other population subgroups.

\section{Variability in the Length of the Follicular and Luteal Phases}

Only about five articles provide data on variability in length of the follicular and/or luteal phase (see Table 6) and, as is true for other menstrual cycle characteristics, the data are limited to crosssectional population averages. Since estimation of phase length requires determination of the timing of ovulation, differences in methods used to assess ovulatory status and in rules used to define the start of the luteal phase create some disparities in phase length estimates. Differences in eligibility criteria also have a marked effect on follicular phase estimates. The term "follicular 
phase" actually refers to gonadotropin-dependent follicular growth, and it is not at all clear to what extent such growth is taking place at the beginning of very long or anovulatory menstrual cycles. Since the start of this gonadotropin-dependent growth is not easily measured, several investigators restricted their samples to ovulatory cycles within a defined range of menstrual cycle lengths (WHO, 1983; Landgren et al., 1980; Lenton et al., 1984a,b) and thus limited the potential length of the follicular phase, a priori.

The World Health Organization (WHO) characterized the distribution of ovarian-phase lengths among women participating in "natural" family planning trials in five countries, estimating day of ovulation by the peak day of cervical mucus (WHO, 1983). Three studies characterized phase length based on daily hormonal profiles from volunteer samples of Swedish and English women with "regular" ovulatory menstrual cycles (Landgren et al., 1980; Lenton et al., 1984a,b). In contrast with other investigators, Lenton et al. (1984a) do not include the day of presumed ovulation in their calculation of the length of the follicular phase. Vollman (1977) and Matsumoto et al. (1962) also report information about population distributions of ovarian-phase lengths with timing of ovulation determined by basal body temperatures. Neither of these latter investigators restricted menstrual cycle length and, consequently, their estimated range of "follicular"-phase lengths differs from the other three studies.

Although the luteal phase is generally described as being considerably less variable than the follicular phase (see, for example, Speroff et al., 1983), this belief is not borne out by the data, if the definition of the follicular phase is limited to the presumable period of gonadotropin-dependent folliculogenesis. As can be seen in Table 6, in the three studies that exclude long menstrual cycles, the follicular phase varies in length from approximately 10 to 23 days (mean=13-15 days), while the luteal phase varies from 8 to 17 days (mean=13-14 days). Inclusion of longer menstrual cycles yielded larger estimates of mean length of the follicular phase (17-18 days) (Matsumoto et al., 1962; Vollman, 1977); however, the 10th to 90th percentiles (13-24 days) are roughly consistent with the other studies. Estimates of luteal phase length are fairly consistent across studies. Length of the follicular and length of the luteal phase are each positively correlated with menstrual cycle length in ovulatory menstrual cycles ( $r=0.55$ and 0.62 , respectively) and negatively correlated with each other $(r=-0.31)$ (WHO, 1983).

As is true for other menstrual cycle characteristics, length of the ovarian phases, especially the follicular phase, changes across the reproductive life span. Mean length of the follicular phase declines from about 14 days at ages 18-24 to about 10.5 days at ages 45-60. Short luteal phases (less than 11 days) are more frequent in both younger and older women (Lenton et al., 1984a,b), but Vollman's data (1977) suggest that once reproductive maturity is attained luteal-phase length remains relatively constant through menopause. From about age 23 through menopause, 
approximately 15 percent of menstrual cycles had short luteal phases. Thus, the increased frequency of very short menstrual cycles at the end of the reproductive life span appears to be due primarily to the increased frequency of short follicular phases (see also Sherman et al., 1979).

However, having reviewed this literature on the probability of ovulation and length of the follicular and luteal phases, it is important to point out that these three phenomena, derived from the classic two-phase model of the ovarian cycle, do not encompass the full range of ovarian function, and thus do not allow for a comprehensive description of the interlinkages between endometrial and ovarian activity. The limitations of the classic two-phase model of ovarian activity become readily apparent in the discrepant definition of the "follicular" phase noted above. Amenorrhea and long cycles correspond to menstrual cycle lengths that fall in the long right tail of the distribution of menstrual cycle lengths. These menstrual phenomena are not explicitly incorporated into the classic two-phase model of ovarian function.

Harlow and Zeger (1991) have argued that a simple extension of the current ovarian model could provide a more complete description of the menstrual cycle. The new model would add a lag time between the end of one ovarian cycle and the successful initiation of the next ovarian cycle. This lag time, referred to as the "waiting period," could reflect an extended period of follicular suppression during which the appropriate conditions for recruitment of a new cohort of follicles are not met (Baird, 1987). Alternative hypotheses of the ovarian events that may underlie this lag period, such as repeated early death of the dominant follicle, are also possible. More information about the hormonal patterns that underlie long menstrual cycles will be needed before specific hypotheses can be definitively evaluated. Nonetheless, an explicit extension of the current twophase model of ovarian cycling to what might be considered a three-phase model offers the possibility of evaluating ovarian activity consistent with both normal menstrual cycling and with delayed menstruation or amenorrhea within a single conceptual framework.

The literature on population variability in ovarian function generally ignores this "waiting period" or phase of follicular suppression. As was noted above, investigators either explicitly restrict their study populations to women with ovulatory menstrual cycles of less than 35-40 days or they define all activity prior to ovulation as "follicular" regardless of the time elapsed from start of menses to ovulation. More clarity about this "third" phase of ovarian function might help elucidate the nature and etiology of menstrual dysfunction as well as the timing of menopause. The literature on lactational amenorrhea offers an interesting model for understanding the phenomenon of follicular suppression and provides some extended series of daily hormonal data (see, for example, Shaaban et al., 1987). Similar data on hormonal parameters in nonpostpartum, nonconception menstrual cycles that last longer than about 40 days are more limited (Matsumoto et al., 1979; Sherman et al., 1979; Metcalf et al., 1982), although recent epidemiologic studies on early pregnancy loss 
should contribute to this literature. These limited data suggest that follicular suppression does occur in many long menstrual cycles but aborted folliculogenesis or otherwise incomplete ovarian cycles also are evident.

\section{Summary}

The literature on variability in ovarian function is sufficient to provide estimates of the average probability of ovulation by age and menstrual cycle length and of the range of variation in the length of the follicular and luteal phases. However, it does not provide a complete picture of ovarian function. No data exist on within-woman variability in ovarian function from cycle to cycle over the reproductive life course. Considerably more investigation is obviously needed to define and describe the ovarian activity underlying the "follicular" phase in long menstrual cycles. An even more important consideration, however, is that evaluation of phase length and the probability of ovulation for the most part begs the question of variability in ovarian hormone production. To the extent that hormone production has been examined, investigations have focused on whether estrogen production was sufficient to achieve ovulation or whether progesterone production was sufficient for the retention of a pregnancy. Although some data exist about changes in the height of the progesterone peak under certain conditions and on changes in estrogen levels with age, few quantitative data exist on population or within-woman variability in hormonal patterns. Substantive evaluation of hormonal patterns is important, not only because such evaluation may lead to a better understanding of menstrual and reproductive dysfunction, but also because it will elucidate how the hormonal environments of women differ. In the final analysis, it is these differences in women's endogenous endocrinologic environments that should explain differences in disease risk.

\section{Variability in the Endocrine Cycle: Production, Secretion, and Metabolism of Steroid and Other Reproductive Hormones}

Most studies on reproductive hormones have focused primarily on explaining the general pattern of "normal" function (that is, mean and peak levels and shape of the curve) as opposed to describing the variability in hormonal profiles. One of the few investigations of the population distribution of hormonal levels is the study by Landgren and colleagues (1980) mentioned above. Table 7 presents the range of mean and peak levels for each of the four major reproductive hormones observed in 68 ovulatory menstrual cycles with lengths from 25 to 36 days. In addition to describing the range of hormonal values, this study also provides preliminary observations on the relationships between hormone levels and quality of the ovarian cycle (as measured by cycle and phase lengths) and on the nature of variability in hormonal patterns.

As is summarized in Table 8, levels of estrogen production and LH secretion appear to be 
important determinants of the quality and function of the entire ovarian cycle, while progesterone production is relevant only to the quality of luteal function. High levels of estrogen during the first six cycle days were associated with a shorter follicular phase $(r=-0.53)$ and a shorter menstrual cycle $(r=-0.44)$. High preovulatory peak estrogen levels were correlated with shorter follicular phases $(r$ $=-0.32$ ). On the other hand, high levels of $\mathrm{LH}$ three to seven days before the $\mathrm{LH}$ peak were associated with both a longer follicular phase $(r=0.43)$ and longer menstrual cycles $(r=0.45)$; high peak levels of LH were also correlated with long menstrual cycles. High peak progesterone levels were associated with a long luteal phase $(r=0.27)$. FSH, though clearly critical to folliculogenesis and the selection of a dominant follicle, was less predictive of the quality of a given ovarian cycle, as FSH levels were not associated with length of ovarian phase or menstrual cycle. These findings provide some of the first data about the interrelationship between various hormonal, ovarian cycle, and menstrual cycle parameters. Further exploration of these relationships may help in defining menstrual dysfunction, in understanding the etiology of menstrual dysfunction, and in identifying a more parsimonious and meaningful set of parameters to use in epidemiologic research.

In regard to hormonal patterns, these data suggest that a given ovarian cycle tends to have consistently high or consistently low LH and estrogen levels relative to other cycles (that is, one LH parameter will sort cycles into the same relative groupings as any other LH parameter), whereas the relative magnitude of $\mathrm{FSH}$ values tends to vary across a given ovarian cycle. It would be of interest to know whether this relative sorting by LH and estrogen levels is consistent across successive cycles for a given woman. We might expect that an individual woman would tend to have ovarian cycles with consistently high or low LH values, but in order to understand menstrual dysfunction, it is also of interest to learn more about variability in levels from ovarian cycle to ovarian cycle. Understanding more about the relative patterns of hormone production from woman to woman is critical to understanding how differences in women's endogenous hormonal milieu influence their risk of menstrual dysfunction, infertility, and chronic disease. Currently, we know very little about what constitutes meaningful variation in hormonal patterns.

Given interest in the processes of ovarian maturation at puberty and senescence at menopause, some information is available about how hormone levels change with age (Table 9). Sherman et al. (1979) compared mean plasma LH, FSH, estradiol, and progesterone levels in women aged 18-30 who had ovulatory menstrual cycles and no evidence of luteal phase inadequacy with plasma hormone levels in women aged 40-45 and 46-56. Metcalf and colleagues (Metcalf, 1979; Metcalf and MacKenzie, 1980; Metcalf and Livesey, 1985) compared LH, FSH, and the urinary progesterone metabolite pregnanediol in weekly urine samples in a larger sample of women between the ages of 20 and 55 over multiple cycles. Neither group of investigators found differences in progesterone levels with age. The reported decreases in estrogen and increases in 
FSH observed in older women are now commonly understood phenomena. LH levels also appear to increase slightly with age: although in the Sherman et al. study this increase was not statistically significant, their sample size was quite small.

Metcalf and colleagues have tried to distinguish the effect of age from the effect of approaching menopause on hormone production. Although no significant differences are observed in the magnitude of the pregnanediol peak in menstrual cycles of 21-35 days duration as women age (Metcalf, 1979; Metcalf and MacKenzie, 1980), pregnanediol levels do appear to decrease during the menopausal transition. Women aged 40-55 who experienced anovulatory menstrual cycles also had significantly lower pregnanediol levels in their ovulatory cycles (mean $=8.7 \mu$ mols $/ 24$ hours). This finding - that progesterone production varies little with age until the onset of the menopausal transition-is consistent with the fact that length of the luteal phase is relatively ageinvariant. On the other hand, FSH and, to a lesser extent, LH levels do appear to exhibit agedependent changes that are unrelated to the proximity of menopause (Table 9) (Metcalf and Livesey, 1985). However, the change in gonadotropin levels in women over 40 who have entered perimenopause is considerably more marked (60.6 percent excreted more than 5 International Units/24 hours, compared with 31.5 percent of women over 40 who were not in perimenopause). Metcalf and Livesey postulate that the age-related change in FSH secretion reflects changes in the pituitary's sensitivity to estrogen feedback. The more pronounced and abrupt change in pituitary function that occurs at the onset of the menopausal transition is not, they argue, as easily explained by a similar alteration in feedback sensitivity.

Actual menopause, interestingly, is not associated with any specific, or predictive, hormonal change (Metcalf et al., 1982). Although transition into perimenopause is usually marked by a sudden increase in the occurrence of long menstrual cycles and anovulation, an increase in the probability of observing high levels of $\mathrm{FSH}$, and a decrease in mean estrogen levels, the last menstrual cycle in a woman's life can nonetheless be ovulatory with normal luteal function (Metcalf et al., 1982). The only change Metcalf and colleagues noted at menopause was that after menopause no evidence of luteal development could be detected. No clear alteration was observed in $\mathrm{LH}, \mathrm{FSH}$, or estrogen secretion, although slight, but barely significant, increases were noted in levels of FSH and LH 15-20 weeks after the last bleed. Thus, the characteristic low estrogen and high gonadotropin levels of older women appear to evolve gradually after the last bleed.

Despite these relatively scant data, sufficient evidence indicates that, in addition to the abrupt hormonal alterations associated with the menarcheal and menopausal transitions, potentially meaningful alterations may also occur in a woman's endogenous hormonal environment throughout her reproductive life. For example, although mean estrogen levels do not seem to vary dramatically during the reproductive life cycle, the fact that menstrual cycles tend to be shorter after age 30-35, 
that shorter menstrual cycles are associated with shorter follicular phases, and that shorter follicular phases are associated with higher estrogen levels suggests that hormonal patterns across the menstrual cycle probably do alter as a woman ages. It is this latter line of questioning, which begins to look for variation in hormonal patterns and to consider the implications of this variation for the endogenous hormonal milieu, that is critical to elucidating the relationship between the endogenous hormonal environment and women's health.

Two very important dimensions of the hormonal environment that require further investigation are pathways of hormonal metabolism and fundamental genetic differences in hormone response. It has long been observed that women tend to have somewhat various bleeding patterns: some women usually have relatively short menstrual cycles while others usually have relatively long cycles. Some women seem prone to amenorrhea while others never experience amenorrhea. Heterogeneous risk in the probability of having a spontaneous abortion has also been described (Wilcox and Gladen, 1982). These basic differences in menstrual bleeding patterns and reproductive behavior suggest that within the population of women meaningful genetic differences in menstrual function exist. More systematic and directed investigation into genetic heterogeneity in menstrual function is needed.

Evidence is also accumulating to indicate that hormone metabolism may play an important role in defining the internal endocrine environment (see, for example, Ball et al., 1975; Fishman, 1981; Kappas et al., 1983; MacLusky et al., 1981). The classic pathway of endogenous estrogen metabolism includes oxidation of estradiol to estrone and subsequent hydroxylation at the $16 \alpha-$ position of the $\mathrm{D}$ ring to produce $16 \alpha$-hydroxyestrone and estriol. For many years these three classic estrogens (estradiol, estrone, and estriol) were thought to be the only endogenous estrogens of significance (Fishman, 1981). However, over the past 10-15 years, the quantitative and biologic importance of hydroxylation of the $A$ ring at the 2- position, and to a lesser extent at the 4- position, has become evident: 2-hydroxyestrone is excreted in approximately equal amounts to estriol (Ball et al., 1975; Fishman, 1981; MacLusky et al., 1981). These 2- and 4-substituted estrogens are known as "catechol estrogens" because their additional hydroxyl group creates a catechol structure that enables these compounds to interact with both estrogen and catecholamine receptors.

The estrogenic properties of the metabolites produced by the $16 \alpha$ - and 2- pathways appear to differ markedly; $16 \alpha$-hydroxyestrone is a potent estrogen, while 2-hydroxyestrone is relatively weak. Although the data are still limited, the proportional distribution of 16- versus 2- hydroxylated metabolites appears to differ substantially among individuals, while total estrogen excretion remains relatively invariant (reviewed in MacLusky et al., 1981). The relative partitioning of estrogen metabolism along one versus the other metabolic pathway may substantially influence the 
estrogenic quality of a woman's endogenous environment. Again, few population-based data exist that describe the relative probabilities of women using one versus another metabolic pathway, and considerably more basic work remains to be done to validate methods for measuring these metabolites. Nonetheless, two small but provocative studies demonstrating that the pharmacokinetics (Goldzieher et al., 1980) and metabolism (Williams and Goldzieher, 1980) of orally administered ethynyl estrogens differ by geographic region point to the importance of pursuing this line of research. After a single oral dose of ethynylestradiol, plasma levels in Nigerian women were consistently lower, and levels in Thai women were consistently higher, than in U.S., Sri Lankan, or Singapore women. Although total urinary excretion did not vary, Nigerian, Sri Lankan, and U.S. women did differ in the relative proportions of 3-, 17-, and 3,17-glucuronides that they excreted: Oxidative metabolism at the 2-, 6-, and 16- positions was substantially more common in U.S. women, less common in the Sri Lankan women, and infrequent in the Nigerian women. Physiologic factors, pathologic conditions, and environmental chemicals have been found to influence the proportional distribution of urinary metabolites (MacLusky et al., 1981). Obese women and men have decreased levels of hydroxylation at the 2- position (Schneider et al., 1983), while persons with systemic lupus erythematous and their family members have increased levels of hydroxylation at the $16 \alpha$ - position (Lahita et al., 1982). It has been hypothesized that decreased 2 hydroxylation may be one of the mechanisms through which obesity places women at increased risk of estrogen-dependent tumors such as endometrial cancer (Schneider et al., 1983). On the other hand, increased 2- hydroxylation may promote carcinogenic activity (possibly through the generation of free radicals) and women at high risk for developing nonfamilial breast cancer have been shown to have higher levels of catechol estrogen excretion (Lemon et al., 1992). Cigarette smoke is an example of an environmental chemical that has been shown to substantially increase 2- hydroxylation (Michnovicz et al., 1986).

The major site for peripheral metabolism of estrogens by 2- hydroxylation is the liver. Metabolism of estrogen along the 2- pathway is an enzyme-catalyzed reaction associated with the microsomal fraction of the cell and dependent on particular groups of enzymes referred to as cytochrome P-450s. Cytochrome P-450s are important because they facilitate metabolism of many compounds and because they are an inducible system. In other words, utilization of a given cytochrome P-450 system makes that system function more rapidly, such that the rate of metabolism of any substance using that particular P-450 system will increase. The liver is also a major site for the metabolism of drugs and environmental chemicals, many of which are also metabolized by, and therefore capable of inducing, the same cytochrome P-450-dependent systems responsible for endogenous estrogen metabolism. Synthetic estrogens are also metabolized by some of the same P-450 enzymes (Guengerich, 1988). Consequently, 
environmental exposures such as cigarette smoke, which influence the expression of this system, are potentially important determinants of endogenous estrogen function and of efficacy and sideeffects of exogenous estrogens. Unfortunately, very little work has ever been done on illuminating the effect of environmental exposures on endocrine production or metabolism, and this area represents a major gap in our scientific understanding of menstruation.

\section{Summary}

Generation of data on population variability in the endocrine cycle is a task that, for the most part, has yet to be undertaken. Additional data need to be generated on basic differences in hormonal patterns, on how these patterns change with age, and on variability in hormone metabolism. In particular, the fact that our systemic internal hormonal environments are perturbable by environmental exposures underlines the need to place substantially more scientific emphasis on determining how differences in metabolism influence both reproductive function and a woman's health profile. 


\section{PART III. BEYOND AGING: OTHER HOST AND ENVIRONMENTAL FACTORS THAT DETERMINE MENSTRUAL FUNCTION}

Describing variation is an essential first step in defining normal function and in distinguishing minor perturbations from pathologic alterations. This section moves from the question of how menstrual cycles vary to the question of why they vary. Age is obviously a major biologic determinant of variability in menstrual characteristics. Moving beyond the effects of aging, regional variations in menstrual function are of particular interest because they can offer clues as to how social and environmental conditions affect menstrual function. Evaluation of regional differences is also critical to understanding how risks of hormone-related disease and response to hormonal interventions might differ among populations.

In fact, marked geographic differences have been reported in the timing of reproductive maturation and, to a lesser extent, senescence (see the review by Gray and Doyle, 1983), with much of the variability in age at menarche attributable to nutritional factors. Regional data for other menstrual parameters are much more limited. With the notable exception of Matsumoto et al.'s work on Japanese women, all of the large prospective studies described previously were conducted on women of European descent. The World Health Organization has published data from studies of women participating in "natural" family planning trials (WHO, 1983) and on adolescents (WHO, 1986) that include women from lesser industrialized countries, and a few scattered studies provide country-specific estimates of average menstrual cycle length (Alvarado et al., 1988; Baanders-Van Halewijn and DeWaard, 1968; Odujinrin and Ekunwe, 1991; Thomas et al., 1990). However, most of these analyses have focused on similarities in menstrual cycle characteristics across regions and have done little to tease out potential differences.

Some provocative data do exist on regional differences in bleed characteristics (WHO, 1981; WHO; 1986; Belsey et al., 1988; Ji et al., 1981); see Table 10. Mexican and Latin American women report shorter bleeding episodes (with a mean of 4 days) while European women report longer episodes (with a mean of 5.9 days) than women in other regions. Data from two studies suggest that Chinese women experience both longer and heavier bleeds (WHO, 1986; Ji et al., 1981). Given the narrow range of variation in length of a bleeding episode (approximately 2-12 days), rather significant shifts in the population distributions of bleed characteristics must be occurring to yield such marked differences.

Although one would not expect major differences in ovarian function from region to region, subtle differences in the timing of age-related changes, or systematically different probabilities of ovulation across the reproductive life cycle, may exist. Two reports have suggested that not only the age of menarche but also the timing of ovarian maturation differs in Dutch as compared with 
Bantu girls (Baanders-Van Halewijn and De Waard, 1968) and in Nigerian girls as compared with girls from industrialized countries (Odujinrin and Ekunwe, 1991). In contrast, Ellison et al. (1989) found that the timing of age-related changes in ovulatory frequency was similar among the Lese of Zaire and European women; however, the Lese ovulate considerably less frequently overall (frequency of ovulatory cycles is 56 percent). The shorter bleeds observed in Mexican women may be attributable to differences in the timing of follicular growth (WHO, 1983), as the follicular phase is significantly shorter and the luteal phase significantly longer in Mexican women compared with women from other countries (13.6 versus 15.0 days and 14.5 versus 13.5 days, respectively). Important regional differences have also been reported in hormone metabolism (Goldzieher et al., 1980; Williams and Goldzieher, 1980).

These data, though highly provocative, are clearly insufficient to evaluate regional differences in menstrual patterns. Furthermore, the biologic mechanisms that underlie the observed differences have never been seriously explored. Knowledge about determinants of variability in menstrual function is in fact largely confined to data measuring the effect of three risk factors (weight, physical activity, and stress) on three menstrual parameters (menstrual cycle length, the probability of ovulation, and adequacy of luteal function). Although these three factors dominate the literature, several other environmental factors-including drugs, chemicals, and diet-may also be critical determinants. This section reviews the data on what we know about why menstrual cycles vary.

\section{Weight, Physical Activity, and Life Stress}

Weight

Extremes of weight have been clinically associated with anovulation and amenorrhea, with both absolute weight and change in weight appearing to influence menstrual function. For the most part, studies of the relationship between weight and menstrual dysfunction have been limited to examinations of clinical populations who presented with amenorrhea or of athletes in industrialized countries.

Extreme environmental or pathological conditions, such as famine and anorexia nervosa, which result in starvation and severe weight loss, are known to provoke amenorrhea (Stein and Susser, 1978; Drew, 1961; Warren, 1983; Pirke et al., 1983; Warren et al., 1975). Amenorrhea associated with weight loss has also been reported in women without other evidence of physical or mental illness. In both cases, weight loss is substantial. Women present at 20 percent to 30 percent below their ideal weight (Vigersky et al., 1977; Falk and Halmi, 1982) with a loss of more than 10 percent of premorbid weight or between 5 and 20 kilograms (Knuth et al., 1977; Graham et al., 1979; Wentz, 1980; Nakamura et al., 1985). In such cases menstruation generally resumes after a mean weight gain of 4 kilograms or gain to within 5-15 percent of ideal weight. 
The impact of weight on menstrual function is also observed in healthy, well-nourished individuals. Studies of female athletes (Dale et al., 1979; Frisch et al., 1980; Carlberg et al., 1983), U.S. college students (Bachmann and Kemmann, 1982), and the general population in Scandinavia (Fries et al., 1974) have demonstrated that individuals with highly variable menstrual cycle lengths or amenorrhea tend to weigh less, to have a lower percentage of body fat, and to report more weight loss than women with regular menstrual cycles. In the only population-based case-control study of risk factors for amenorrhea, cases reported weight loss of 5 or more kilograms and recent dieting more frequently than age-matched controls (Fries et al., 1974).

Ellison and colleagues (Ellison et al., 1989) have conducted several detailed studies of ovarian function among Lese women of the Ituri Forest in Zaire and among women living in the Boston area in the United States. When the Lese women were observed during a period of seasonal food shortages the probability of ovulation and peak level of progesterone production were correlated with both weight-for-height at the start of the study and with amount of weight lost during the study period. Moderate weight loss among normal-weight Boston women resulted in similar patterns of ovarian suppression (Lager and Ellison, 1987). Other studies of ovarian function have demonstrated an increase in the percentage of menstrual cycles with inadequate luteal phases when women lost just 5 percent of their initial weight (Schweiger et al., 1987) and experienced a loss of, on average, only 1 kilogram (Pirke et al., 1989). Ellison argues that both acute and moderate weight loss lead to alterations in ovarian function, the degree of ovarian suppression depending on the severity and duration of weight loss. He also argues that weight stabilization will precipitate a return toward clinically normal ovarian function, even before significant weight gain occurs (Ellison and Cabot, 1990), suggesting that cognitive factors may help mediate the effects of weight on menstrual function.

This more complex model of an interplay among cognition, weight loss, and menstrual function helps resolve some apparent inconsistencies in the literature. Recovery of weight after severe weight loss is not always associated with a return to normal menstrual function (Falk and Halmi, 1982; Nakamura et al., 1985; Kohmura et al., 1986), and up to one-third of women with anorexia nervosa stop menstruating before significant weight loss occurs (Warren, 1983). Even in the situation of famine, it has been argued, the onset of amenorrhea could reflect a physiologic response to severe emotional stress (Mencken et al., 1981), and dietary restraint independent of actual weight loss has been shown to alter ovarian function (Schweiger et al., 1992) and menstrual cycle length (Harlow and Matanoski, 1991).

The association between weight and menstrual function is not confined to the lower end of the weight spectrum; however, considerably fewer data are available on women who are heavy as opposed to thin. Obesity has been associated with amenorrhea and polycystic ovarian disease 
(Friedman and Kim, 1985; Harlass et al., 1984). One population-based study of U.S. college women found that women at the upper end of the weight spectrum had the highest probability of having long menstrual cycles (Harlow and Matanoski, 1991). Obese women with infrequent menses have reduced serum hormone-binding globulin and increased serum estrogen concentrations (Friedman and Kim, 1985), and obesity is also associated with increased metabolism of estrogen along the $16 \alpha$ - pathway. All of these hormonal changes tend to yield a more potent estrogen environment.

The precise mechanism through which weight may be related to menstrual function has not been definitively established and it is probable that more than one mechanism is operative. First, reproductive function may depend on nutritional status, with either direct caloric energy balance or food composition being the relevant nutritional factor. The potential connection between nutrition and reproductive function has long been suggested by observations that girls of lower socioeconomic status and girls from less industrialized countries have a later age of menarche (Drew, 1961; Frisch and McArthur, 1974; Stein and Susser, 1978; Gray and Doyle, 1983). Ellison and Cabot (1990) argue that the data are more consistent with a theory of negative energy balance than of nutritional thresholds. Only a few studies have examined the role of food composition (see Additional Host and Environmental Factors, below; Hill et al., 1984; Pirke et al., 1986; Schweiger et al., 1987).

Second, body fat may directly influence endocrine function, as fat tissue is a reservoir for steroid hormones and a site of estrogen production (Grodin et al., 1973; Fishman et al., 1975; Nimrod and Ryan, 1975; Perel and Killinger, 1979; Deslypere et al., 1985; Longcope et al., 1986; Friedman and Kim, 1985). Estrogen has been shown to stimulate the growth and replication of fat cells (Roncari and Van, 1978) and obesity appears to influence the concentration of sex hormonebinding globulin and estrogen metabolism (Schneider et al., 1983; Friedman and Kim, 1985). Abdominal fat accumulation may also indirectly influence sex hormone levels by increasing cortisol levels, altering feedback signals to the pituitary (Bjorntorp, 1991).

Finally, both weight and reproductive function may be affected by a third factor, such as underlying disease (for example, anorexia nervosa) or concomitant environmental exposure (for example, stress). The evidence cited above-that cognitive factors associated with dietary restraint can influence menstrual function-argues that more complex models of the determinants of menstrual function are probably needed. 


\section{Physical Activity}

High and moderate levels of physical activity can alter menstrual function, although the reported rate of menstrual disturbance among athletes varies considerably from study to study. Women athletes, particularly ballet dancers and runners, have a higher frequency of amenorrhea, anovulation, and luteal phase defects than nonathletes (Abraham et al., 1982; Malina et al., 1978). Recreational exercise has also been found to increase mean menstrual cycle length, the probability of having a long menstrual cycle, and the probability of anovulation in school girls. Data on the effect of training intensity are inconsistent, but the reported frequency of amenorrhea is generally higher in studies of collegiate or national athletes than in studies of recreational runners. Many of the apparent discrepancies in the literature are largely attributable to divergent definitions of dysfunction (for example, definitions of amenorrhea range from delayed menses to no menses for two, three, four, or six months) or to failure to control for age (Speroff and Redwine, 1980; Baker et al., 1981; Glass et al., 1987).

Initially the high frequency of amenorrhea and delayed menses was attributed to low body weight and/or low body fat among athletes, and a number of investigators examined this hypothesis. In general, amenorrheic runners weigh less, have lower weight-to-height ratios, have less body fat, and report more weight loss than other runners or nonrunner controls (Dale et al., 1979; Speroff and Redwine, 1980; Schwartz et al., 1981; Shangold and Levine, 1982; Galle et al., 1983; Glass et al., 1987; Feicht et al., 1978; Ouellette et al., 1986). The most definitive study used hydrostatic methods to compare the body composition of 14 athletes who had had no menses for three months with 28 athletes who had menstrual cycles of 23-35 days (Carlberg et al., 1983). All weight parameters were lower in amenorrheic athletes, including total weight, percent of ideal weight, percent fat, fat weight, and lean body weight.

Evidence that halting training without weight gain restores normal menses suggests, however, that physical training also has an effect independent of weight (Warren, 1980). Four prospective studies support this hypothesis (Prior et al., 1982; Bullen et al., 1985; Ellison and Lager, 1986; Bernstein et al., 1987). In a classic study, Bullen et al. (1985) monitored ovarian function in 28 women with ovulatory menstrual cycles prior to and during a five-week intensive training program. Training provoked abnormal luteal function and anovulation in all but 5 of 53 observed menstrual cycles. Anovulation was most frequent in women fed a diet that ensured weight loss but also occurred in women who maintained their pretraining weight. In another study, U.S. high school girls who engaged in two or more hours of hard exercise per week had a twofold elevation in risk of anovulation, and menstrual cycles were 2.4 days shorter in women who were above the 50th percentile of activity level than in less active women (Bernstein et al., 1987).

The specific mechanism by which physical activity induces change in menstrual function is 
unclear. The probable hormonal pathway is inhibition of $\mathrm{GnRH}$ and gonadotropin activity accompanied by a decline in serum estrogen levels (Cumming et al., 1994). Cumming and colleagues hypothesize that these documented hormonal alterations reflect a physiologic response to stress that, in the presence of additional risk factors, may be sufficient to affect menstrual function. Some data do support this theory that physiologic and emotional stress play an etiologic role in exercise-associated amenorrhea. Amenorrheic athletes are significantly more likely than other runners to perceive running as stressful (Schwartz et al., 1981) and to report higher levels of emotional distress (Galle et al., 1983) and subjective stress (Schweiger et al., 1988). Higher mean serum (Glass et al., 1987; Ding et al., 1988) and urinary (Loucks et al., 1989) cortisol levels have also been demonstrated in amenorrheic compared with eumenorrheic runners. However, since moderate levels of aerobic activity also alter ovarian function and are less consistent with a stress model (Ellison and Lager, 1986; Bernstein et al., 1987; Harlow and Matanoski, 1991), alternative mechanisms such as negative energy balance remain plausible (Ellison and Cabot, 1990; Schweiger et al., 1988).

Women who experience menstrual alterations after intense physical activity may be more susceptible to menstrual dysfunction. Amenorrheic athletes tend to have a later menarche (Feicht et al., 1978; Wakat et al., 1982; Baker et al., 1981; Oian et al., 1984) and to report a history of highly variable or long menstrual cycles (Speroff and Redwine, 1980; Schwartz et al., 1981; Shangold and Levine, 1982). Moderate exercise is also more likely to provoke long cycles among women with a propensity for such cycles (Harlow and Matanoski, 1991). However, little is understood about differential susceptibility to menstrual dysfunction, and more information is needed about the nature of variability in menstrual patterns (see Part II) before such susceptibility can be adequately described.

\section{Stress}

Although psychological stress is generally acknowledged to affect menstruation and is often considered the principal cause of menstrual dysfunction (Drew, 1961; Fries et al., 1974; Green, 1977; Kreiger and Hughes, 1980), scientific investigation of the association between stress and menstrual function is actually quite limited. The literature consists mainly of studies of major life changes, of catastrophic events such as incarceration and war, and of girls leaving home to go to school or the army (Drew, 1961; Osofsky and Fisher, 1967; Boehm and Salerno, 1973; Metcalf and Mackenzie, 1980; Tudiver, 1983). In a review of the extant literature, Drew (1961) concluded that the amenorrhea observed in these studies was attributable to psychological stress characterized by separation from home and family, hopelessness, and threat to the individual.

Although clearly significant when they occur, catastrophic events such as incarceration in a 
concentration camp are rare events. Their importance in explaining the prevalence of menstrual dysfunction in the general population is limited. Studies of more common events such as leaving home to go to school (Wilson et al., 1984; Osofsky and Fisher, 1967; Matsumoto et al., 1979), to the military (Boehm and Salerno, 1973), or to work (Metcalf and Mackenzie, 1980) lend support to Drew's theory of an association between the experience of separation and amenorrhea. However, the designs of most of these studies are seriously flawed. Some lack comparison groups and present rates of amenorrhea that differ little from rates observed in the general population (Boehm and Salerno, 1973; Osofsky and Fisher, 1967). Others compare menstrual history with prospective observations of cycle length (Matsumoto et al., 1979; Wilson et al., 1984). Nonetheless, in a welldesigned cross-sectional study, Metcalf and Mackenzie (1980) have shown that young women who live at home ovulate more frequently than do women who live in flats or hostels. Five to eight years after menarche, 72 percent of girls living at home ovulated, compared with only 40 percent of women who lived away from home. The living environment had a minimal effect in women whose reproductive systems were more mature.

Data from the few extant population-based studies are inconsistent. In a cross-sectional survey of U.S. college women, history of perceived emotional upset, history of death or separation from close relatives, and self-perceived excessive physical or mental workload did not differ between women with and without amenorrhea (Bachmann and Kemmann, 1982). Psychological state and life events were also found to be unrelated to excessive bleeding (Gath et al., 1987). On the other hand, a population-based case-control study in Scandinavia did find that stressful life events and the consumption of tranquilizers were more common among amenorrheic cases (Fries et al., 1974). A case-control study of dysfunctional uterine bleeding found that the dysfunctional cases reported more stressful life events within the past month and a higher level of perceived stress associated with these events than did the controls (Tudiver, 1983). The discrepancy in findings may be due to differences in the types of life events examined, to the focus on rare events such as deaths, or to failure to specify an appropriate risk period. (For example, life events in the past month may affect current menstrual cycle length, while events in the past year may not.)

A prospective study that focused on the acute effects of stress during a given menstrual cycle (Harlow and Matanoski, 1991) found that major life events associated with loss and separation did not influence cycle length, but events associated with gain or newness—such as starting a new job, starting college, and starting a new relationship — increased the probability of having a long cycle. Additionally, minor events that marked an increased demand for performance, such as exams or competitions, and having a high level of perceived stress also increased the risk of having a long cycle. These authors hypothesize that life situations involving an increased demand for performance while coping with new circumstances or an increased burden may be a more relevant 
construct than are loss or separation to explain the occurrence of menstrual dysfunction in the general population.

As is true for physical activity, the mechanism through which stress influences menstrual function remains uncertain. Central psychogenic disturbances may be mediated through the hypothalamus via changes in prolactin or the endogenous opiates (Kreiger and Hughes, 1980; Warren, 1983). Systemic changes in the hormonal environment, such as elevation in basal cortisol levels, which represent the body's physiologic response to stress, may provoke alterations in hypothalamic response. However, relatively few data are available on gonadotropin and steroid hormone changes that occur during stress-associated amenorrhea.

\section{Summary}

All three of these factors-weight, exercise, and life stress-influence menstrual function. Fairly extensive data are available on the effects of weight and physical activity as well as on the mechanisms that underlie these effects. The presence of multiple risk factors may either potentiate impairment of function or possibly moderate the impact of specific risk factors (Ellison and Cabot, 1990). Weight loss combined with hard exercise is more likely to produce alterations in ovarian function than is hard exercise alone (see, for example, Bullen et al., 1985). Physical exercise may have a stronger impact on menstrual function when training conditions are more stressful (see Schwartz et al., 1981; Loucks et al., 1989) or moderate the impact of stressful life conditions when exercise acts as a stress-reduction behavior (Harlow and Matanoski, 1991).

Repetition of studies documenting the presence of weight and exercise effects is not generally necessary. Rather, more focus should be placed on examining the influence of weight at the upper end of the weight spectrum and of recreational activity in gynecologically mature women (Bonen, 1992), on understanding the role of hard physical activity when it occurs in the context of women's daily work life as opposed to occurring in the context of exercise, and on evaluating the interaction of low weight and physical activity on reproductive function in less industrialized countries, where women typically are occupied in nonaerobic but energy-intensive tasks. Additional attention to the potentially beneficial effects of moderate exercise in mediating the impact of stress is also warranted. Data from more broad-based population surveys and from cross-cultural studies will be critical to understanding the relative importance of weight and physical activity in explaining the level of menstrual dysfunction in different populations. One study suggests that exercise-associated amenorrhea may not occur as frequently in Nigerian athletes (Okonofua et al., 1990). In order to clarify the mechanisms through which weight influences menstrual function, a more systematic investigation of the role of fat in endocrine production, metabolism, storage, and clearance is needed. In particular, given that the site of fat deposition is relevant to both a woman's endocrine 
profile and her disease risk (Bjorntorp, 1991), studies of the role of fat distribution in menstrual function should also be initiated.

Research needs in the area of stress are much more fundamental. Given the widely accepted belief that stress is a major determinant of menstrual function and a significant cause of pathology, the paucity of scientific investigations and the poorly developed conceptual framework for defining relevant constructs of stress are quite notable. A wider literature clearly indicates that stress is an important determinant of reproductive function more generally (see, for example, Mamelle et al., 1984, 1989). Further investigation of the acute effects of specific stressors and the chronic effects of cumulative life stress, development of more precise and relevant stress constructs, and evaluation of physiologic mechanisms are obviously needed.

\section{Additional Host and Environmental Factors that May be Important Determinants of Menstrual Function}

Weight and physical activity are clearly relevant to menstrual function. However, if we know anything about reproductive function, we know that it is a system responsive to multiple environmental signals. A major problem to date has been the lack of systematic attention paid to these other signals. Table 11 presents a list of environmental factors for which some evidence currently exists suggesting their probable impact on menstrual function. In the case of many factors (for example, sound, light, and electromagnetic-fields), considerable data from the animal literature provide a biologic rationale for investigating potential effects on human menstrual function. For other factors (for example, smoking), the biologic rationale is provided by epidemiologic evidence of an impact on other reproductive endpoints and on the endocrine environment. Yet, adequate population-based studies quantifying the impact of these factors on menstrual, ovarian, or endocrine function have generally not been undertaken. Exceptions include some investigations on the interplay between specific drug consumption and metabolism of steroid contraceptives, a small and conflicting body of literature on menstrual synchrony, and some preliminary data on smoking. The importance of expanding theoretical constructs of what constitutes a relevant stressor was emphasized in the preceding section, and could include consideration of the multiple dimensions of work stress, family interactions, chronic psychological stress, and tension between multiple social roles. This section reviews some of the more promising clues in the literature on diet, chemicals, and the physical and social environment that might serve as priority foci for future research.

\section{Diet}

As noted above, much of the regional variability in age at menarche is attributed to differences in nutritional status, and negative energy balance is thought to be one mechanism through which 
both weight and physical activity influence menstrual function. In addition to absolute caloric consumption, some provocative studies suggest that diet composition-the amount of meat, protein, or fat consumed-might also influence menstrual function. Vegetarian diets have been associated with anovulation, decreased pituitary responsiveness, and infrequent cycling (fewer than 10 menstrual cycles per year) (Hill et al., 1984; Pirke et al., 1986; Pedersen et al., 1991).

Amenorrheic runners report consuming fewer calories, less red meat, and less fat than menstruating runners (Kaiserauer et al., 1989). In an experimental study, women had slightly longer menstrual cycles and slightly longer bleeding periods while consuming a low-fat (20 percent) diet than while consuming a high-fat (40 percent) diet (Jones et al., 1987). Preliminary data suggest that both dietary fat and the indoles present in cruciferous vegetables may influence estrogen metabolism (Longcope, 1994), although the data are somewhat inconsistent (Kappas et al., 1983). If dietary macronutrients are proven to influence estrogen metabolism, the public health implications would be enormous: diet is a pre-eminently modifiable risk factor.

\section{Environmental Chemicals}

Induction of the cytochrome P-450 metabolizing system by drugs or environmental chemicals and the consequent effects on metabolism and clearance of steroid hormones deserves considerably more attention. Anticonvulsants such as phenobarbitone, some antibiotics, and rifampicin appear to reduce contraceptive efficacy (Back and Orme, 1994; Back et al., 1981). The data for these specific drug-contraceptive interactions are fairly extensive, but data for other drugs and most antibiotics remain sketchy. Evaluation of the impact of these drugs on normal menstruation is practically nonexistent, although minimal information is available on the effects of phenobarbital (Levin et al., 1968), and more extensive data are available on the effects of various chemotherapeutic agents. Cytotoxic drugs induce ovarian failure (Warne et al., 1973; Chapman et al., 1979; Rose and Davis, 1977), although return of normal menstrual function after completing treatment occurs in at least some women (Horning et al., 1981; Gershenson, 1988). Knowledge about interactions between pharmaceutical drugs and menstrual function is clearly important for clinical populations during periods of treatment. However, studies are also needed to evaluate the potential effects of recreational drugs (for example, tobacco, marijuana, cocaine, and alcohol), environmental chemicals (for example, pesticides), and industrial chemicals (for example, solvents), which affect large numbers of women, often for extended periods of time.

One chemical that has received considerable attention and serves as a good model of the broad range of potential chemical effects on menstrual and reproductive function is tobacco smoke (Mattison, 1982). Tobacco smoke is metabolized by some of the same cytochrome P-450s as is estrogen, has been shown to alter estrogen metabolism (Michnovicz et al., 1986), and is associated 
with follicular-phase plasma estrogen and progesterone levels (Zumoff et al., 1990). Smoking is also associated with various estrogen-dependent diseases such as osteoporosis and endometrial cancer (Baron, 1984), is a risk factor for infertility (Baird and Wilcox, 1985; Howe et al., 1985; Phipps et al., 1987), and has been associated with an earlier menopause (Baron, 1984). In a few preliminary studies, smoking has been suggested as a risk factor for dysmenorrhea, infrequent menstrual cycles, and heavy or prolonged bleeding (Sloss and Frerichs, 1983; Brown et al., 1988).

Despite this rather impressive evidence that chemicals alter endocrine function, no other chemical has been seriously evaluated. A few authors have pointed to the potential implications of chemical induction of liver metabolism (Kappas et al., 1983; Harlow, 1986; Guengerich, 1988) and early reports have suggested the potential for pesticides such as DDT (Heinrichs et al., 1971; Duby et al., 1971) and solvents such as para-xylene (Ungvary et al., 1981) to alter liver endocrine metabolism. Anecdotal evidence from as early as the 1940s suggests that xylene exposure produces bleeding disruptions and menorraghia (Varney, 1944), and one small study in Colorado reported menstrual alterations in farm laborers (Chase et al., 1973). More recent reports that DDT may be associated with increased risk of breast cancer and that dioxin may promote the development of endometriosis underline the necessity of placing more focus on the question of how chemicals alter women's hormonal environment.

\section{The Physical Environment}

Variations in the length of the day have long been known to regulate the timing of estrus in animals that are seasonal breeders. Over the past decade, researchers have demonstrated that these photoperiod effects are mediated through melatonin excretion from the pineal gland and that melatonin helps regulate the hypothalamic-pituitary-ovarian axis in seasonal breeders (Karsch et al., 1984, 1986). More recent studies have demonstrated that sheep actually have an endogenous circannual estrus cycle (that is, they will undergo estrus in the absence of any environmental clues) and that daylight entrains this endogenous cycle to synchronize seasonal reproduction (Karsch et al., 1989). Alterations in melatonin secretion were subsequently noted in women with hypothalamic amenorrhea (Berga et al., 1988), and patterns of melatonin secretion appear to differ between athletes with and without amenorrhea (Laughlin et al., 1991). These results suggest that more attention to the influence of environmental signals such as daylight on human endocrine function and to the impact of factors such as electromagnetic fields on melatonin secretion (Wilson, 1989) are warranted. In addition to the effect of light, consideration should be given more generally to how data from animal studies might be applicable to understanding determinants of human menstrual dysfunction. Some very intriguing data exist, for instance, on the negative impact of loud and continuous noise on ovarian function (Singh and Rao, 1970; Singh, 1972; Zondek and Tamari, 1967; 
Beardwood et al., 1975), and further thought might be given to the potential impact of noise pollution on human reproductive function.

\section{The Social Environment}

The question of whether women who work or live together start "cycling" together is one that always generates considerable interest; however, studies of this phenomenon have produced inconsistent results and many are methodologically weak (Graham and McGrew, 1980; McClintock, 1971; Skandhan et al., 1979; Wilson et al., 1991; Little et al., 1989). Nonetheless, evidence from both animal and human studies do suggest that social interactions can modify endocrine function (Faulkes et al., 1990), although a simple theory of social proximity is probably not sufficient to explain menstrual synchrony. Some studies suggest that pheromones driven by same-sex contact (Cutler et al., 1986) or opposite-sex contact (Preti et al., 1986) will entrain menstrual cycles, reducing variability in cycle length and synchronizing the onset of menses. Others argue that a range of common environmental clues are the relevant mechanism (Little et al., 1989). Whatever the underlying mechanisms, further consideration of the role of social factors such as social networks, increasing social violence, and social crowding is warranted.

\section{Conclusion}

This discussion of the potential determinants of menstrual function has not been exhaustive; however, it has illustrated the spectrum of factors that deserve further evaluation. More attention is particularly warranted for those factors, such as diet, that are amenable to public health interventions. Given the widespread use of pesticides and the increasing participation of women in industrial production throughout the world, investigation of the impact of chemical exposures on menstrual function and on contraceptive efficacy should also be a priority. Finally, only one study to date has explicitly examined variation in menstrual function by socioeconomic status (Munster et al., 1992). Since the probability of exposure to most risk factors (for example, diet, work environment, environmental chemicals) will differ by socioeconomic status, studies of the effect of social status on the prevalence of menstrual complaints are also a priority. 


\section{The Importance of Considering Environmental Impacts on Menstrual Endpoints Other than Ovulation and Cycle Length}

In addition to evaluating a broader range of potential risk factors, a need exists to assess the impact of these risk factors on a broader spectrum of menstrual endpoints. Most of the extant literature focuses on the ways in which various exposures affect the probability of ovulation and the length of the menstrual cycle. Ellison and Cabot (1990), for example, have made significant empirical and conceptual contributions to our understanding of how weight and exercise influence ovarian function. Their explicit interest is in observing the ovarian cycle as a sensitive indicator of environmental insults to human reproductive potential. Although, clearly, reproduction is an important outcome of menstrual function, this focus has not advanced our understanding of abnormal bleeding or of hormonal influences on chronic disease risk. Virtually no data exist on environmental determinants of bleeding duration and amount of flow (Belsey et al., 1988; Harlow and Campbell, 1994) or dysmenorrhea. A narrow focus on the ovary can also produce a conceptual blindness that limits our ability to identify environmental influences on ovarian function specifically and menstrual function more generally. Although the data are sparse, it is apparent that hepatic metabolism is a significant pathway through which the endocrine environment can be altered. The potential importance of chemicals and drugs becomes increasingly evident when one considers how these substances might interact with hepatic metabolism and alter hormonal feedback. More focus should therefore be placed on understanding determinants of variability in hormonal patterns and endocrine metabolism. 


\section{PART IV. POPULATION PREVALENCE OF MENSTRUAL DYSFUNCTION}

Heretofore, this report has focused on describing population variability without explicitly differentiating normal from abnormal function. Data on the population prevalence of menstrual dysfunction are scant, and evaluation of potential risk factors has generally focused on three aspects of menstrual dysfunction: anovulation, inadequate luteal phase, and amenorrhea. Research on other types of menstrual morbidity is much more limited.

Historically, menstrual dysfunction was defined primarily in terms of disruptions in bleeding patterns - that is, menorraghia (heavy or prolonged bleeding), oligomenorrhea (infrequent menstruation), and amenorrhea (cessation of menses). Definitions based on ovarian functionanovulation and luteal deficiency-are now more predominant. These functional disturbances may or may not manifest as alterations in bleeding patterns. Excessive or prolonged uterine bleeding may be referred to as dysfunctional uterine bleeding when associated with anovulation, while amenorrhea is commonly subclassified by type of underlying hormonal alteration (hyperpituitaryhypogonadism). An entirely separate construct of menstrual dysfunction stems from a consideration of pain and other symptomatology associated with the onset of menses (dysmenorrhea).

Both bleeding disturbances and functional disturbances are clearly relevant constructs. The former may be pathological to the extent that they disrupt activities of daily living, are indicative of ovarian alterations incompatible with pregnancy or of underlying pathology such as fibroids or cancer, or are associated with significant blood loss. Functional disturbances may be considered pathological to the extent that they interfere with the capacity to reproduce. In the absence of a desire to become pregnant, however, the pathological nature of anovulation or luteal phase inadequacy is uncertain. Dysmenorrhea, or menstrual cramps and symptoms such as nausea, which are associated with the sloughing of the endometrium, may be severe enough to disrupt a woman's daily activities. When more is understood about the association between hormone profiles and subsequent disease risk, functional disturbances may be deemed pathological to the extent that they reflect alterations in the endocrine environment and place a woman at increased risk of developing chronic disease. Although some authors have begun to recommend preventive medical treatment for ovulatory alterations based on possible long-term risks of chronic disease (see, for example, Bernstein et al., 1987; Henderson et al., 1985), our scientific knowledge of these relationships is far too limited to define menstrual dysfunction in such terms at this time.

This section reviews the limited data that exist on population distributions of four categories of menstrual morbidities: functional disorders, cycle length disorders, bleeding disorders, and menstrual cramps. As part of this review, the problem of finding valid and reliable operational 
definitions of these different menstrual morbidities is discussed. Although the definition of anovulation is rather straightforward, definitions of "cessation" of menses or "inadequate" luteal phase are less obvious. Premenstrual syndrome is not addressed, as a thorough review of that literature is beyond the scope of this report.

\section{Functional Ovulatory Disorders: Anovulation and Luteal Phase Defects}

Luteal phase deficiency is defined as the production of progesterone during the luteal phase at levels insufficient to sustain a pregnancy (Andrews, 1979; Jones, 1976). Luteal phase deficiencies are thought to result from aberrant folliculogenesis, specifically from inadequate FSH stimulation during the follicular phase (Speroff et al., 1983; Smith et al., 1985). Decreases in the length and the peak height of the post-ovulatory progesterone rise are referred to as short luteal phase and inadequate luteal phase, respectively. Clinically, a short luteal phase is defined as a luteal phase of less than eight days (Lee, 1987), although Lenton et al. (1984a) suggest that luteal phases of less than 11 days have a high probability of being abnormal. Based on analysis of statistical distributions, their data indicate that 100 percent of luteal phases shorter than 10 days would be classified as abnormal, compared with 74 percent of 10-day phases, 22 percent of 11-day phases, and 2 percent of 12-day phases. Inadequate luteal function is generally defined as a luteal phase in which progesterone levels do not reach 16 nanomole/liter for at least five days (Landgren et al., 1980).

Although 3.5 percent of women who are evaluated for infertility (Jones, 1976) and 23-38 percent of women with recurrent spontaneous abortions (Speroff et al., 1983) are reported to have luteal phase defects, little information is available on the prevalence of this condition within the population. Some estimates are available from the population studies described in Part II. Doring (1969) reported that 37 percent of menstrual cycles in women aged 18-20 years as compared with 9 percent of cycles in women aged 35-39 years had temperature elevations lasting less than 10 days. Using a definition of eight days, 3.2 percent of women in the multinational WHO study of participants in "natural" family planning programs (WHO, 1983) and 2.1 percent of women in a smaller clinical study (Lenton et al., 1984a) had short luteal phases. Landgren et al. (1980) determined that 6 percent of the women in their study demonstrated insufficient progesterone production. However, their definition of dysfunction was derived by taking the 95th percentile of progesterone production; thus, the prevalence is rather tautological.

Anovulation is, simply, the absence of ovulation. Disturbances occurring at any point prior to or during gonadotropin-dependent folliculogenesis in the delicate balance of hormonal feedback can disrupt ovulation. Specifically, anovulation may result from alteration or suppression of the pulsatile release of $\mathrm{GnRH}$ from the hypothalamus, from inadequate or ill-timed stimulation of the ovary by 
FSH or LH, from insufficient elaboration of estradiol, or from interference with the local or peripheral activity of estradiol. In most studies, anovulation is inferred from the absence of an LH peak, the absence of a rise in progesterone, or the absence of a rise in basal body temperature. Although anovulation can occur without any apparent change in menstrual cycle length, amenorrhea, short cycles, and dysfunctional uterine bleeding may also result. Data on population distributions of anovulation were presented in Part II, Table 6. To review, over half of the menstrual cycles of adolescent girls, one-quarter of menstrual cycles of women in their early $20 \mathrm{~s}$, and one-third of menstrual cycles of women over 50 are anovulatory. During the years of reproductive maturity, from the mid-20s to the mid-40s, only 2-7 percent of cycles are anovulatory (Doring, 1969; Vollman, 1968; Metcalf, 1983).

\section{Menstrual Cycle Length Disorders: Amenorrhea and Oligomenorrhea}

Amenorrhea is defined as the cessation of menses. Clinically, the term usually refers to an absence of menses for six months or longer; research definitions tend to use shorter intervals and are highly inconsistent (see Table 12). The term oligomenorrhea is used to define an absence of menses for intervals shorter than amenorrhea or to characterize unevenly spaced menses.

Definitions of "long" cycles, "short" cycles, and "irregularity" are even more ambiguous. In the case of amenorrhea, the persisting definitional ambiguity may reflect our lack of understanding about the nature of variation in ovarian function (Harlow and Zeger, 1991).

Few studies have been conducted on the population distribution of secondary amenorrhea, that is, amenorrhea occurring after the onset of menarche. Pettersson et al. (1973) gathered information on a random sample of Scandinavian women aged 18-45 years using a mail questionnaire. They reported a one-year incidence rate of 3.3 percent, a one-year prevalence of 4.4 percent, and a point prevalence of 1.8 percent for amenorrhea of more than three months duration. Bachmann and Kemmann (1982), in a mail survey to U.S. college students, reported a point prevalence of 11.3 percent for oligomenorrhea (menstrual-cycle lengths of 35-90 days) and of 2.6 percent for amenorrhea of more than 90 days. The difference in point prevalence rates of amenorrhea in these two studies reflects the fact that long menstrual cycles are more common in young women. In one of the only community-based studies of the prevalence of gynecological illness from lesser industrialized countries, Bang et al. (1989) reported that 20.3 percent of study participants in a small Indian village complained of amenorrhea. On examination, 4.7 percent were found to have amenorrhea and 22.4 percent were classified as having "oligomenorrhea/hypomenorrhea" (no operational definitions provided). One large population-based cross-sectional study from Denmark found that almost 30 percent of women aged 15-44 experienced at least one menstrual cycle longer than 35 days and variation in cycle length over 14 
days in the past year (Munster et al., 1992).

\section{Bleeding Disorders: Menorraghia and Dysfunctional Uterine Bleeding}

The term used to describe excessive blood loss independent of ovulatory status is menorraghia. Excessive blood loss is defined as blood loss of more than 80 milliliters per menses (Hallberg et al., 1966). Dysfunctional uterine bleeding refers to several patterns of altered bleeding that result from anovulation, and may be characterized by excessive and/or prolonged blood flow. In the presence of normal ovulation, conditions such as coagulation disorders, endometriosis, uterine infections, and possibly prostaglandin imbalances can also cause heavy bleeding (Mishell et al., 1984; Rees, 1987; Smith et al., 1981). In contrast to studies of anovulation or amenorrhea, little substantive research has been undertaken on menstrual morbidities that are characterized by excessive bleeding, despite the facts that such disorders are more likely than amenorrhea to interfere with a woman's daily life and that abnormal bleeding is a major indication for performing hysterectomy.

Few studies have estimated the population prevalence of menorraghia. An English study estimated the yearly incidence of menorraghia to be seven cases per 1,000 women based on a review of medical records in one practice (Stott, 1983). The median age at clinical presentation was 35-39 years. Bang et al. (1989) report that 4.9 percent of women in an Indian village complained of profuse periods, but a significantly larger proportion, 15.2 percent, were diagnosed as having menorraghia. A population-based survey in Australia (Wood, 1972) found a similar number of women (5.1 percent) reporting prolonged (more than seven days) menstrual bleeding.

Little information exists on risk factors for menorraghia. In one case series, 51 percent of women with abnormal bleeding had no evidence of organic pathology (Fraser, 1992). Low iron levels are associated with increased blood loss (Hallberg et al., 1966) and anemia seems to be an important clinical/nutritional risk factor. In the English study, menorraghia cases were more likely to have had an associated iron- deficiency anemia than were age-matched controls (Stott, 1983). In the Bang et al. (1989) study, 83 percent of the women had iron-deficiency anemia. Intrauterine devices substantially augment blood flow, although devices containing progesterone tend to diminish flow. Data on other potential risk factors are very preliminary. Case-control studies suggest that menorraghia may be associated with other cardiovascular problems (Stott, 1983) and that women with dysfunctional uterine bleeding are more likely to report recent stressful life changes (Tudiver, 1983). In support of this latter result, experimental data suggest that blood coagulation factor activity may decrease in response to prolonged stress (Palmblad et al., 1977). Prolonged bleeding may be more common in smokers (Wood, 1972) and heavy flow may be more common in obese women (Hartz et al., 1979). Case reports have suggested that menorroghia may result from 
mild hypothyroidism (Wilansky and Greisman, 1989; Stoffer, 1982).

\section{Menstrual Cramps: Dysmenorrhea}

Although the term dysmenorrhea is sometimes used to refer to a broad panorama of symptomatology, it is appropriately defined as abdominal pain, cramping, or backache associated with menstrual bleeding. Related gastrointestinal symptomatology, such as nausea or diarrhea, may also occur. Primary dysmenorrhea refers to pain in the absence of other gynecologic morbidity and generally occurs only in ovulatory cycles. Secondary dysmenorrhea refers to menstrual pain associated with other gynecologic morbidity, such as endometriosis or pelvic inflammatory disease. The proximate cause of primary dysmenorrhea is secretion of prostaglandins, which both increase uterine contractibility and sensitize pain receptors. Again, population-based data on the prevalence of dysmenorrhea are limited. Most women experience at least mild cramping during at least some menstrual cycles. No more than 5-10 percent of women appear to experience severe and incapacitating pain.

Studies of dysmenorrhea have focused on adolescents. In a Finnish study, 54 percent of girls aged 10-20 reported at least occasional pain, while 13 percent reported that they always experienced pain. Prevalence increased with time since menarche: in the first year postmenarche, only 7 percent of girls reported having cramps, as opposed to 25 percent in the fifth to ninth year (Widholm, 1979). Data from a national sample of U.S. adolescents are quite similar: 60 percent reported ever having pain or discomfort, while 14 percent reported frequently missing school because of cramps. Several Swedish studies (Andersch and Milsom, 1982; Svanberg and Ulmsten, 1981) report similar results, while a Nigerian study of university students found a slightly higher prevalence (72 percent) (Thomas et al., 1990). As would be expected given the association with ovulatory cycles, the prevalence of dysmenorrhea during adolescence increases with years since menarche (Klein and Litt, 1981). Exercise, on the other hand, appears to decrease menstrual cramping (Okonofua et al., 1990). Since dysmenorrhea is more likely to occur during ovulatory cycles, factors such as physical exercise, which reduce the probability of ovulation, would be expected to reduce the probability of pain. However, other mechanisms, such as elevated endorphin levels, may also be operative.

Studies in adult women are less consistent and often focus on subgroups of working women. In Bang et al.'s (1989) Indian study, 15 percent of women complained of dysmenorrhea while 57 percent were found to experience some level of pain on examination. In an Australian survey (Wood, 1972), 29 percent of women reported experiencing moderate or marked discomfort. In contrast, 75 percent of the mothers of the girls in the Finnish study (Widholm, 1979) reported experiencing pain with menstruation. Although dysmenorrhea is often touted as the greatest cause of lost work time for women, the data disprove this assertion (Sturgis, 1923; Baetjer, 1946). 
Svennerud (1959), in a comprehensive study, determined that dysmenorrhea accounted for only 3.7 percent and 2.5 percent of absences among female factory and office workers, respectively. Data from the National Health Interview Survey reveal that the greatest cause of lost work time for women is, in fact, influenza (NCHS, 1978).

In one of the few studies to consider risk factors for dysmenorrhea in adult women, Mergler and Vezina (1985) demonstrated that exposure to cold in slaughterhouses significantly increased both the prevalence of dysmenorrhea and the likelihood of taking sick leave. Increased severity of dysmenorrhea is correlated with amount of menstrual flow and nulliparity, while women who use oral contraceptives report less severe pain. Although one study found that smoking was associated with fewer reports of menstrual cramps (Andersch and Milsom, 1982), two other studies (Wood, 1972; Brown et al., 1988) found that smokers reported more dysmenorrhea.

\section{Summary}

Both descriptive research and etiologic research in the area of menstrual dysfunction are insufficient. For the more commonly evaluated dysfunctions of anovulation, amenorrhea, and luteal phase defects, research deficiencies were outlined at the end of Parts II and III. Considerably more attention should be paid, however, to dysmenorrhea and bleeding disorders, which cause substantial disruption to women's daily lives. Inadequate data exist on the population prevalence of abnormal bleeding, particularly during the menopausal transition, when such bleeding is likely to lead to hysterectomy. Basic research still needs to be conducted to describe the population patterns of these disorders and to identify potentially modifiable risk factors. 


\section{PART V. MENSTRUAL CYCLING, PHYSIOLOGIC FUNCTION, AND WOMEN'S LONG-TERM HEALTH STATUS}

This report has focused so far on the menstrual cycle as a health endpoint in and of itself. This section considers what is known about the broader impact of menstrual function on women's health. Two issues of critical importance are the role of the endocrine cycle in regulating diverse aspects of normal physiologic function and the relationship between menstrual characteristics and women's long-term risk of developing chronic diseases such as osteoporosis, cancer, and cardiovascular disease.

Considerable data indicate that hormones play an important role in the development of breast, endometrial, and ovarian cancer (Kelsey, 1993). Cessation of menstrual function at the time of menopause is associated with an increased risk of osteoporosis (Sowers and Galuska, 1993) and possibly cardiovascular disease (Barrett-Connor and Bush, 1989). The beneficial effect of estrogen replacement therapy (contraindications notwithstanding) supports a hormonally mediated etiology for each of these conditions. The accumulated evidence suggests that endogenous endocrine profiles throughout a woman's reproductive life are relevant to her long-term health. However, mechanisms relating menstrual function to a woman's long-term health profile are not well understood. Studies of hormonal risk factors have generally used relatively crude markers of endocrine function-for example, age at menarche, age at menopause, and pregnancy-related variables such as parity or age at first birth. The few studies that have examined the effect of menstrual history itself have yielded inconsistent results (Choi et al., 1978; Sherman et al., 1982; Olsson et al., 1983; La Vecchia et al., 1985). A larger problem, however, is that rigorous studies of the association between endocrine profiles and chronic disease have seldom been conducted, despite the fact that pharmacologic interventions have been widely introduced.

Unfortunately, studies of women's health tend to either completely ignore hormonal influences or to consider them in isolation from other biologic and environmental risk factors. This conceptual schism was illustrated recently by two major epidemiologic studies of heart disease in women. The first study is a prospective study of the natural history of heart disease in men and women aged 45 to 65 (ARIC, 1989). Even though this study observes women as they move through the menopausal transition, consideration of changing hormone profiles and the occurrence of menopause did not inform the original design of the study.

The second study is a large clinical trial designed to evaluate the efficacy of various regimens of estrogen and progesterone on cardiovascular risk factors (Barrett-Connor and Bush, 1991). These hormonal regimens are not compared with other standard treatments such as aspirin, cholesterol-lowering drugs, diet, and physical activity, despite the fact that clinical trials in men have 
proved these treatments efficacious. It is necessary to emphasize that both studies are well designed and will make important contributions to our knowledge of heart-disease risk in women. However, the failure to study the role of hormonal and nonhormonal risk factors in a more integrated manner remains of concern. Whether one is interested in studying common infections, heart disease, or breast cancer, an important step in identifying the biologic mechanisms through which the menstrual cycle influences disease risk will be to become better observers of the physiologic rhythms engendered by menstrual function.

\section{Changes in Physiologic Function During the Menstrual Cycle}

Although research is sparse, the menstrual cycle appears to modulate several aspects of women's physiology. Sporadic reports of variation across the menstrual cycle have been published over the last century for a diverse set of physiologic parameters. In recent years, interest in premenstrual syndrome has stimulated research on whether changes occur in a wide variety of physical and psychological symptoms during the premenstruum. However, systematic investigations of variability related to the menstrual cycle in relevant physiologic systems are limited. Nonetheless, data on circulatory, metabolic, and immunologic alterations suggest that cyclic hormonal variation is an important determinant of variability for some physiological phenomena.

For example, heart rate, pulse transit time, and blood pressure (Kaplan et al., 1990; Dunne et al., 1991) appear to vary systematically across the menstrual cycle, while hemodynamic and hemostatic responses to psychological stress may be elevated during the luteal phase (Manhem et al., 1991; Tersman et al., 1991; Jern et al., 1991). Whether these systematic fluctuations have functional or clinical implications remains uncertain; however, they are of sufficient magnitude to confound research results. Thus, timing of measurements during the menstrual cycle must be considered in the design of studies that plan to measure cardiovascular response (Kaplan et al., 1990).

Perhaps of more immediate relevance to women's everyday lives are cyclic changes that have been identified in energy metabolism. Webb (1986), in a controlled calorimetric experiment in sedentary conditions, found that women's 24-hour energy expenditure increased an average of 9 percent during the luteal phase, with some women expending up to 16 percent more energy. Sleeping metabolic rate has also been shown to increase an average of 8 percent in the luteal phase (Meijer et al., 1992). An earlier study of dietary intake found that women consume approximately 500 more calories in the luteal as compared with the follicular phase (Dalvit, 1981) and that this caloric increase stems from an approximate 50 percent increase in carbohydrate consumption (Dalvit-McPhillips, 1983). Based on Webb's data, premenstrual increases in 
carbohydrate consumption presumably reflect changing metabolic needs.

Experimental findings that resting muscle glycogen content and muscle glycogen repletion following exercise are higher during the luteal phase (Hackney, 1990; Nicklas et al., 1989) suggest that hormonal changes during the menstrual cycle also alter carbohydrate metabolism and storage. Furthermore, studies in diabetic patients have demonstrated that insulin sensitivity decreases during the luteal phase, at least for a subset of patients (Valdes and Elkind-Hirsch, 1991; Widom et al., 1992). Clearly, more investigation of alterations in physiological requirements is needed before the impact of menstrual function on women's metabolism and food requirements can be fully understood. Labeling such changes in physiological requirements "sweet cravings" does little to help women understand and adapt to their metabolic needs. Failure to account for stage of the menstrual cycle in analyzing food frequency data may confound results.

\section{Immune Function}

Potentially, one of the most important physiologic impacts of the menstrual cycle is its influence on immune function. Sex hormones affect differentiation, maturation, emigration, and function of lymphocytes, modulate immunoregulatory mechanisms, and influence monocyte and macrophage activity (Ahmed et al., 1985). Progesterone and estrogen may prove either immunosuppressive or immuno-enhancing depending on the dose, as immuno-endocrine effects are target-cell-specific and hormone- and dose-dependent. However, despite the relatively large body of literature on differences between males and females in immune response, changes in immune parameters during pregnancy, and effects of pharmacologic and physiologic doses of estrogen, progesterone, and testosterone on in vitro systems and on in vivo animal models (reviewed in Paavonen, 1987; Ahmed et al., 1985), only a handful of reports discuss change in immune response during the human menstrual cycle.

The literature on menstrual-cycle-related variability in immune response has examined natural killer (NK) activity (Sulke et al., 1985; White et al., 1982; Thyss et al., 1984; Gonik et al., 1985), lymphocyte numbers and subtypes (Bolis et al., 1983; Tumbo-Oeri, 1985; Coulam et al., 1983; Raptopoulou and Goulis , 1977; Mathur et al., 1979; Eichler and Keiling, 1988; Krzanowski, 1985), serum CA125 levels (Lehtovirta et al., 1990), contact sensitivity to allergens (Alexander, 1988; Agner et al., 1991), cellular immune response to Candida infection (Kalo-Klein and Witkin, 1989), HIV infectibility of macrophages (Olafsson et al., 1991), detection of papillomavirus (McNicol et al., 1990), and chlamydial infection (Rosenthal and Landefeld, 1990). Most of this literature describes preliminary findings and can only serve to suggest potentially important lines of research.

For example, T-lymphocytes appear to be an important target cell for reproductive hormone activity (Ahmed et al., 1985). Studies of variation over the menstrual cycle have evaluated 
lymphocyte numbers, percent distribution of lymphocytes or lymphocyte subsets, and lymphocyte activity. Unfortunately, methodological errors such as imprecise techniques, small samples, infrequent sampling, and lack of hormonal data are serious enough to invalidate the findings of most studies (Coulam et al., 1983; Eichler and Keiling, 1988; Tumbo-Oeri, 1985; Raptopoulou and Goulis, 1977). (See Table 13.) Studies with sufficiently large samples that correlate immune parameters with hormone measurements suggest that number and percent of lymphocytes do vary by menstrual cycle stage (Krzanowski, 1985; Bolis et al., 1983; Mathur et al., 1979).

The most rigorous study (Mathur et al., 1979) obtained blood samples from 18 women two to three times per week. Notably, gross comparisons of follicular-phase samples with luteal-phase samples indicated that only monocyte and granulocyte counts exhibited statistically significant increased counts in the luteal phase. However, when fluctuations of plasma estradiol and progesterone were evaluated in a detailed manner, more pronounced variation was observed. White blood cell, lymphocyte, and total T-lymphocyte counts were inversely correlated with estrogen levels, the lowest counts occurring at the time of the follicular estrogen peak. Monocyte and granulocyte counts rose during the luteal phase, the highest count coinciding with the progesterone peak. Active T-cell counts did not fluctuate.

Whether or not sex hormones influence lymphocyte numbers or subset distributions, the more important question is probably whether physiologic variation occurs in immune function. Estrogens have been shown to inhibit T-suppressor and natural killer function and modulate the production and/or secretion of various lymphokines in vitro (Ahmed et al., 1985). Estrogen receptors have been located on T-suppressor but not T-helper cells (Stimson, 1988) and the depressive effect of estrogen on in vitro T-cell activity affects only the T-suppressor subset (Stimson, 1988; Ahmed et al., 1985). Bolis et al. (1983) found that the percent of T-suppressor cells was significantly depressed in the pre-ovulatory phase (cycle day $10+/-2$ ) as opposed to the luteal (day $23+/-1$ ) or menstrual phase.

Cyclic change in NK cytotoxicity has been demonstrated during the estrus cycle of mice, with a single peak in activity occurring during met-estrus-2 (Furukawa et al., 1984), and the data suggest that the suppressive effects of estrogen are indirectly mediated by phagocytic cells such as monocytes or macrophages. Conflicting data from the human literature on NK activity (see Table 13) also suffer from serious methodological problems (White et al., 1982; Thyss et al., 1984; Gonik et al., 1985). In the one study that compared cytotoxicity levels at seven points across the menstrual cycle (based on the timing of three to four samples per woman), NK activity dropped significantly in the periovulatory period (Sulke et al., 1985).

Progesterone also modulates lymphocyte function and cytotoxicity (Szekeres-Bartho et al., 1985). Kalo-Klein and Witkin (1989) suggest that the cellular immune response to the presence of Candida albicans and the inhibition of Candida germination are reduced in the late luteal phase and 
that women are more susceptible to infection during the premenstruum. They subsequently showed that in vitro lymphocyte proliferation in response to Candida albicans was reduced by 50 percent in the presence of luteal-phase concentrations of progesterone (Kalo-Klein and Witkin, 1991). In contrast, low levels of progesterone characteristic of the follicular phase appeared to stimulate lymphocyte proliferation. As was true for estrogen effects on NK activity (Furukawa et al., 1984), the effect of progesterone on lymphocyte response appeared to be mediated by monocytes (KaloKlein and Witkin, 1991).

At least some of the various immunoregulatory proteins secreted by lymphocytes, monocytes, and macrophages are affected by female sex hormones. Interleukin-1 (IL-1) production by peripheral monocytes and peritoneal macrophages, for instance, does appear to be under hormonal control (Polan et al., 1988; Hu et al., 1988), with low levels stimulating and higher levels inhibiting human peripheral monocyte IL-1 activity (Polan et al., 1988). Female sex hormones also influence other aspects of immune function, including phagocytic activity of macrophages and monocytes and possibly antibody production by B cells (Ahmed et al., 1985). Even fewer data are available on potential menstrual-cycle-related variation in these parameters. T- and B-cell responsiveness to antigenic challenge has been demonstrated to vary during the estrus cycle of mice (Krzych et al., 1978). Two preliminary reports suggest that women's response to antigenic challenge may also be stronger during the premenstruum (Alexander, 1988; Agner et al., 1991).

In summary, estrogen and progesterone are important modulators of cellular, and possibly of humoral, immune response. Nonetheless, the physiological and clinical implications of variation in the endogenous hormone environment during the menstrual cycle remain unknown. Most studies of menstrual variation suffer from such serious methodological flaws that their findings must be discounted. Systematic investigation of the importance of fluctuations in the endogenous hormonal environment for immune function is clearly warranted. Simple comparisons between follicular and luteal phases ought to be avoided because of the high probability that variation linked to fluctuations in estrogen, $\mathrm{LH}$, or FSH levels will not be detected. Furthermore, hormone and immune measurements must be coupled and use of frequent sampling in adequate numbers of women is essential. Information on cyclic variation in immune function will be relevant not only to understanding women's disease patterns but also to determining appropriate protocols for measuring immune status in epidemiologic and clinical studies.

\section{Plasma Lipids and Lipoproteins}

While much is known about the effect of exogenous hormones on lipid parameters and risk of coronary heart disease, the relevance of these findings to understanding the effect of the endogenous hormonal environment on lipid parameters is unclear (Godsland et al., 1987). Except 
for evaluations of the effects of menopausal status, little attention has been paid to how inter-woman differences in the hormonal environment may alter lipid parameters. The question of cyclic variability in lipid profiles deserves attention because of its potential significance for risk of coronary heart disease, the leading cause of death in American women.

To provide some background, higher levels of total cholesterol appear to be predictive of coronary heart disease, while high-density lipoprotein cholesterol (HDL-C), particularly the $\mathrm{HDL}_{2}$ subfraction, exerts a protective effect and may be the most important lipid parameter in women (Bush et al., 1988). Women have higher levels of HDL-C at all ages than do men (Lipid Research Clinics, 1980). The importance of low-density lipoprotein cholesterol (LDL-C) and triglyceride levels remains controversial, but triglycerides are more consistently a risk for women than for men in epidemiologic studies (Austin, 1991). Exogenous estrogen administration increases HDL-C (especially the $\mathrm{HDL}_{2}$ subfraction) and triglycerides and decreases LDL-C. Given alone, progestins have opposite effects (Knopp, 1988; Bush et al., 1988; Miller, 1990). Little is known about the effect of cyclic estrogen-progestin therapy, which may now be the most common form of postmenopausal hormone replacement therapy (HRT). Preliminary findings suggest that adding progestin may prevent the increase in triglycerides seen with estrogen alone without negating the beneficial HDL-C and LDL-C effects (Egeland et al., 1990; Barrett-Connor et al., 1989; Nabulsi et al., 1993).

Studies of the effect of endogenous hormonal changes on lipids and lipoproteins have examined puberty, pregnancy, and menopause, in addition to the menstrual cycle. While HDL-C concentrations decrease by about 10 milligrams/deciliter with puberty in boys, no similar change is observed in girls (Lipid Research Clinics, 1980). During pregnancy, large increases in both LDL-C and HDL-C are observed (Barrett-Connor and Bush, 1991). Postmenopausal white women exhibit a more atherogenic lipid profile than do their premenopausal counterparts, including higher total cholesterol, LDL-C, very-low-density lipoprotein (VLDL-C), and triglycerides (Hjortland et al., 1976; Lindquist and Bengtsson, 1980; Bush et al., 1984; Matthews et al., 1989). Cross-sectional studies show no effect on HDL-C, but two recent prospective studies have also reported slightly but significantly lower HDL-C levels postmenopausally (Matthews et al., 1989; Jensen et al., 1990).

Studies of the effect of menstrual cycle stage on lipid parameters (see Table 14) are equivocal and have many of the same methodological problems observed in the immune studies described above. They vary considerably in sample size, lipids measured, definition of cycle phases, and timing and frequency of sampling. The study populations also differ markedly by age, menstrual cycle length and baseline lipid levels. One study (Hemer et al., 1985) that included a large sample size $(\mathrm{N}=114)$ drew only one blood sample per woman. The largest of the studies that drew multiple blood samples per woman included just 37 women (Lebech et al., 1990). Most studies imputed cycle phases based on the 28-day model, despite observed variability in menstrual cycle lengths. 
Only 9 of the 16 studies evaluated hormonal levels. In 12 of the 15 studies with multiple lipid measurements per woman, only two to four samples were drawn per cycle and the timing of blood draws during the cycle differed from study to study: some captured the pre-ovulatory increase in estrogens, and others did not. From an analytical viewpoint, it may also have been necessary to model a lag time between major hormonal fluctuations and lipid parameters to account for the halflife of lipoproteins in the blood (Kuller et al., 1990).

Nonetheless, the results provide some support for the hypothesis that lipid and lipoprotein concentrations vary during the menstrual cycle. Total cholesterol (Low-Beer et al., 1977; Krauss et al., 1979; Mattsson et al., 1984; Hemer et al., 1985; Jones et al., 1988; Lebech et al., 1990), triglycerides (Low-Beer et al., 1977; Krauss et al., 1979; Kim and Kalkhoff, 1979; Mattsson et al., 1984; Tikkanen et al., 1986; Jones et al., 1988), LDL (Kim and Kalkhoff, 1979; Mattsson et al., 1984; Lebech et al., 1990), and VLDL (Mattsson et al., 1984; Tikkanen et al., 1986) appear to decline during the luteal phase. Two recent studies found the lowest levels of total cholesterol during menstruation (Lussier-Cacan et al., 1991; Tangney et al., 1991). Findings for HDL-C are somewhat more equivocal (Kim and Kalkhoff, 1979; Basdevant et al., 1981; Demacker et al., 1982; Mattsson et al., 1984; Hemer et al., 1985; Tikkanen et al., 1986; Jones et al., 1988; Lebech et al., 1990), possibly due to differential effects of sex hormones on HDL subfractions (Barclay et al., 1965; Krauss et al., 1979).

In summary, as was true for immune function, our knowledge of the effects of menstrual function on lipid profiles is quite rudimentary despite the considerable evidence of an association between sex hormones and lipids. Additional studies using larger sample sizes, more frequent measurements, and hormonal measurements are obviously required to characterize menstrual cycle effects on lipid parameters. However, the data also suggest that additional hypotheses need exploration. Kim and Kalkhoff's (1979) finding of a luteal phase decrease in apo B is worthy of further study, as the lipoproteins may be better predictors of coronary heart disease risk than are lipoproteins (Avogaro et al., 1979). Tikkanen et al.'s (1986) finding of decreased hepatic lipase activity in the luteal phase also deserves attention. Hepatic lipase activity is thought to be involved in degrading $\mathrm{HDL}_{2}$, is lower in women than in men, and is suppressed by exogenous estrogen administrations (Tikkanen et al., 1986; Godsland et al., 1987). It could thus account for higher $\mathrm{HDL}_{2}$ levels in women. The work of Tikkanen et al. indicate that both direct and indirect mechanisms for menstrual-related fluctuations in lipid parameters warrant exploration.

The effect of environmental factors such as diet on the relationship between the menstrual cycle and lipids also deserves more consideration. Diet appears to influence both the endogenous hormonal environment (see Additional Host and Environmental Factors, in Part III) and lipid parameters (Bush et al., 1988). Jones et al. (1988) noted differences in cyclic fluctuations in lipid 
parameters depending upon the fat content of the diet. Furthermore, in societies in which coronary heart disease is rare, gender differences in plasma lipoproteins levels are much reduced. Though the reasons for this difference are not well studied or understood, an interaction with some aspect of socioeconomic status, such as diet, has been proposed (Godsland et al., 1987).

\section{Summary}

The menstrual cycle appears to influence important aspects of women's physiologic function. Given the paucity of information, a systematic program of research on physiologic variation across the menstrual cycle ought to be undertaken for a wide range of parameters. In addition, the potential influence of other host and environmental factors, such as genetics, diet, or stress, on these associations could be explored. Both the immune and lipid literature suggest that greater attention should be given to indirect mechanisms through which reproductive hormones may exert their effects. Clearly, variation in immune competence and lipid parameters is of great clinical interest. However, factors of great relevance to women's daily lives, such as metabolic need, should not be overlooked.

\section{Menstrual History and Risk of Chronic Disease}

Much of the evidence linking sex hormones to cancer, cardiovascular disease, and osteoporosis is derived from data on exogenous steroids or from evaluation of the effects of menarche, menopause, or pregnancy. Despite preliminary evidence that the hormonal environment throughout reproductive life might be a relevant indicator of long-term disease risk, few studies have directly examined the role of menstrual characteristics or endocrine metabolism in explaining chronic disease risk. Failure to systematically investigate the role of life-time exposures to endogenous hormones may be keeping us from identifying important prevention strategies.

For example, in most western countries, mortality rates associated with coronary heart disease are lower for women than for men at all ages (Eaker et al., 1989; Johansson et al, 1983; Godsland et al., 1987). Because of this marked protection, considerable research has focused on the protective role of female sex hormones, most notably estrogen, in lowering the risk of coronary heart disease (Barrett-Connor and Bush, 1991). A recent meta-analysis of 31 studies examining the effect of postmenopausal exogenous estrogen use on coronary heart disease found a 50 percent reduction in risk among current users (Stampfer et al., 1991). However, our understanding of the potential role of endogenous hormones in defining lifetime risk is minimal.

Studies of endogenous hormonal effects on coronary heart disease risk that have focused on the occurrence and timing of reproductive events such as puberty, pregnancy, and, more frequently, menopause do not provide a coherent story. The effect of parity on coronary heart disease risk is 
equivocal (Barrett-Connor and Bush, 1991). Age at menarche is not significantly associated with risk of coronary heart disease (Colditz et al., 1987; La Vecchia et al., 1987). In general, postmenopausal women exhibit a more atherogenic lipid profile than do premenopausal women, including higher total cholesterol, LDL-C, triglycerides, and, in some studies, a slight decrease in HDL-C (Matthews et al., 1989). However, whether or not passage through menopause moves women from a lower-risk to a higher-risk status remains uncertain. While surgical menopause via bilateral oophorectomy appears to be consistently associated with increased risk of coronary heart disease (Colditz et al., 1987), the effect of natural menopause is less clear and is confounded by the promotional effects of age and smoking (Willett et al., 1983) on both natural menopause and coronary heart disease.

Metcalf's work (see Variability in the Endocrine Cycle, in Part II of this report) has suggested that the low estrogen levels characteristic of older women, which presumably are relevant to changing lipid profiles, evolve gradually and reach their nadir only sometime after menopause. On the other hand, age at menopause is a reflection of a woman's endogenous hormonal environment, and that lifetime exposure may in fact be the causal factor in heart disease risk. One provocative case-control study found a significantly increased risk of myocardial infarction before age 55 in women with a history of frequent menstrual cycles less than 21 or more than 35 days long (La Vecchia et al., 1987).

Interestingly, results from work in an animal model shed more light on the possible effects of lifetime exposure to a relatively estrogen-deprived hormonal milieu (Clarkson et al., 1989). Female macaques have a 28-day menstrual cycle with estrogen and progesterone changes similar to those in humans. The male:female ratio for coronary artery atherosclerosis is similar to that seen in North American white populations, and the females of the species have higher HDL levels than do the males. Social subordination is associated with an increased probability of anovulatory cycles, luteal-phase deficiency, and lower estradiol peaks such that these animals are chronically estrogendepleted (Adams et al., 1985a; 1985b). Relative to dominant females, subordinate females have depressed HDL levels and a threefold elevation in coronary atherosclerosis independent of the lipid effect. Although each is associated with a decrease in HDL, both pregnancy and oral contraceptive use decrease rather than increase atherosclerosis, suggesting that progesterone-induced adverse lipoprotein changes may not be important in the face of adequate estrogen levels (Adams et al., 1987).

The menstrual cycle has been evaluated somewhat more extensively as a potential risk factor for breast cancer and osteoporosis. Although the data are, again, somewhat inconsistent (Sherman et al., 1982), long or "irregular" cycles have also been found to be protective for breast cancer (Frisch et al., 1985; La Vecchia et al., 1985; Olsson et al., 1983) as well as for ovarian cancer 
(Parazzini et al., 1989). Short menstrual cycles were also found in one study to be a risk factor for certain lung cancers (Gao et al., 1987).

Despite some inconsistent reports (Baker and Demers, 1988), menstrual characteristics do appear to predict bone mass in premenopausal (Drinkwater et al., 1990) and collegiate (Lloyd et al., 1988) athletes, with regular cycling women having higher bone density than women with a history of long cycles. Two recent studies of bone loss (Prior et al., 1990) and bone mass (Sowers et al., 1990) suggest that menstrual cycle characteristics and estradiol levels in premenopausal women may be the most important predictors of long-term risk of osteoporosis. Over a one-year period, menstrual cycle characteristics were a better predictor of bone loss in premenopausal women than was level of physical activity (Prior et al., 1990). Premenopausal women in the lowest fifth percentile of femoral bone mass had significantly lower estradiol levels and higher luteinizing hormone levels than controls (Sowers et al., 1990). These data suggest that early differences in a woman's hormonal milieu are related to peak adult bone mass.

In summary, the data on menstrual cycle characteristics as risk factors for chronic disease, though limited, are sufficient to suggest that this avenue of research could be productive both in explaining women's long-term health status and in identifying prevention strategies for premenopausal women. However, while ovulatory disturbances may be protective for some chronic diseases, such as breast cancer (Henderson et al., 1985), they are probably a risk factor for others, such as osteoporosis (Prior et al., 1990) and possibly heart disease. In the absence of sufficient epidemiologic research on the relationship between menstrual function and multiple aspects of women's health, calls for interventions based on preliminary findings for isolated disease outcomes are probably inappropriate (Bernstein et al., 1987; Henderson et al., 1985).

Given the role of sex hormones in regulating a wide variety of physiologic parameters, consideration ought to be given to developing a paradigm of women's health based on identification of what might constitute an optimal hormonal balance. Such an understanding of the relationship between menstrual characteristics, ovarian hormones, and risk of chronic disease could then lead to innovative, preventive strategies with important public health implications.

Throughout this report, it has been suggested that our conception of the menstrual cycle needs to be broadened from a simple focus on ovulation to a broader perspective of the endocrine environment, and that we need to begin thinking about the broad implications of this endocrine environment for women's health. To date, not only have we not satisfactorily characterized population distributions of women's endogenous hormonal environments, but we have few clues about what might constitute the optimal endogenous endocrine environment to promote long-term health. The multiple, complex, interdependent, and dose-dependent effects of estrogen and progesterone on the immune system and physiologic function are of particular concern when one 
considers the potential impact of long-term and widespread pharmacologic interventions such as steroid contraception and hormone replacement therapies. Evaluation of the health consequences of steroid contraception and estrogen-replacement therapy ultimately depends upon gaining a better understanding of the complex relationship between the menstrual cycle and women's health. 


\section{PART VI. DEFINING A RESEARCH AGENDA FOR THE MENSTRUAL CYCLE}

Based on the above review, it is obvious that a comprehensive program of research is needed in order to begin filling the myriad gaps in scientific knowledge about the menstrual cycle. Given the lack of knowledge about many fundamental aspects of menstrual function and about linkages between the menstrual cycle and other physiologic systems, the importance of conducting basic research cannot be underestimated. For those physiologic parameters that fluctuate across the menstrual cycles, careful consideration of this source of variation in epidemiologic study designs is essential to the validity of study results. Basic science studies will need to be undertaken to fill this fundamental gap in knowledge.

In some instances, evaluation of questions that have not yet been asked or well developed, such as how endocrine metabolism varies among women, may need to take priority if we wish to make substantial gains in our understanding of women's reproductive and long-term health. Although the National Institutes of Health have begun several research initiatives focused on menopause and the health effects associated with the cessation of reproductive life, considerably more focus needs to be given to the menstrual cycle itself, as its influence extends over 30 to 40 years of a woman's life. Specific recommendations for research program priorities include the following:

1. More population-based studies of the natural variability in menstrual cycles across the reproductive life course need to be conducted in ethnically, culturally, and socially diverse populations. In addition to information on cycle length and the probability of ovulation, these studies should also describe variability in bleed duration and amount, hormonal patterns, and metabolic pathways. Host and environmental factors that may influence this variability should also be examined, with an emphasis on the role of diet, environmental chemicals, and the social environment.

2. Epidemiologic studies of age-specific incidence and prevalence of menstrual dysfunction, particularly abnormal bleeding, are needed in all ethnic groups. Case-control studies to examine risk factors for abnormal bleeding should also be a high priority.

3. Basic research on changes in physiologic function across the menstrual cycle should be undertaken for most physiologic parameters; however, because of their significance to women's health profile, research on cyclic changes in immune function, metabolism, and cardiovascular function should be priorities.

4. Systematic investigation of the relationship between menstrual cycle characteristics and risk of chronic disease, including evaluation of hormone profiles and physiologic risk factors in premenopausal women, is also essential.

5. In addition to this substantive research program, development of simpler quantitative hormonal assays are needed to facilitate investigation of inter-woman differences in hormonal patterns and endocrine metabolism. 
Finally, the ubiquitous methodological error of equating cycle day with the endocrine level of a standardized 28-day model menstrual cycle must also be addressed. Studies that assume that ovulation occurs on cycle day 14, that the luteal phase invariably lasts 14 days, and that variation in cycle length is due to variation in length of the follicular phase should no longer be considered acceptable science. In the general population of women, who exhibit considerable variability in their hormonal patterns and marked variation in phase length by age, standardized cycle days are neither precise nor valid measures of endocrine levels. Use of this proxy measure is likely to lead to misclassification and, therefore, to invalid results. Such misclassification is especially likely if the subcategorization is more detailed than follicular/luteal phase. Furthermore, as was evident from studies of immune parameters and lipid profiles, simple follicular/luteal classification may not be sufficient to detect meaningful variation. To the extent that it is important, for a given parameter, to identify (1) change associated with peak as opposed to basal estrogen levels; (2) peak levels as opposed to the presence of progesterone; (3) relative increases in hormones; or (4) the effect of change in gonadotropin levels, more frequent sampling coupled with hormonal data will be critical. 


\section{BIBLIOGRAPHY}

Abraham, S. F., P. J. Beumont, I. S. Fraser et al. 1982. Body weight, exercise and menstrual status among ballet dancers in training. British Journal of Obstetrics and Gynecology.

Adams, M. R., J. R. Kaplan, and D. R. Koritnik. 1985a. Psychosocial influences on ovarian endocrine and ovulatory function in Macaca Fascicularis. Physiology and Behavior 35:935-40.

Adams, M. R., J. R. Kaplan, T. B. Clarkson et al. 1985b. Ovariectomy, social status and atherosclerosis in cynomolgus monkeys. Arteriosclerosis 5:192-200.

1987. Pregnancy-associated inhibition of coronary artery atherosclerosis in monkeys: Evidence of a relationship with endogenous estrogen. Arteriosclerosis 7:378-84.

Agner, T. A., P. Damm, and S. O. Skouby. 1991. Menstrual cycle and skin reactivity. Journal of the American Academy of Dermatology 24:566-70.

Ahmed, S. A., J. Penhale, N. Talal et al. 1985. Sex hormones, immune responses, and autoimmune diseases. American Journal of Pathology 121:531-51.

Aldercreutz, H. and G. Tallqvist. 1959. Variations in the serum total cholesterol and hematocrit values in normal women during the menstrual cycle. Scandinavian Journal of Clinical and Laboratory Investigation 11:1-9.

Alexander, S. 1988. Patch testing and menstruation (letter). The Lancet (September 24): 751.

Alvarado, G., R. Rivera, R. Ruiz et al. 1988. Características del patrón de sangrado menstrual en un grupo de mujeres normales de durango. Ginecología y obstetricia de México 56:127-31.

Andersch, B. and I. Milsom. 1982. An epidemiologic study of young women with dysmenorrhea. American Journal of Obstetrics and Gynecology 144:655-60.

Andrews, W. C. 1979. Luteal phase defects. Fertility and Sterility 32:501-509.

ARIC Investigators. 1989. The Atherosclerosis Risk in Communities (ARIC) study: Design and objectives. American Journal of Epidemiology 129:687-702.

Austin, M. A. 1991. Plasma triglyceride and coronary heart disease. Arteriosclerosis and Thrombosis 11(1):2-14.

Avogaro, P. et al. 1979. Are apolipoproteins better discriminators than lipids for atherosclerosis? The Lancet (April 28):901-03.

Baanders-Van Halewijn, E. A. and F. De Waard. 1968. Menstrual cycles shortly after menarche in European and Bantu girls. Human Biology 40:314-22.

Bachmann, G. and E. Kemmann. 1982. Prevalence of oligomenorrhea and amenorrhea in a college population. American Journal of Obstetrics and Gynecology 144:98-102.

Back, D. J. and M. L. E. Orme. 1994. Pharmacokinetic drug interactions with oral contraceptives. In Steroid Contraceptives and Women's Response: Regional Variability in Side Effects and Pharmacokinetics. Ed. R. Snow and P. Hall. New York: Plenum Publishing Corporation, 10324.

Back, D. J., A. M. Breckenridge, F. E. Crawford et al. 1981. Interindividual variation and drug 
interactions with hormonal steroid contraceptives. Drugs 21:46-61.

Badwe, R. A., W. M. Gregory, M. A. Chaudary et al. 1991. Timing of surgery during menstrual cycle and survival of premenopausal women with operable breast cancer. The Lancet (May 25) 337:1261-64.

Baetjer, A. M. 1946. Women in Industry: Their Health and Efficiency. Philadelphia: W. B. Saunders, 199.

Baird, D. D. and A. J. Wilcox. 1985. Cigarette smoking associated with delayed conception. Journal of the American Medical Association 253:2979-83.

Baird, D. T. 1987. A model for follicular selection and ovulation: Lessons From superovulation. Journal of Steroid Biochemistry 27:15-23.

Baker, E. and L. Demers. 1988. Menstrual status in female athletes: Correlation with reproductive hormones and bone density. Obstetrics and Gynecology 72:683-87.

Baker, E. R., R. S. Mathur, R. F. Kirk et al. 1981. Female runners and secondary amenorrhea: Correlation with age, parity, milage, and plasma hormonal and sex-hormone-binding globulin concentrations. Fertility and Sterility 36:183-87.

Ball, P., H. P. Gelbke, R. Knuppen et al. 1975. The excretion of 2-hydroxyestrone during the menstrual cycle. Journal of Clinical Endocrinology and Metabolism 40:406-08.

Bang, R. A., A. T. Bang, M. Baitule et al. 1989. High prevalence of gyneacological diseases in rural Indian women. The Lancet (January 14): 85-88.

Barclay, M., R. K. Barclay, V. P. Skipski et al. 1965. Fluctuations in human serum lipoproteins during the normal menstrual cycle. Biochemical Journal 96:205-09.

Baron, J. A. 1984. Smoking and estrogen-related disease. American Journal of Epidemiology 119:9-22.

Barrett-Connor, E. and T. L. Bush. 1989. Estrogen replacement and coronary heart disease. In Heart Disease in Women, Ed. P. S. Douglas. Philadelphia: F.A. Davis Company, chapter 10.

_ 1991. Estrogen and coronary heart disease in women. Journal of the American Medical Association 265:1861-67.

Barrett-Connor, E., D. L. Wingard, and M. H. Criqui. 1989. Postmenopausal estrogen use and heart disease risk factors in the 1980's: Rancho Bernado revisited. Journal of the American Medical Association 261:2095-2100.

Basdevant, A., B. de Lignieres, B. Bigorie et al. 1981. Estradiol, progesterone and plasma lipids during the menstrual cycle. Diabete and Metabolisme 7:1-4.

Beardwood, C. J., C. A. Mundell, W. H. Utian et al. 1975. Gonadotropin excretion in response to audiostimulation of human subjects. American Journal of Obstetrics and Gynecology 121:682-87.

Belsey E. M. and S. Perogoudov. 1988. Task Force on Long-Acting Systemic Agents for Fertility Regulation. Determinants of menstrual bleeding patterns among women using natural and hormonal methods of contraception: I. Regional Variations. Contraception 38:227-42. 
Berga, S., J. Mortola, and S Yen. 1988. Amplification of nocturnal melatonin secretion in women with functional hypothalamic amenorrhea. Journal of Clinical Endocrinology and Metabolism $66: 242-44$.

Bernstein, L., R. K. Ross, R. A. Lobo et al. 1987. The effects of moderate physical activity on menstrual cycle patterns in adolescence: Implications for breast cancer prevention. British Journal of Cancer 55:681-85.

Bernstein, S. J. et al. 1992. Hysterectomy: A Literature Review and Ratings of Appropriateness. Santa Monica: The RAND Corporation.

Bjorntorp, P. 1991. Metabolic implications of body fat distribution. Diabetes Care 14:1132-43.

Boehm, F. H. and N. J. Salerno. 1973. Menstrual abnormalities in the wave recruit population. Military Medicine 138:30-31.

Bolis, P. F., M. Franchi, L. Babilonti et al. 1983. T-lymphocyte subsets in normal menstrual cycle. Clinical and Experimental Obstetrics and Gynecology 10(2-3):115-17.

Bonen, A. 1992. Recreational exercise does not impair menstrual cycles: A prospective study. International Journal of Sports Medicine 13:110-20.

Brown, S., M. Vessey, and I. Stratton. 1988. The influence of method of contraception and cigarette smoking on menstrual patterns. British Journal of Obstetrics and Gynaecology 95:905-10.

Bullen, B. A., G. S. Skrinar, I. Z. Beitins et al. 1985. Induction of menstrual disorders by strenuous exercise in untrained women. New England Journal of Medicine 312:1349-53.

Bush, T. L., L. P. Fried, and E. Barrett-Connor. 1988. Cholesterol, lipoproteins, and coronary heart disease in women. Clinical Chemistry 34(8B):B60-B70.

Bush, T., L. Cowan, G. Heiss et al. 1984. Ovarian function and lipid/lipoprotein levels: Results from the Lipid Research Clinics Program. American Journal of Epidemiology 120:489.

Campbell, O. M. R. and R. H. Gray. 1993. Characteristics and determinants of postpartum ovarian function in women in the United States. American Journal of Obstetrics and Gynecology 169:55-60.

Carlberg, K. A., M. T. Buckman, G. T. Peake et al. 1983. Body composition of oligo/amenorrheic athletes. Medical Science in Sports and Exercise 15:215-17.

Chapman, R. M., S. B. Sutcliffe, J. S. Malpas et al. 1979. Cytotoxic-induced ovarian failure in women with Hodgkin's disease: I. Hormone Function. Journal of the American Medical Association 242:1877-81.

Chase, H. P., S. E. Barnett, N. Welch et al. 1973. Pesticides and U.S. farm labor families. Rocky Mountain Medical Journal 70:27-31.

Chiazze, L., F. T. Brayer, J. J. Macisco et al. 1968. The length and variability of the human menstrual cycle. Journal of the American Medical Association 203(6):377-80.

Choi, N. W., G. R. Howe, A. B. Miller et al. 1978. An epidemiologic study of breast cancer. American Journal of Epidemiology 107(6):510-21. 
Clarkson, T. B., M. S. R. Adams, J. R. Kaplan et al. 1989. Pathophysiology of coronary artery atherosclerosis: animal studies of gender differences. In Heart Disease in Women. Ed. P.S. Douglas. Philadelphia: FA Davis Company, 147-58.

Colditz, G. A., W. C. Willett, M. J. Stampfer et al. 1987. A prospective study of age at menarche, parity, age at first birth, and coronary heart disease in women. American Journal of Epidemiology 126:861-70.

Collett, M. E., G. E. Wertenberge, V. M. Fiske et al. 1954. The effect of age upon the pattern of the menstrual cycle. Fertility and Sterility 5:437-48.

Coulam, C. B., J. C. Silverfield, R. E. Kazmar et al. 1983. T-lymphocyte subsets during pregnancy and the menstrual cycle. American Journal of Reproductive Immunology 4:88-90.

Cumming, D. C., G. D. Wheeler, and V. J. Harber. 1994. Physical activity, nutrition and reproduction. Annals of the New York Academy of Science 709:55-76.

Cutler, W. B., G. Preti, A. Krieger et al. 1986. Human axillary secretions influence women's menstrual cycles: The role of donor extract from men. Hormones and Behavior 20:463-73.

Dale, E., D. H Gerlach, and A. L. Wilhite. 1979. Menstrual dysfunction in distance runners. Obstetrics and Gynecology 54(1):47-53.

Dalvit, S. P. 1981. The effect of the menstrual cycle on patterns of food intake. American Journal of Clinical Nutrition 34:1811-15.

Dalvit-McPhillips, S. P. 1983. The effect of the human menstrual cycle on nutrient intake. Physiology and Behavior 31:209-12.

Demacker, P. N. M., R. W. B. Schade, A. F. H. Stalenhoef et al. 1982. Influence of contraceptive pill and menstrual cycle on serum lipids and high-density lipoprotein cholesterol concentrations. British Medical Journal 284:1213-15.

Deslypere, J. P., L. Verdonck, A. Vermeulen et al. 1985. Fat tissue: A steroid reservoir and site of endocrine metabolism. Journal of Clinical Endocrinology and Metabolism 61:564-70.

Ding, J. H., C. B. Sheckter, B. L. Drinkwater et al. 1988. High serum cortisol levels in exerciseassociated amenorrhea. Annals of Internal Medicine 108:530-34.

Doring, G. K. 1969. The incidence of anovular cycles in women. Journal of Reproduction and Fertility Supplement 6:77-81.

Drew, F. L. 1961. The epidemiology of secondary amenorrhea. Journal of Chronic Disease 14:396407.

Drinkwater, B. L., B. Bruemner, C. H. Chesnut et al. 1990. Menstrual history as a determinant of current bone density in young athletes. Journal of the American Medical Association 263:54548.

Dunne, F. P., D. G. Barry, J. B. Ferriss et al. 1991. Changes in blood pressure during the normal menstrual cycle. Clinical Science 81:515-18.

Duby, R. T., H. F. Travis, and C. E. Terrill. 1971. Uterotrophic activity of DDT in rats and mink and 
its influence on reproduction in the rat. Toxicology of Applied Pharmacology 18:348-55.

Eaker, E. E. et al. 1989. Epidemiology and risk factors for coronary heart disease in women. Heart Disease in Women. Ed. P. S. Douglas. Philadelphia: F.A. Davis and Company, Chapter 8.

Egeland, G. M., L. H. Kuller, K. M. Matthews et al. 1990. Hormone replacement therapy and lipoprotein changes during early menopause. Obstetrics and Gynecology 76:776-82.

Eichler, F. and R. Keiling. 1988. Variations in the percentages of lymphocyte subtypes during the menstrual cycle in women. Biomedicine and Pharmacotherapy 42:285-87.

Ellison, P. T., N. R. Peacock, C. Lager et al. 1989. Ecology and ovarian function among Lese women of the Ituri Forest, Zaire. American Journal of Physical Anthropology 78:519-26.

Ellison, P. T. and T. D. Cabot. 1990. Human ovarian function and reproductive ecology: New hypotheses. American Anthropologist 92:933-52.

Ellison, P. T. and C. Lager. 1986. Moderate recreational running is associated with lowered salivary progesterone profiles in women. American Journal of Obstetrics and Gynecology 154:100003.

Falk, J. R. and K. A. Halmi. 1982. Amenorrhea in anorexia nervosa: Examination of the critical body weight hypothesis. Biological Psychiatry 17:799-806.

Faulkes, C. G., D. H. Abbot, J. V. Jarvis et al. 1990. Social suppression of ovarian cyclicity and wild colonies of naked mole-rats Heterocephalus Glaber. Journal of Reproduction and Fertility 88:559-68.

Feicht, C. B., T. S. Johnson, B. J. Martin et al. 1978. Secondary amenorrhea in athletes. The Lancet 2:1145-46.

Fishman, J. 1981. Biological action of catechol oestrogens. Journal of Endocrinology 89 Supplement:59-65.

Fishman, J., R. M. Boyar, L. Hellman et al. 1975. Influence of body weight on estradiol metabolism in young women. Journal of Clinical Endocrinology and Metabolism 41:989-91.

Flug, D., R. H. Largo, and A. Prader. 1984. Menstrual patterns in adolescent Swiss girls: A longitudinal study. Annals of Human Biology 11:495-508.

Fraser, I. S., G. McCarron, R. Markham et al. 1984. A preliminary study of factors influencing perception of menstrual blood loss volume. American Journal of Obstetrics and Gynecology 149:788-93.

- 1985. Blood and total fluid content of menstrual discharge. Obstetrics and Gynecology 65:194-98.

Fraser, I. S. 1992. Hysteroscopy and laparoscopy in women with menorrhagia. American Journal of Obstetrics and Gynecology 162:1264-9.

Friedman, C. I. and M. H. Kim. 1985. Obesity and its effect on reproductive function. Clinical Obstetrics and Gynecology 28:645-63.

Fries, H., S. J. Nillius, and F. Pettersson. 1974. Epidemiology of secondary amenorrhea: II. A 
retrospective evaluation of etiology with special regard to psychogenic factors and weight loss. American Journal of Obstetrics and Gynecology 118:473-79.

Frisch, R. E. and J. W. McArthur. 1974. Menstrual cycles: Fatness as a determinant of minimum weight for height necessary for maintenance or onset. Science 185:949-51.

Frisch, R. E., G. Wyshak, and L. Vincent. 1980. Delayed menarche and amenorrhea in ballet dancers. New England Journal of Medicine 303(1):17-9.

Frisch, R. E., G. Wyshak, N. L. Albright et al. 1985. Lower prevalence of breast cancer and cancers of the reproductive system among former college athletes compared to non-athletes. British Journal of Cancer 52:885-91.

Furukawa, K., K. Hoh, K. Okamura et al. 1984. Changes in NK cell activity during the estrous cycle and pregnancy in mice. Journal of Reproductive Immunology 6:353-63.

Galle, P. C., E. W. Freeman, M. G. Galle et al. 1983. Physiologic and psychologic profiles in a survey of women runners. Fertility and Sterility 39:633-39.

Gao, Y. T., W. J. Blot, W. Zheng et al. 1987. Lung cancer among Chinese women. International Journal of Cancer 40:604-09.

Gath, D., M. Osborn, G. Bungay et al. 1987. Psychiatric disorder and gynaecological symptoms in middle age women: A community survey. British Medical Journal 294:213-18.

Gershenson, D. M. 1988. Menstrual and reproductive function after treatment with combination chemotherapy for malignant ovarian germ cell tumors. Journal of Clinical Oncology 6:270-75.

Glass, A. R., P. A. Deuster, S. B. Kyle et al. 1987. Amenorrhea in olympic marathon runners. Fertility and Sterility 48(5):740-45.

Godsland, I. F., V. Wynn, D. Crook et al. 1987. Sex, plasma lipoproteins, and atherosclerosis: Prevailing assumptions and outstanding questions. American Heart Journal 114(6):1467-1503.

Goldhirsch, A., R. D. Gelber, J. Forbes et al. 1991. Timing breast cancer surgery (letter). The Lancet (September 14) 338:691-92.

Goldzieher, J. W., T. S. Dozier, A. de la Pena et al. 1980. Plasma levels and pharmacokinetics of ethynyl estrogens in various populations. Contraception 21:1-16.

Gonik, B., L. Loo, R. Bigelow et al. 1985. Influence of menstrual cycle variations on natural killer cytotoxicity and antibody-dependent cellular cytotoxicity to cells infected with herpes simplex virus. Journal of Reproductive Medicine 30(6):493-96.

Graham, C. A. and W. C. McGrew. 1980. Menstrual synchrony in female undergraduates living on a coeducational campus. Psychoneuroendocrinology 5:245-52.

Graham, R. L., D. L. Grimes, R. D. Gambrell et al. 1979. Amenorrhea secondary to voluntary weight loss. Southern Medical Journal 72:1259-61.

Graves, E. J. 1992. National hospital discharge survey: Annual summary, 1990. Vital Health Statistics: 13.

Gray, R. H. and P. E. Doyle. 1983. The epidemiology of conception and fertility. In Obstetrical 
Epidemiology. Ed. S.L. Barron and A.M. Thomson. London: Academic Press, 25-60.

Green, T. H. 1977. Gynecology: Essentials of Clinical Practice. Third Edition. Boston: Little, Brown and Company.

Gregory, W. M., M. A. Richards, and I. S. Fentiman. 1992. Optimal timing of initial breast cancer surgery (letter). Annals of Internal Medicine 116:268-69.

Grodin, J. M., P. K. Siiteri, P. C. MacDonald et al. 1973. Source of estrogen production in postmenopausal women. Journal of Clinical Endocrinology and Metabolism 36:207-14.

Guengerich, F. P. 1988. Oxidation of 17-ethynylestradiol by human liver cytochrome P-450. Molecular Pharmacology 33:500-08.

Hackney, A. C. 1990. Effects of the menstrual cycle on resting muscle glycogen content. Hormone and Metabolic Research 22(12):647.

Hallberg, L., A. M. Hogdahl, L. Nilsson et al. 1966. Menstrual blood loss-a population study. Acta Obstetrica y Gynecologica Scandinavia 45:320-51.

Harlass, F. E., S. R. Plymate, B. L. Fariss et al. 1984. Weight loss is associated with correction of gonadotropin and sex steroid abnormalities in the obese anovulatory female. Fertility and Sterility 42:649-52.

Harlow, S. D. 1986. Function and dysfunction: A historical critique of the literature on menstruation and work. Health Care for Women International 7:39-50.

Harlow, S. D. and B. C. Campbell. 1994. Host factors that influence the duration of menstrual bleeding. Epidemiology 5:352-55.

Harlow, S. D. and G. M. Matanoski. 1991. The association between weight, physical activity and stress and variation in the length of the menstrual cycle. American Journal of Epidemiology 133:38-49.

Harlow, S. D. and S. L. Zeger. 1991. Application of longitudinal methods to the analysis of menstrual diary data. Journal of Clinical Epidemiology 44:1015-25.

Hartz, A. J., P. N. Baboriak, A. Wong et al. 1979. The association of obesity with infertility and related menstrual abnormalities in women. International Journal of Obesity 3:57-73.

Heinrichs, W. L., R. J. Gellert, L. Bakke et al. 1971. Persistent estrous syndrome following DDT administration to neonatal rats. Clinical Research 19:171.

Hemer, H. A., V. V. Valles de Bourges, J. J. Ayala et al. 1985. Variations in serum lipids and lipoproteins throughout the menstrual cycle. Fertility and Sterility 55:80-84.

Henderson, B. E., R. K. Ross, H. L. Judd et al. 1985. Do regular ovulatory cycles increase breast cancer risk? Cancer 56:1206-08.

Hill, P., L. Garbaczewski, N. Haley et al. 1984. Diet and follicular development. American Journal of Clinical Nutrition 39:771-77.

Hjortland, M. C., P. M. Mcnamara, and W. B. Kannel. 1976. Some atherogenic concomitants of menopause. The Framingham Study. American Journal of Epidemiology 103:304-11. 
Horning, S. J., R. T. Hoppe, H. S. Kaplan et al. 1981. Female reproductive potential after treatment for Hodgkin's disease. New England Journal of Medicine 304:1377-82.

Howe, G., C. Westhoff, M. Vessey et al. 1985. Effects of age, cigarette smoking and other factors on fertility: Findings in a large prospective study. British Medical Journal 290: 1697-700.

Hrushesky, W. J. M., A. Z. Bluming, S. A. Gruber et al. 1989. Menstrual influence on surgical cure of breast cancer. The Lancet (October 21) 2:949-52.

Hu, S-K, Y. L. Mitcho, N. C. Rath et al. 1988. Effect of estradiol on Interleukin 1 synthesis by macrophages. International Journal of Immunopharmacology 10(3):247-52.

Jensen, J., L. Nilas, and C. Christiansen. 1990. Influence of menopause on serum lipids and lipoproteins. Maturitas 12:321-31.

Jern, C., K. Manhem, E. Eriksson et al. 1991. Hemostatic responses to mental stress during the menstrual cycle. Thrombosis and Haemostasis 66:614-18.

Ji, L., L. Y. Ma, S. Zeng et al. 1981. Menstrual blood loss in healthy Chinese women. Contraception 23:591-601.

Johansson, S. et al. 1983. Myocardial infarction in women. Epidemiology Review 5:67-95.

Jones, D. Y., J. T. Judd, P. R. Taylor et al. 1987. Influence of dietary fat on menstrual cycle and menses length. Human nutrition. Clinical Nutrition 41:341-45.

—. 1988. Menstrual cycle effect on plasma lipids. Metabolism 37(1):1-2.

Jones, G. S. 1976. The luteal phase defect. Fertility and Sterility 27:351-56.

Jones, H. W. and G. S. Jones. 1981. Novak's Textbook of Gynecology. Tenth Edition. Baltimore: Williams and Wilkins.

Kaiserauer, S., A. C. Snyder, M. Sleeper et al. 1989. Nutritional, physiological, and menstrual status of distance runners. Medical Science in Sports and Exercise 21:120-25.

Kalo-Klein, A. and S. S. Witkin. 1989. Candida albicans: Cellular immune system interactions during different stages of the menstrual cycle. American Journal of Obstetrics and Gynecology 161(3):1132-36.

. 1991. Regulation of the immune response to Candida albicans by monocytes and progesterone. American Journal of Obstetrics and Gynecology 164:1351-54.

Kaplan, B. J., S. F. Whitsett, J. W. Robinson et al. 1990. Menstrual cycle phase is a potential confound in psychophysiology research. Psychophysiology 27(4):445-50.

Kappas, A., K. E. Anderson, A. H. Conney et al. 1983. Nutrition-endocrine interactions: Induction of reciprocal changes in the $\Delta^{4}-5 \alpha$-reduction of testosterone and the cytochrome P-450dependent oxidation of estradiol by dietary macronutrients in man. Proceedings of the National Academy of Sciences 80:7646-49.

Karsch, F. J., E. L. Bittman, D. L. Foster et al. 1984. Neuroendocrine basis of seasonal reproduction. Recent Program in Hormone Research 40:185-232. 
Karshch, F. J., E. L. Bittman, J. E. Robinson et al. 1986. Melatonin and photorefractoriness: Loss of response to the melatonin signal leads to seasonal reproductive transitions in the ewe. Biology of Reproduction 34:265-74.

Karsch, F. J., J. E. Robinson, C. J. Woodfill et al. 1989. Circannual cycles of luteinizing hormone and prolactin secretion in ewes during prolonged exposure to a fixed photoperiod: Evidence for an endogenous reproductive rhythm. Biology of Reproduction 41:1034-46.

Kelsey, J. L. 1993. Epidemiologic Reviews: Breast Cancer. Baltimore: Johns Hopkins University School of Hygiene and Public Health.

Kim, H-J and R. K. Kalkhoff. 1979. Changes in lipoprotein composition during the menstrual cycle. Metabolism 28(6):663-68.

Klein, J. R. and I. F. Litt. 1981. Epidemiology of adolescent dysmenorrhea. Pediatrics 68:661-64.

Knopp, R. H. 1988. Cardiovascular effects of endogenous and exogenous sex hormones over a woman's lifetime. American Journal of Obstetrics and Gynecology 158(6):1630-43.

Knuth, V. A., M. J. Hull, and H. S. Jacobs. 1977. Amenorrhea and loss of weight. British Journal of Obstetrics and Gynaecology 84:801-07.

Kohmura, H., A. Miyake, and T. Aono. 1986. Recovery of reproductive function in patients with anorexia nervosa: A ten-year follow-up study. European Journal of Obstetrics, Gynecology and Reproductive Biology 22:293-96.

Krauss, R. M., F. T. Lindgren, J. Wingerd et al. 1979. Effects of estrogens and progestins on high density lipoproteins. Lipids 14(1):113-18.

Kreiger, D. T. and J. C. Hughes (eds.). 1980. Neuroendocrinology. Sunderland, Mass.: Sinauer Associates, Inc.

Krzanowski, M. 1985. Low human T4:T8 lymphocyte ratios around ovulation time. Chronobiologia 12:254.

Krzych, U., H. R. Strausser, J. P. Bressler et al. 1978. Quantitative differences in immune response during the various stages of the estrous cycle in female BALB/c mice. Journal of Immunology 121(4):1603-05.

Kuller, L. G., E. N. Mellahn, J. Gutai et al. 1990. Lipoproteins, Estrogens, and the Menopause. In The Menopause: Biological and Clinical Consequences of Ovarian Failure: Evolution and Management. Norwell, MA: Serono Symposia USA, pp 179-97.

Lager, C. and P. T. Ellison. 1987. Effects of moderate weight loss on ovulatory frequency and luteal function in adult women. American Journal of Physical Anthropology 72:221-22.

Lahita, R. G., L. Bradlow, J. Fishman et al. 1982. Estrogen metabolism in systemic lupus erythematosus. Arthritis and Rheumatism 25(7):843-46.

Landgren, B. M., A. L. Unden, and E. Diczfalusy. 1980. Hormonal profile of the cycle in 68 normally menstruating women. Acta Endocrinologica 94:89-98.

Langer, T., W. Strober, R. I. Levy. 1972. The metabolism of low density lipoprotein in familial type II 
hyperlipidemia. Journal of Clinical Investigation 51:1528-36.

Laughlin, G. A., A. B. Loucks, and S. S. C. Yen. 1991. Marked augmentation of nocturnal melatonin secretion in amenorrheic athletes, but not in cycling athletes: Unaltered by opioidergic or dopaminergic blockade. Journal of Clinical Endocrinology and Metabolism 73(6):1321-26.

La Vecchia, C., A. Decarli, S. Franceschi et al. 1987. Menstrual and reproductive factors and the risk of myocardial infarction in women under fifty-five years of age. American Journal of Obstetrics and Gynecology 157(5):1108-12.

La Vecchia, C., A. Decarli, S. di Pietro. 1985. Menstrual cycle patterns and the risk of breast disease. European Journal of Cancer and Clinical Oncology 21(4):417-22.

Lebech, A-M, A. Kjaer, P. E. Lebech et al. 1990. Metabolic changes during the normal menstrual cycle: a longitudinal study. American Journal of Obstetrics and Gynecology 163(1):414-16.

Lee, C. S. 1987. Luteal phase defects. Obstetrical and Gynecological Survey 42:267-74.

Lehtovirta, P., D. Apter, V. H. Stenman et al. 1990. Serum CA 125 levels during the menstrual cycle. British Journal of Obstetrics and Gynaecology 97:930-33.

Lemon, H. M., J. W. Heidel, and J. F. Rodriguez-Sierra. 1992. Increased catechol estrogen metabolism as a risk factor for nonfamilial breast cancer. Cancer 69:457-65.

Lenton, E. A., B. M. Landgren, and L. Sexton. 1984a. Normal variation in the length of the luteal phase of the menstrual cycle: Identification of the short luteal phase. British Journal of Obstetrics and Gynaecology 91:685-89.

Lenton, E. A., B. M. Landgren, L. Sexton et al. 1984b. Normal variation in the length of the follicular phase of the menstrual cycle: Effect of chronological age. British Journal of Obstetrics and Gynaecology 91:681-84.

Levin, W., R. M. Welch, and A. H. Conney. 1968. Effect of phenobarbital and other drugs on the metabolism and uterotrophic action of estradiol-17-beta and estrone. Journal of Pharmacology and Experimental Therapeutics 159:362-71.

Lindquist, O. and C. Bengtsson. 1980. Serum lipids, arterial blood pressure and body weight in relation to the menopause: Results from a population study of women in Goteborg, Sweden. Scandinavian Journal of Clinical and Laboratory Investigation 40:629-36.

Lipid Research Clinics Population Studies Data Book: The Prevalence Study. 1980. Bethesda, MD: United States Department of Health and Human Services. NIH publication 80-1527.

Little, B. B., D. S. Guzick, R. M. Malina et al. 1989. Environmental influences cause menstrual synchrony, not pheromones. American Journal of Human Biology 1:53-57.

Lloyd, T., C. Myers, J. R. Buchanan et al. 1988. Collegiate women athletes with irregular menses during adolescence have decreased bone density. Obstetrics and Gynecology 72:639-42.

Longcope, C. 1994. Diet and estrogen metabolism. In Steroid Contraceptives and Women's Response: Regional Variability in Side Effects and Pharmacokinetics. Ed. R Snow and P Hall. New York: Plenum Publishing Corporation, 143-52. 
Longcope, C., R. Baker, C. C. Johnstone et al. 1986. Androgen and estrogen metabolism: Relationship to obesity. Metabolism 35:235-37.

Loucks, A. B., J. F. Mortola, L. Girton et al. 1989. Alterations in the hypothalamic-pituitary-ovarian and the hypothalamic-pituitary-adrenal axes in athletic women. Journal of Clinical Endocrinology and Metabolism 68:402-11.

Low, S. C., M. H. Galea, and R. W. Blamey. 1991. Timing breast cancer surgery (letter). The Lancet (September 14) 338:691.

Low-Beer, T. S., A. C. B. Wicko, K. W. Heaton et al. 1977. Fluctuations of serum and bile lipid concentrations during the menstrual cycle. British Medical Journal 1:1568-70.

Lussier-Cacan, S., M. Xhignesse, J-L. Desmarais et al. 1991. Cyclic fluctuations in human serum lipid and apolipoprotein levels during the normal menstrual cycle: Comparison with changes occurring during oral contraceptive therapy. Metabolism 40:849-54.

MacLusky, N. J., F. Naftolin, L. C. Krey et al. 1981. The catechol estrogens. Journal of Steroid Biochemistry 15:111-24.

Malina, R. M., W. W. Spirudoso, C. Tate et al. 1978. Age at menarche and selected menstrual characteristics in athletes at different competitive levels and in different sports. Medical Science in Sports and Exercise 10:218-22.

Mamelle, N. et al. 1984. Prematurity and occupational activity during pregnancy. American Journal of Epidemiology 119:309-22.

. 1989. Development and use of a self-administered questionnaire for assessment of psychologic attitudes toward pregnancy and their relation to a subsequent premature birth. American Journal of Epidemiology 130:989-98.

Manhem, K., C. Jern, M. Pilhall et al. 1991. Haemodynamic responses to psychosocial stress during the menstrual cycle. Clinical Science 81:17-22.

Mathur, S., R. S. Mathur, J. M. Goust et al. 1979. Cyclic variations in white cell subpopulations in the human menstrual cycle: Correlations with progesterone and estradiol. Clinical Immunology and Immunopathology 13:246-53.

Matsumoto, S., Y. Nogami, and S. Ohkuri. 1962. Statistical studies on menstruation; A criticism on the definition of normal menstruation. Gunma Journal of Medical Science 11:294-318.

Matsumoto, S., T. Tamada, and S. Konuma. 1979. Endocrinological analysis of environmental menstrual disorders. International Journal of Fertility 24(4):233-9.

Matthews, K. A., E. Meilahn, L. H. Kuller et al. 1989. Menopause and risk factors for coronary heart disease. New England Journal of Medicine 321(10):641-6.

Mattison, D. R. 1982. The effects of smoking on fertility from gametogenesis to implantation. Environmental Research 28:410-33.

Mattsson, L-A, G. Silverstolpe, G. Samsioe et al. 1984. Lipid composition of serum lipoproteins in relation to gonadal hormones during the normal menstrual cycle. European Journal of Obstetrics, Gynecology, and Reproductive Biology 17:327-35.

McClintock, M. K. 1971. Menstrual synchrony and suppression. Nature 229:244-45.

McNicol, P. J, F. B. Guijon, M. Paraskevas et al. 1990. Effect of the menstrual cycle on detection 
and typing of human papillomavirus in uterine cervical cells. American Journal of Obstetrics and Gynecology 162(4):1037-41.

Meijer, G. A. L., K. R. Westerterp, W. H. M. Saris et al. 1992. Sleeping metabolic rate in relation to body composition and the menstrual cycle. American Journal of Clinical Nutrition 55:637-40.

Mencken, J. et al. 1981. The nutrition-fertility link: An evaluation of the evidence. Journal of Interdisciplinary History 11:425-41.

Mergler, D. and N. Vezina. 1985. Dysmenorrhea and cold exposure. Journal of Reproductive Medicine 30:106-11.

Metcalf, M. G. 1983. Incidence of ovulation from the menarche to the menopause: Observations of 622 New Zealand women. New Zealand Medical Journal 96(738):645-48.

1979. The incidence of ovulatory cycles in women approaching the menopause. Journal of Biosocial Science 11:39-48.

Metcalf, M. G. and J. H. Livesey. 1985. Gonadotropin excretion in fertile women: Effect of age and the onset of the menopausal transition. Journal of Endocrinology 105:357-62.

Metcalf, M. G. and J. A. MacKenzie. 1980. Incidence of ovulation in young women. Journal of Biosocial Science 12:345-52.

Metcalf, M. G., R. A. Donald, and J. H. Livesey et al. 1982. Pituitary-ovarian function before, during and after the menopause: A longitudinal study. Clinical Endocrinology 17:489-94.

Michnovicz, J. J., R. J. Hershcopf, H. Naganuma et al. 1986. Increased 2-hydroxylation of estradiol as a possible mechanism for the anti-estrogenic effect of cigarette smoking. New England Journal of Medicine 315(21):1305-09.

Miller, V. T. 1990. Dyslipoproteinemia in women. Endocrinology and Metabolism Clinics of North America 19(2):381-98.

Mishell, D. R., H. W. Fisher, P. J. Haynes et al. 1984. Menorraghia: A symposium. Journal of Reproductive Medicine 29:763-82.

Munster, K., L. Schmidt, and P. Helm. 1992. Length and variation in the menstrual cycle-a crosssectional study from a Danish county. Reproductive Science 99:422-29.

Nabulsi, A. A., A. R. Folsom, A. W. White et al. 1993. Association of hormone-replacement therapy with various cardiovascular risk factors in postmenopausal women. New England Journal of Medicine 328:1069-75.

Nakamura, Y., Y. Yoshimura, T. Oda et al. 1985. Clinical and endocrine studies of patients with amenorrhea associated with weight loss. Clinical Endocrinology 23:643-51.

National Center for Health Statistics (NCHS). 1978. Current estimates from the Health Interview Survey, 1978. Vital and Health Statistics. DHEW Publication No. (HSM)78-154, Series 10(126):18.

Nicklas, B. J., A. C. Hackney, R. L. Sharp et al. 1989. The menstrual cycle and exercise: Performance, muscle glycogen, and substrate responses. International Journal of Sports Medicine 10:264-69. 
Nimrod, A. and K. J. Ryan. 1975. Aromatization of androgens by human abdominal and breastfat tissue. Journal of Clinical Endocrinology and Metabolism 40:367-72.

Odujinrin, O. M. T. and E. O. Ekunwe. 1991. Epidemiologic survey of menstrual patterns amongst adolescents in Nigeria. West African Journal of Medicine 10, no. 3-4 (July-December): 24449.

Oian, P., L. B. Augestad, K. Molne et al. 1984. Menstrual dysfunction in Norwegian top athletes. Acta Obstetrica Gynecologica Scandinavica 63:693-97.

Okonofua, F. E., J. A. Bologun, S. O. Ayangade et al. 1990. Exercise and menstrual function in Nigerian university women. African Journal of Medicine and Medical Sciences 19:185-90.

Olafsson, K., M. S. Smith, P. Marshburn et al. 1991. Variation of HIV infectibility of macrophages as a function of donor, stage of differentiation, and site of origin. Journal of Acquired Immune Deficiency Syndromes 4(2):154-64.

Oliver, M. F. and G. S. Boyd. 1953. Changes in the plasma lipids during the menstrual cycle. Clinical Science 12:217-22.

Olsson, H., M. Landin-Olsson, B. Gullberg et al. 1983. Retrospective assessment of menstrual cycle length in patients with breast cancer, in patients with benign breast disease, and in women without breast disease. Journal of the National Cancer Institute 70(1):17-20.

Osofsky, H. J. and S. Fisher. 1967. Psychological correlates of the development of amenorrhea in a stress situation. Psychosomatic Medicine 29(1):15-23.

Ouellette, M. D., M. G. MacVicar, and J. Harlan. 1986. Relationship between percent body fat and menstrual patterns in athletes and nonathletes. Nursing Research 35(6):330-33.

Paavonen, T. 1987. Hormonal regulation of lymphocyte functions. Med Biol 65:229-40.

Palmblad, J., M. Blomback, N. Egberg et al. 1977. Experimentally induced stress in man: Effects on blood coagulation and fibrinolysis. Journal of Psychosomatic Research 21:87-92.

Parazzini, F., C. La Vecchia, E. Negri et al. 1989. Menstrual factors and the risk of epithelial ovarian cancer. Journal of Clinical Epidemiology 42:443-48.

Pedersen, A. B., M. J. Bartholomew, L. A. Dolence et al. 1991. Menstrual differences due to vegetarian and nonvegetarian diets. American Journal of Clinical Nutrition 53:879-85.

Perel, E. and D. W. Killinger. 1979. The interconversion and aromitization of androgens by human adipose tissue. Journal of Steroid Biochemistry 10:623-27.

Pettersson, F., H. Fries, and S. J. Nillius. 1973. Epidemiology of secondary amenorrhea I. Incidence and prevalence rates. American Journal of Obstetrics and Gynecology 117(1):8086.

Phipps, W. R., D. W. Cramer, I. Schiff et al. 1987. The association between smoking and female infertility as influenced by cause of the infertility. Fertility and Sterility 48(3):377-82.

Pirke, K. M., R. G. Laessle, V. Schweiger et al. 1989. Dieting causes menstrual irregularities in normal weight young women through impairment of episodic luteinizing hormone secretion. 
Fertility and Sterility 51(2):263-68.

Pirke, K. M., M. M. Fichter, M. Warnhoff et al. 1983. Hypothalamic regulation of gonadotropin secretion in anorexia nervosa and in starvation. International Journal of Eating Disorders 2:151-58.

Pirke, K. M., V. Schweiger, R. Laessle et al. 1986. Dieting influences the menstrual cycle: Vegetarian versus nonvegetarian diet. Fertility and Sterility 46:1083-88.

Polan, M. L., A. Daniele, A. Kuo et al. 1988. Gonadal steroids modulate human monocyte Interleukin-1 (IL-1) activity. Fertility and Sterility 49(6):964-68.

Preti, G., W. B. Cutler, C. R. Garcia et al. 1986. Human axillary secretions influence women's menstrual cycles: The role of donor extract of females. Hormones and Behavior 20:474-82.

Prior, J. C., K. Cameron, B. H. Yuen et al. 1982. Menstrual cycle changes with marathon training: Anovulation and short luteal phase. Canadian Journal of Applied Sports Science 7:173-77.

Prior, J. C., Y. M. Vigna, M. T. Schecter et al. 1990. Spinal bone loss and ovulatory disturbances. New England Journal of Medicine 323:1221-27.

Raptopoulou, M. and G. Goulis. 1977. Physiological variations of T-cells during the menstrual cycle. Clinical and Experimental Immunology 28:458-60.

Ratajczak, H. V., R. B. Sothern, and W. J. M. Hrishesky. 1988. Estrous influence on surgical cure of a mouse breast cancer. Journal of Experimental Medicine 168:73-83.

Rees, N. 1987. Menorraghia. British Medical Journal 294:759-62.

Roncari, D. A. and R. L. Van. 1978. Promotion of human adiposite precursor replications by 17- $\beta$ estradiol in culture. Journal of Clinical Investigation 62:503-08.

Rose, D. P. and T. E. Davis. 1977. Ovarian function in patients receiving adjuvant chemotherapy for breast cancer. The Lancet (June):1174-76.

Rosenthal, G. E. and C. S. Landefeld. 1990. The relaxation of chlamydial infection of the cervix to time elapsed from the onset of menses. Journal of Clinical Epidemiology 43(1):15-20.

Sanborn, G. F., B. J. Martin, and W. W. Wagner. 1982. Is athletic amenorrhea specific to runners? American Journal of Obstetrics and Gynecology 143:859-61.

Schneider, J., H. L. Bradlow, G. Strain et al. 1983. Effects of obesity on estradiol metabolism: decreased formation of nonuterotropic metabolites. Journal of Clinical Endocrinology and Metabolism 6(5):973-78.

Schwartz, B., D. C. Cumming, E. Riordan et al. 1981. Exercise associated amenorrhea: A distinct entity? American Journal of Obstetrics and Gynecology 141:662-70.

Schweiger, U., F. Herrmann, R. Laessle, et al. 1987. Diet induced menstrual irregularities: Effects of age and weight loss. Fertility and Sterility 48:746-51.

Schweiger, U., R. Laessle, M. Schweiger. 1988. Caloric intake, stress, and menstrual function in athletes. Fertility and Sterility 49(3):447-50. 
Schweiger, U., R. Tuschl, P. Platte et al. 1992. Everyday eating behavior and menstrual function in young women. Fertility and Sterility 57:771-775.

Senie, R. T., P. P. Rosen, P. Rhodes et al. 1991. Timing of breast cancer excision during the menstrual cycle influences duration of disease-free survival. Annals of Internal Medicine 115:337-42.

Shaaban, M. M., G. H. Sayed, and S. A. Ghaneimmah. 1987. The recovery of ovarian function during breast-feeding. Journal of Steroid Biochemistry 27:1043-52.

Shangold, M. M. and H. S. Levine. 1982. The effect of marathon training upon menstrual function. American Journal of Obstetrics and Gynecology 143(8):862-69.

Sherman, B. M., R. B. Wallace, and A. E. Treloar. 1979. The menopausal transition: Endocrinological and epidemiological considerations. Journal of Biosocial Science 6:19-35.

Sherman, B. M., R. B. Wallace, J. A. Bean et al. 1982. Cyclic ovarian function and breast cancer. Cancer Research 42 (Supplement): 3286s-3288s.

Shortridge, L. A. 1988. Assessment of menstrual variability in working populations. Reproductive Toxicology 2:171-76.

Singh, K. B. 1972. Effects of sound on the female reproductive system. American Journal of Obstetrics and Gynecology 112:981-91.

Singh, K. B. and P. S. Rao. 1970. Studies on the polycystic ovaries of rats under continuous auditory stress. American Journal of Obstetrics and Gynecology 108:557-64.

Skandhan, K. P., A. K. Pandya, S. Skandhan et al. 1979. Synchronization of menstruation among intimates and kindreds. Panminerva Medica 21:131-34.

Sloss, E. M. and R. R. Frerichs. 1983. Smoking and menstrual disorders. International Journal of Epidemiology 12:107-09.

Smith, S. K., M. H. Abel, R. W. Kelly et al. 1981. A role for prostacyclin $\left(\mathrm{PGl}_{2}\right)$ in excessive menstrual bleeding. The Lancet (March) 1:522-24.

Smith, S. K., E. A. Lenton, I. O. Cooke et al. 1985. Plasma gonadotropin and ovarian steroid concentrations in women with a short luteal phase. Journal of Reproduction and Fertility 75:363-68.

Sowers, M. R. and D. A. Galuska. 1993. Epidemiology of bone mass in premenopausal women. In Epidemiologic Reviews. Ed. H. K. Armenian, L. Gordis, J. L. Kelsey et al. Baltimore: The Johns Hopkins University School of Hygiene and Public Health, 15:374-98.

Sowers, M. R., B. Shapiro, M. A. Gilbraith et al. 1990. Health and hormonal characteristics of premenopausal women with lower bone mass. Calcified Tissue International 47:130-135.

Speroff, L., R. H. Glass, and N. G. Kase. 1983. Clinical Gynecologic Endocrinology and Infertility. Third Edition. Baltimore: Williams and Wilkins.

Speroff, L. and D. B. Redwine. 1980. Exercise and menstrual dysfunction. Physician and Sports Medicine 8:42-52. 
Stampfer, M. J., G. A. Colditz, W. C. Willett et al. 1991. Postmenopausal estrogen therapy and cardiovascular disease. Ten-year follow-up from the nurses' health study. New England Journal of Medicine 325:756-62.

Stein, Z. and M. Susser. 1978. Famine and fertility. In Nutrition and Human Reproduction. Ed. W. H. Mosley. New York: Plenum Press, 123-45.

Stimson, W. H. 1988. Oestrogen and human t lymphocytes: Presence of specific receptors in the tsuppressor/cytotoxic subset. Scandinavian Journal of Immunology 28:345-50.

Stoffer, S. S. 1982. Menstrual orders and mild thyroid insufficiency. Menstrual Disorders 72(2):7582.

Stott, P. C. 1983. The outcome of menorrhagia: A retrospective case control study. Journal of the Royal College of General Practitioners (November) 33:715-20.

Sturgis, M. C. 1923. Observations on dysmenorrhea occurring in women employed in a large department store. Journal of Industrial Hygiene 5:53-56.

Sulke, A. N.,D. B. Jones, P. J. Wood et al. 1985. Variation in natural killer activity in peripheral blood during the menstrual cycle. British Medical Journal 290:884-86.

Svanberg, L. and U. Ulmsten. 1981. The incidence of primary dysmenorrhea in teenagers. Archives of Gynecology 230:173-77.

Svennerud, S. 1959. Dysmenorrhea and absenteeism: Some gynecologic and socio-medical aspects. Acta Obstetrica and Gynecologica Scandinavica 38 (Supplement 2).

Szekeres-Bartho, J., G. Falkay, A. Torok et al. 1985. The mechanism of the inhibitory effect of progesterone on lymphocyte cytotoxicity: I. Progesterone-treated lymphocytes release a substance inhibiting cytotoxicity and prostaglandin synthesis. American Journal of Reproductive Immunology and Microbiology 9:15-18.

Tangney, C., C. Brownie, and S. Wu. 1991. Impact of menstrual periodicity on serum lipid levels and estimates of dietary intakes. Journal of the American College of Nutrition 10:107-13.

Tersman, Z., A. Collins, and P. Eneroth. 1991. Cardiovascular responses to psychological and physiological stressors during the menstrual cycle. Psychosomatic Medicine 53:185-97.

Thomas, K. D., F. E. Okonofua, and O. Chiboka. 1990. A study of the menstrual patterns of adolescents en Ile-Ife, Nigeria. International Journal of Gynecology and Obstetrics 33:31-34.

Thyss, A., C. Caldani, C. Bourcier et al. 1984. Comparison of natural killer activity during the first and second halves of the menstrual cycle in women (letter). British Journal of Cancer 50:12728.

Tikkanen, M. J., T. Kuusi, and E. A. Nikkila. 1986. Variation of postheparin plasma hepatic lipase by menstrual cycle. Metabolism 35(2):99-104.

Treloar, A. E., R. E. Boynton, B. G. Behn et al. 1967. Variation of the human menstrual cycle through reproductive life. International Journal of Fertility 12(1):77-126.

Tudiver, F. 1983. Dysfunctional uterine bleeding and prior life stress. Journal of Family Practice 17:999-1003. 
Tumbo-Oeri, A. G. 1985. T and B lymphocyte populations in peripheral blood during the menstrual cycle in normal Kenyan women. East African Medical Journal 62(2):90-95.

Ungvary, G., B. Varga, E. Horvath et al. 1981. Study on the role of maternal sex steroid production and metabolism in the embryotoxicity of para-xylene Toxicology 19:263-68.

Valdes, C. T. and E. Elkind-Hirsch. 1991. Intravenous glucose tolerance test-derived insulin sensitivity changes during the menstrual cycle. Journal of Clinical Endocrinology and Metabolism 72:642-46.

Varney, W. H. 1944. Medical management of complaints of women in the explosives industry. Industrial Medicine 13:122-24.

Vigersky, R. A., A. E. Anderson, R. H. Thompson et al. 1977. Hypothalamic dysfunction in secondary amenorrhea associated with simple weight loss. New England Journal of Medicine 297: 1141-45.

Vollman, R. F. 1968. The length of the premenstrual phase by age of women. In Proceedings of the Fifth World Congress on Fertility and Sterility, 1966. Exerpta Medica International Congress, Series 133:1171-75.

Vollman, R. F. 1977. The Menstrual Cycle. Philadelphia: W. B. Saunders and Company.

Wakat, D., K. A. Sweeney, and A. D. Rogol. 1982. Reproductive system function in women crosscountry runners. Medical Science in Sports and Exercise 14(4):263-9.

Warne, G. L., K. F. Fairley, J. B. Hobbs et al. 1973. Cyclophosphamide-induced ovarian failure. New England Journal of Medicine 289:1159-62.

Warren, M. P. 1980. The effects of exercise on pubertal progression and reproductive function in girls. Journal of Clinical Endocrinology and Metabolism 51:1150-57.

1983. Effects of undernutrition on reproductive function in the human. Endocrine Reviews 4:363-77.

Warren, M. P., R. Jewelewicz, I. Dyrenfurth et al. 1975. The significance of weight loss in the evaluation of pituitary response to $\mathrm{LH}-\mathrm{RH}$ in women with secondary amenorrhea. Journal of Clinical Endocrinology and Metabolism 40:601-11.

Webb, P. 1986. 24-hour energy expenditure and the menstrual cycle. American Journal of Clinical Nutrition 44:614-19.

Wentz, A. C. 1980. Body weight and amenorrhea. Obstetrics and Gynecology 56:482-87.

White, D., D. B. Jones, T. Cooke et al. 1982. Natural killer (NK) activity in peripheral blood lymphocytes of patients with benign and malignant breast disease. British Journal of Cancer 46:611-16.

Widholm, O. 1979. Dysmenorrhea during adolescence. Acta Obstetrica and Gynecologica Scandinavica 87 (supplement): 61-66.

Widom, B., M. P. Diamond, and D. C. Simonson. 1992. Alterations in glucose metabolism during menstrual cycle in women with IDDM. Diabetes Care 15:213-20. 
Wilansky, D. L. and B. Greisman. 1989. Early hypothyroidism in patients with menorrhagia. American Journal of Obstetrics and Gynecology 160:673-77.

Wilcox, A. J. and B. C. Gladen. 1982. Spontaneous abortion: The role of heterogeneous risk and selective fertility. Early Human Development 7:165-78.

Willett, W. et al. 1983. Cigarette smoking, relative weight, and menopause. American Journal of Epidemiology 117(6):651-58.

Williams, M. C. and J. W. Goldzieher. 1980. Chromatographic patterns of urinary ethynyl estrogen metabolites in various populations. Steroids 36(3):255-82.

Wilson, C., S. J. Emans, J. Mansfield et al. 1984. The relationships of calculated percent body fat, sports participation, age, and place of residence on menstrual patterns in healthy adolescent girls at an independent New England high school. Journal of Adolescent Health Care 5:24853.

Wilson, F. W. 1989. EMF field effects and pineal function in humans (meeting abstract). Abstracts of the Bioelectromagnetics Society, 11th Annual Meeting, Tucson, Arizona, 18-22 June, 2.

Wilson, H. C., S. H. Kiefhaber, and V. Gravel. 1991. Two studies of menstrual synchrony: Negative results. Psychoneuroendocrinology 16:353-59.

Wood, C. 1972. Gynaecological survey in a metropolitan area of Melbourne. The Australian and New Zealand Journal of Obstetrics and Gynaecology 12:147-56.

Woods, M., E. J. Schaeffer, A. Morrill et al. 1987. Effect of menstrual cycle on plasma lipids. Journal of Clinical Endocrinology and Metabolism 65:321-3.

World Health Organization Task Force on Adolescent Reproductive Health. 1986. World Health Organization Multicenter Study on Menstrual and Ovulatory Patterns in Adolescent Girls. Journal of Adolescent Health Care 7:236-44.

World Health Organization Task Force on Methods for the Determination of the Fertile Period. 1983. A prospective multicenter trial of the ovulation method of natural family planning. III.

Characteristics of the menstrual cycle and of the fertile phase. Fertility and Sterility 40(6):7738.

World Health Organization Task Force on Psychosocial Research in Family Planning, Special Programme of Research, Development and Research Training in Human Reproduction. 1981. Women's bleeding patterns: Ability to recall and predict menstrual events. Studies in Family Planning 12:17-27.

Zondek, B. and I. Tamari. 1967. Effects of auditory stimulation on reproduction. In Effect of External Stimuli on Reproduction. CIBA Foundation Study Group No. 26. Boston: Little Brown and Co., 4-19.

Zumoff, B., L. Miller, C. D. Levit et al. 1990. The effect of smoking on serum progesterone, estradiol, and luteinizing hormone levels over a menstrual cycle in normal women. Steroids 55:507-11. 
TABLES 
TABLE 1: Menstrual cycle length (days) by age, results of four studies

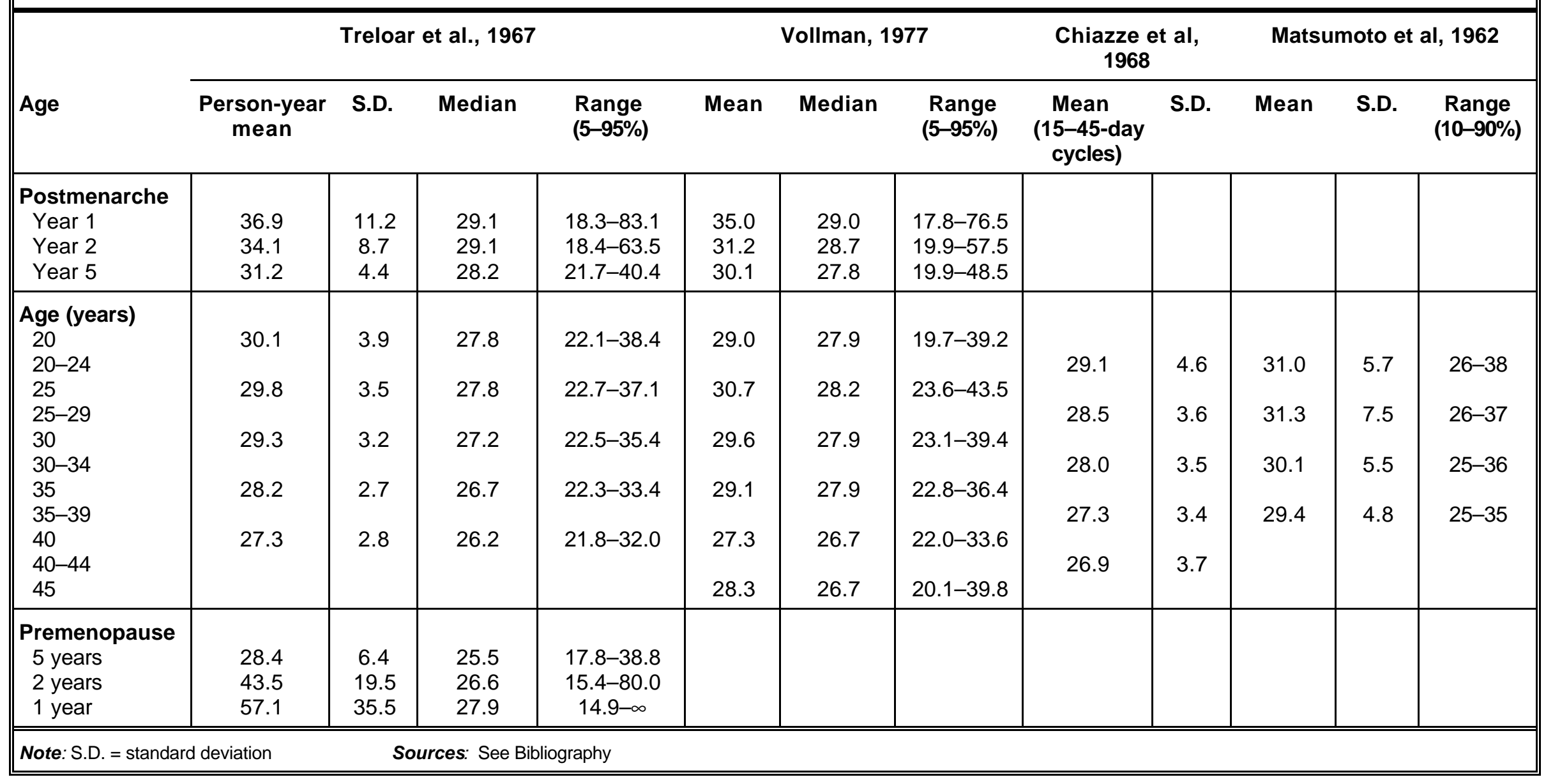




\begin{tabular}{|c|c|c|c|c|c|c|c|}
\hline TABLE 2: & $\begin{array}{l}\text { By-woman prob } \\
\text { segment } t+1 \text { (1 }\end{array}$ & $\begin{array}{l}\text { ilities } \\
\text { wom }\end{array}$ & $\begin{array}{l}\text { ransitio } \\
\text { ontribut }\end{array}$ & $\begin{array}{l}\text { segm } \\
1,082 \mathrm{~s}\end{array}$ & $\begin{array}{l}\text { length } \\
\text { ment } p\end{array}$ & n segr & \\
\hline \multirow{2}{*}{$\begin{array}{c}\text { Length of } \\
\text { segment } \\
t \text { (days) }\end{array}$} & \multirow{2}{*}{$\begin{array}{l}\text { Total number } \\
\text { of transitions }\end{array}$} & \multicolumn{6}{|c|}{ Probability of length of segment $t+1$ (days) } \\
\hline & & $<17$ & $17-25$ & $26-34$ & $35-43$ & $44-59$ & $>59$ \\
\hline$<17$ & 14 & .09 & .41 & .25 & .19 & .06 & .00 \\
\hline $17-25$ & 207 & .02 & .18 & .65 & .09 & .06 & .00 \\
\hline $26-34$ & 708 & .01 & .18 & .65 & .10 & .03 & .03 \\
\hline $35-43$ & 103 & .03 & .10 & .65 & .16 & .03 & .03 \\
\hline $44-59$ & 33 & .04 & .07 & .66 & .10 & .06 & .07 \\
\hline$>59$ & 17 & .04 & .25 & .40 & .07 & .21 & .04 \\
\hline \multicolumn{8}{|c|}{$\begin{array}{l}\text { Source: Reprinted from Journal of Clinical Epidemiology } 44 \text { (1991): 1015-25, S.D. Harlow and S.L. Zeger, Application } 0 \\
\text { longitudinal methods to the analysis of menstrual diary data, Copyright 1991, with kind permission from Elsevier Science } \\
\text { Ltd, The Boulevard, Langford Lane, Kidlington OX5 1GB, UK. }\end{array}$} \\
\hline
\end{tabular}




\section{TABLE 3: $\quad$ By-segment transition probabilities from segment $t$ to segment $t+1(17,287$ segment pairs from 701 women aged 13-52 years)}

\begin{tabular}{|c|c|c|c|c|c|}
\hline \multirow{2}{*}{ Segment $t$ days } & \multicolumn{5}{|c|}{ Probability by segment $t+1$ days } \\
\hline & $20-24$ & 25-34 & $35-44$ & $45-59$ & $>59$ \\
\hline $20-24$ & .15 & .73 & .08 & .03 & .007 \\
\hline $25-34$ & .06 & .84 & .08 & .02 & .004 \\
\hline $35-43$ & .06 & .61 & .26 & .06 & .02 \\
\hline $\begin{array}{l}44-59 \\
\end{array}$ & .06 & .56 & .25 & .10 & .03 \\
\hline$>59$ & .06 & .50 & .22 & .16 & .07 \\
\hline
\end{tabular}




\section{TABLE 4: Blood loss per bleeding episode}

\begin{tabular}{|c|c|c|c|c|}
\hline \multirow[b]{2}{*}{ Variable } & \multicolumn{4}{|c|}{ Volume of blood loss (mls) } \\
\hline & Mean & S.E. & Median & $\begin{array}{l}\text { Ninetieth } \\
\text { percentile }\end{array}$ \\
\hline All women & 43.3 & 2.3 & 30.0 & 83.9 \\
\hline Age 15 & & & 28.4 & 65.1 \\
\hline Age 23 & & & 30.6 & 77.8 \\
\hline Age 30 & & & 30.9 & 86.3 \\
\hline Age 40 & & & 30.8 & 87.1 \\
\hline Age 45 & & & 29.5 & 88.1 \\
\hline Age 50 & & & 36.4 & 133.1 \\
\hline $\begin{array}{l}\text { Women with normal bleeds } \\
\text { Subjective report } \\
\text { Subjective report and adequate iron levels }\end{array}$ & $\begin{array}{l}38.5 \\
33.2\end{array}$ & $\begin{array}{l}1.9 \\
1.6\end{array}$ & & \\
\hline $\begin{array}{l}\text { Note: } \text { S.E. = standard error } \\
\text { a haemoglobin concentration }=>12 \mathrm{~g} / 100 \mathrm{ml} \text { blood; pl } \\
\text { (MCHC = mean corpuscular hemoglobin concentration } \\
\text { Source: L. Hallberg et al., "Menstrual blood loss-a p p } \\
\text { (1966):320-51, @ 1966 Munkgaard International Publis }\end{array}$ & ation $=$ & $\begin{array}{l}\mathrm{ug} / 1 \mathrm{C} \\
\text { rica } y \\
\text { lark. }\end{array}$ & $\begin{array}{l}\text { losma; } 1 \\
\text { ologica }\end{array}$ & $\begin{array}{l}=>30 \% \\
\text { dinavia } 45\end{array}$ \\
\hline
\end{tabular}




\section{TABLE 5: $\quad$ Probability of anovulation, findings from four studies}

\begin{tabular}{|c|c|c|c|c|}
\hline Study & $\begin{array}{c}\text { Ovulation } \\
\text { measurement } \\
\text { method }\end{array}$ & $\begin{array}{l}\text { Cycle length } \\
\text { (days) }\end{array}$ & Age (years) & $\begin{array}{c}\text { Percent } \\
\text { anovulatory } \\
\text { cycles }\end{array}$ \\
\hline $\begin{array}{l}\text { By cycle length } \\
\text { Vollman, } 1977\end{array}$ & BBT & $\begin{array}{c}16-21 \\
25-30 \\
>59\end{array}$ & all ages & $\begin{array}{c}22-44 \% \\
2-4 \% \\
41 \%\end{array}$ \\
\hline Matsumoto et al., 1962 & BBT & $\begin{array}{c}<25 \\
25-38 \\
>38\end{array}$ & 20-39 & $\begin{array}{c}17 \% \\
3 \% \\
18 \%\end{array}$ \\
\hline $\begin{array}{l}\text { By age } \\
\text { Doring, } 1969\end{array}$ & BBT & all cycles & $\begin{array}{l}12-14 \\
18-20 \\
21-25 \\
26-40 \\
41-50\end{array}$ & $\begin{array}{c}60 \% \\
20 \% \\
13 \% \\
3-7 \% \\
12-15 \%\end{array}$ \\
\hline Vollman, 1977 & BBT & all cycles & $\begin{array}{c}1 \text { year post- } \\
\text { menarche } \\
29 \\
40-45\end{array}$ & $\begin{array}{r}56 \% \\
1 \% \\
34 \%\end{array}$ \\
\hline Metcalf, 1983 & weekly urine & all cycles & $\begin{array}{c}10-14 \\
20-24 \\
30-39 \\
>50\end{array}$ & $\begin{array}{c}52 \% \\
28 \% \\
2 \% \\
34 \%\end{array}$ \\
\hline $\begin{array}{l}\text { By age and cycle length } \\
\text { Metcalf, } 1983\end{array}$ & weekly urine & $\begin{array}{l}20-35 \\
36-49\end{array}$ & $\begin{array}{l}10-24 \\
40-55 \\
\\
10-24 \\
40-55\end{array}$ & $\begin{array}{l}35 \% \\
11 \% \\
38 \% \\
68 \%\end{array}$ \\
\hline
\end{tabular}




\begin{tabular}{|c|c|c|c|c|c|}
\hline \multirow{3}{*}{$\begin{array}{l}\text { TABLE 6: } \\
\text { Variable }\end{array}$} & \multicolumn{5}{|c|}{$\begin{array}{l}\text { timates of the length of the follicular and luteal phase, findings from five } \\
\text { estigations }\end{array}$} \\
\hline & \multicolumn{3}{|c|}{ Long menstrual cycles excluded } & \multicolumn{2}{|c|}{$\begin{array}{l}\text { All menstrual cycle } \\
\text { lengths included }\end{array}$} \\
\hline & WHO, 1983 & $\begin{array}{l}\text { Landgren } \\
\text { et al., } 1980\end{array}$ & $\begin{array}{l}\text { Lenton et al, } \\
1984 a, b\end{array}$ & $\begin{array}{l}\text { Vollman, } \\
1970\end{array}$ & $\begin{array}{l}\text { Matsumoto } \\
\text { et al., } 1962\end{array}$ \\
\hline $\mathrm{N}$ (women) & 687 & 68 & 299 & 524 & $\mathrm{n} / \mathrm{a}$ \\
\hline $\mathrm{N}$ (cycles) & 6,427 & 68 & 327 & 13,785 & 2,500 \\
\hline Method & Mucus & Blood & Blood & BBT & BBT \\
\hline Selection criteria & $\begin{array}{l}\text { Peak day, present } \\
\text { NFP user }\end{array}$ & $\begin{array}{c}\text { Ovulatory } \\
25-36 \text { days }\end{array}$ & $\begin{array}{l}\text { Ovulatory } \\
<41 \text { days }\end{array}$ & Biphasic & Biphasic \\
\hline $\begin{array}{l}\text { Follicular phase } \\
\text { Mean length (days) } \\
10 \%-90 \% \\
5 \%-95 \%\end{array}$ & $\begin{array}{c}15 \\
10.5-19\end{array}$ & $\begin{array}{l}15.1^{\mathrm{a}} \\
10-23\end{array}$ & $\begin{array}{c}12.9^{\mathrm{a}} \\
10.3-16.3\end{array}$ & $\begin{array}{c}17.4 \\
10.8-27.2\end{array}$ & $\begin{array}{c}17.9 \\
13-24\end{array}$ \\
\hline $\begin{array}{l}\text { Luteal phase } \\
\text { Mean length (days) } \\
10 \%-90 \% \\
5 \%-95 \%\end{array}$ & $\begin{array}{c}13.5 \\
8.7-17.2\end{array}$ & $\begin{array}{c}13 \\
11-17\end{array}$ & $\begin{array}{c}14.1 \\
11.3-17.0\end{array}$ & $\begin{array}{c}11.7 \\
6.9-15.3\end{array}$ & $\begin{array}{c}12.7 \\
11-15\end{array}$ \\
\hline
\end{tabular}




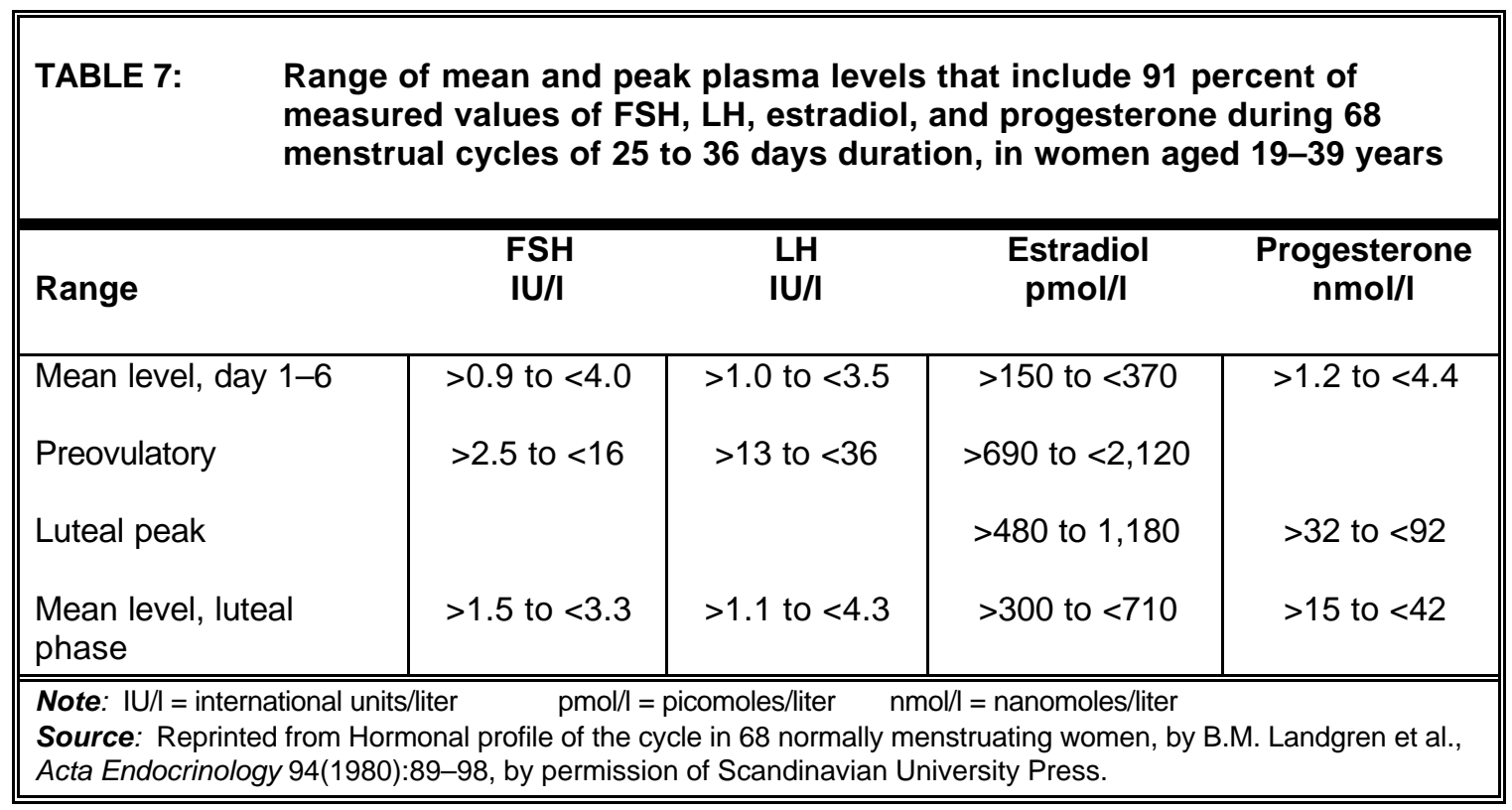




\begin{tabular}{|c|c|c|}
\hline TABLE 8: & \multicolumn{2}{|c|}{$\begin{array}{l}\text { Association between hormonal levels and menstrual cycle and ovarian } \\
\text { phase lengths }\end{array}$} \\
\hline \multirow[b]{2}{*}{ Variable } & \multicolumn{2}{|c|}{ Length of cycle/phase } \\
\hline & Short & Long \\
\hline Menstrual cycle & High estrogen (day 1-6) & $\begin{array}{l}\text { High prepeak LH } \\
\text { High peak LH }\end{array}$ \\
\hline Folicular phase & $\begin{array}{l}\text { High estrogen (day 1-6) } \\
\text { High estrogen (pre-ovulatory peak) }\end{array}$ & High prepeak LH \\
\hline Luteal phase & & High peak progesterone \\
\hline
\end{tabular}




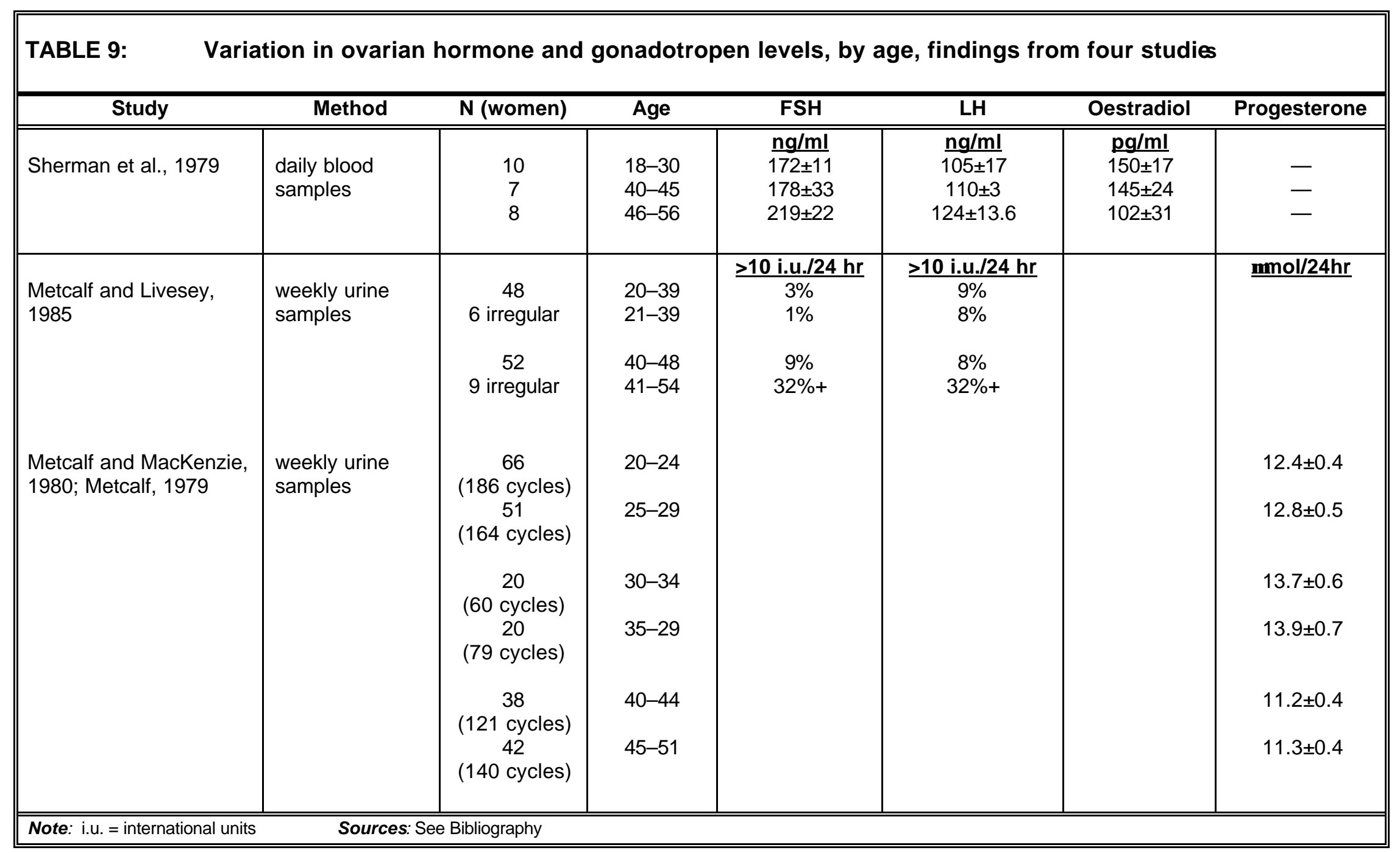




\begin{tabular}{|c|c|c|c|}
\hline \multicolumn{4}{|c|}{ Regional variation in menstrual blood loss, findings from five studies } \\
\hline Study & Country & $\begin{array}{l}\text { Mean duration } \\
\text { (days) }\end{array}$ & Mean loss (mls) \\
\hline WHO, 1981 & $\begin{array}{l}\text { Mexico } \\
\text { India (high caste) } \\
\text { India (low caste) } \\
\text { Egypt } \\
\text { Indonesia } \\
\text { Philippines } \\
\text { Yugoslavia } \\
\text { United Kingdom } \\
\text { Pakistan }\end{array}$ & $\begin{array}{l}4.0 \\
4.4 \\
4.0 \\
4.4 \\
4.4 \\
4.8 \\
4.8 \\
5.3 \\
5.6\end{array}$ & \\
\hline Belsey et al., $1988^{a}$ & $\begin{array}{l}\text { Mexico } \\
\text { Europe }\end{array}$ & $\begin{array}{l}4.0 \\
5.9\end{array}$ & \\
\hline WHO, $1986^{b}$ & $\begin{array}{l}\text { Sri Lanka } \\
\text { Hong Kong }\end{array}$ & $\begin{array}{l}4.3 \\
6.0\end{array}$ & \\
\hline Hallberg et al., 1966 & Sweden & & $43.4+/-2.3$ \\
\hline Ji et al., 1981 & China & & $56.3+/-2.8$ \\
\hline
\end{tabular}




\begin{tabular}{|c|c|}
\hline TABLE 11: & $\begin{array}{l}\text { and environmental factors that might be } \\
\text { eterminants of menstrual function }\end{array}$ \\
\hline Factor & Types \\
\hline Stress & $\begin{array}{l}\text { Family stress } \\
\text { Occupational stress } \\
\text { Role conflict } \\
\text { Chronic stress }\end{array}$ \\
\hline Diet & $\begin{array}{l}\text { Meat } \\
\text { Fat } \\
\text { Caffeine } \\
\text { Micronutrients }\end{array}$ \\
\hline Chemicals & $\begin{array}{l}\text { Drugs } \\
\text { Environmental chemicals (pesticides) } \\
\text { Occupational chemicals (solvents) } \\
\text { Tobacco }\end{array}$ \\
\hline Physical environment & $\begin{array}{l}\text { Sound } \\
\text { Electromagnetic fields } \\
\text { Light } \\
\text { Ergonomic factors }\end{array}$ \\
\hline Social environment & $\begin{array}{l}\text { Female group synchrony } \\
\text { Intersex synchrony } \\
\text { Violence } \\
\text { Crowding } \\
\text { Social status } \\
\text { Social support }\end{array}$ \\
\hline
\end{tabular}




\begin{tabular}{|c|c|c|}
\hline TABLE 12: & \multicolumn{2}{|c|}{ Operational definitions of menstrual dysfunction in the literature } \\
\hline Condition & Definition & Study \\
\hline Amenorrhea & $\begin{array}{l}\text { Delayed menses } \\
\text { No menses for } 2 \text { months } \\
\text { No menses for } 4 \text { months } \\
\text { No menses for } 6 \text { months } \\
\text { No menses for } 90 \text { days ( } 3 \text { months) } \\
<3 \text { cycles per year } \\
<4 \text { cycles per year }\end{array}$ & $\begin{array}{l}\text { Boehm and Salerno, } 1973 \\
\text { Drew, } 1961 \\
\text { Oian et al., } 1984 \\
\text { Galle et al., 1983; Shangold and Levine, } \\
\text { 1982; Wakat et al., } 1982 \\
\text { Frisch et al., 1980; Pettersson et } \\
\text { al., 1973; Shortridge, } 1988 \\
\text { Glass et al., } 1987 \\
\text { Ouellette et al., 1986; Sanborn, } 1982\end{array}$ \\
\hline Irregularity & $\begin{array}{l}\text { Cycles }<22 \text { or }>50 \text { days } \\
\text { Cycles }>37 \text { days } \\
\text { Cycles }>38 \text { days } \\
\text { Frequent cycles }<21 \text { or }>35 \text { days } \\
\text { Cycles that vary by }>5 \text { days }\end{array}$ & $\begin{array}{l}\text { Wilson et al., } 1984 \\
\text { Shangold and Levine, } 1982 \\
\text { Frisch et al., } 1980 \\
\text { La Vecchia et al., } 1985 \\
\text { Olsson et al., } 1983\end{array}$ \\
\hline
\end{tabular}




\begin{tabular}{|c|c|c|c|c|c|}
\hline TABLE 13: & dies of the variability & n immune parameters across th & menstrual cyc & & \\
\hline Study & $\begin{array}{l}\text { Number of women } \\
\text { and cycles }\end{array}$ & $\begin{array}{l}\text { Number and timing of blood } \\
\text { draws }\end{array}$ & $\begin{array}{l}\text { Hormonal } \\
\text { measures }\end{array}$ & Immune parameters & Results \\
\hline $\begin{array}{l}\text { T-lymphocytes } \\
\text { Raptopoulou and } \\
\text { Goulis, } \quad 1977\end{array}$ & $\begin{array}{l}10 \text { women } \\
\text { ages } 19-25, \\
1 \text { cycle }\end{array}$ & $\begin{array}{l}3 \text { samples per cycle } \\
1 \text { week before, during, and } 1 \\
\text { week after menses }\end{array}$ & no & $\begin{array}{l}\text { total lymphocytes, } \\
\% \text { T-lymphcytes, } \\
\text { number T-lymphocytes } \\
\text { number neutrophils }\end{array}$ & $\begin{array}{l}\text { decrease during menses } \\
\text { no change }\end{array}$ \\
\hline $\begin{array}{l}\text { Mathur et al., } \\
1979\end{array}$ & $\begin{array}{l}16 \text { women, } \\
\text { ages unknown, } \\
1 \text { cycle }\end{array}$ & $\begin{array}{l}\text { up to } 12 \text { samples per cycle } \\
\text { (2-3 per week) }\end{array}$ & $\begin{array}{l}\text { progesterone, } \\
\text { estradiol }\left(\mathrm{E}_{2}\right) \text {, } \\
\mathrm{LH}\end{array}$ & $\begin{array}{l}\text { total lymphocyte and T- } \\
\text { lymphocyte counts } \\
\text { monocyte and granulocyte } \\
\text { counts }\end{array}$ & $\begin{array}{l}\text { negative correlation with } \\
E_{2} ; \text { nadirs at follicular and } \\
\text { luteal } E_{2} \text { peaks } \\
\text { positive correlation with } \\
\text { progesterone }\end{array}$ \\
\hline Bolis et al., 1983 & $\begin{array}{l}27 \text { women, ages } 23- \\
30,1 \text { cycle }\end{array}$ & $\begin{array}{l}3 \text { samples per cycle: } \\
\text { day } 10 \pm 2 \text {, day } 23 \pm 1 \text {, menses }\end{array}$ & $\begin{array}{l}\text { no basal body } \\
\text { temperature }\end{array}$ & $\begin{array}{l}\text { total T-lymphocytes } \\
\text { T helper } \\
\text { T suppressor }\end{array}$ & $\begin{array}{l}\text { no change } \\
\text { preovulatory increase } \\
\text { preovulatory decrease }\end{array}$ \\
\hline $\begin{array}{l}\text { Coulam et al., } \\
1983\end{array}$ & $\begin{array}{l}5 \text { women, ages } 18- \\
30,1 \text { cycle }\end{array}$ & $\begin{array}{l}\text { up to } 8 \text { samples per cycle (every } \\
3-4 \text { days) }\end{array}$ & no & \begin{tabular}{|l|}
$\%$ of total T, T-helper, \\
T-suppressor lymphocytes
\end{tabular} & no variation observed \\
\hline $\begin{array}{l}\text { Krzanowski, } \\
1985\end{array}$ & $\begin{array}{l}63 \text { women, ages } 18- \\
48,1 \text { cycle }\end{array}$ & 1 sample per cycle & no & \begin{tabular}{|l|} 
T-helper:T-suppressor ratio \\
\end{tabular} & $\begin{array}{l}\text { maximum day } 1-4 \\
\text { minimum day } 21-24\end{array}$ \\
\hline $\begin{array}{l}\text { Tumbo-Oeri, } \\
1985\end{array}$ & $\begin{array}{l}14 \text { women, ages } 19- \\
32,1 \text { cycle }\end{array}$ & $\begin{array}{l}3 \text { samples per cycle, } \\
6 \text { days before, during, and } 6 \\
\text { days after menstruation }\end{array}$ & no & $\begin{array}{l}\text { T and B lymphocyte } \\
\text { numbers and percent }\end{array}$ & $\begin{array}{l}\text { decreased during } \\
\text { menstruation }\end{array}$ \\
\hline $\begin{array}{l}\text { Eichler and } \\
\text { Keiling, } 1988\end{array}$ & $\begin{array}{l}6 \text { women, ages } 30- \\
44,3 \text { cycles }\end{array}$ & $\begin{array}{l}5 \text { samples per cycle, days } 1 \\
13,14,15,25\end{array}$ & no & $\begin{array}{l}\text { lymphocyte } \\
\text { subset counts }\end{array}$ & no differences observed \\
\hline
\end{tabular}




\begin{tabular}{|c|c|c|c|c|c|}
\hline $\begin{array}{l}\text { TABLE 13: } \\
\text { Continued }\end{array}$ & & & & & \\
\hline Study & $\begin{array}{l}\text { Number of women and } \\
\text { cycles }\end{array}$ & $\begin{array}{l}\text { Number and timing of blood } \\
\text { draws }\end{array}$ & $\begin{array}{l}\text { Hormonal } \\
\text { measures }\end{array}$ & Immune parameters & Results \\
\hline $\begin{array}{l}\text { Natural killer (NK) } \\
\text { cells } \\
\text { White et al., } 1982\end{array}$ & $\begin{array}{l}14 \text { women, ages } 21 \text { to } \\
\text { perimenopause, } \\
1 \text { cycle }\end{array}$ & 1 sample per cycle & no & natural killer activity & $\begin{array}{l}\text { higher activity in } 2 d \text { half } \\
\text { than } 1 \text { st half of cycle }\end{array}$ \\
\hline Thyss et al, 1984 & $\begin{array}{l}13 \text { women, ages } 29-39, \\
1 \text { cycle }\end{array}$ & $\begin{array}{l}2 \text { samples per cycle, day } 7 \pm 1 \\
\text { and } 23 \pm 1\end{array}$ & no & natural killer activity & $\begin{array}{l}\text { no difference between } \\
1 \text { st and } 2 \mathrm{~d} \text { half of cycle }\end{array}$ \\
\hline Sulke et al., 1985 & $\begin{array}{l}18 \text { women, mean age } \\
26.1,1 \text { cycle }\end{array}$ & 3-4 samples per cycle & estradiol & natural killer activity & $\begin{array}{l}\text { NK activity depressed } \\
\text { during ovulation, not } \\
\text { correlated with } \mathrm{E}_{2} \\
\text { concentration }\end{array}$ \\
\hline Gonik et al., 1985 & $\begin{array}{l}13 \text { women, mean age } \\
27,1 \text { cycle }\end{array}$ & $\begin{array}{l}3 \text { samples per cycle, up to } 10 \\
\text { days before, during, and up to } \\
12 \text { days after menses }\end{array}$ & no & natural killer activity & no differences observed \\
\hline $\begin{array}{l}\text { Skin reactivity } \\
\text { Agner et al., } 1991\end{array}$ & $\begin{array}{l}29 \text { women, ages } 20-40, \\
1 \text { cycle }\end{array}$ & $\begin{array}{l}2 \text { challenges per cycle: } \\
\text { day } 1 \text {, day } 9-11\end{array}$ & no & patch test & $\begin{array}{l}\text { stronger response } \\
\text { elicited on day } 1 \text { than } \\
\text { on day } 9-11\end{array}$ \\
\hline $\begin{array}{l}\text { Ca-125 levels } \\
\text { Lehtovirta et al., } \\
1990\end{array}$ & $\begin{array}{l}16 \text { women, ages } 15-32, \\
1 \text { cycle }\end{array}$ & approximately 8 times per cycle & $\begin{array}{l}\text { estradiol, } \\
\text { progesterone, } \\
\text { LH }\end{array}$ & Ca-125 levels & $\begin{array}{l}\text { higher week } 1 \text { than at } \\
\text { mid-cycle, negatively } \\
\text { correlated with } \\
\text { progesterone }\end{array}$ \\
\hline
\end{tabular}




\section{TABLE 14: Study findings on variation in lipid and lipoproteins across the menstrual cycle}

\begin{tabular}{|c|c|c|c|c|c|c|c|c|c|}
\hline Study & $\begin{array}{l}\text { Number of } \\
\text { women } \\
\text { and cycles }\end{array}$ & $\begin{array}{l}\text { Frequency of } \\
\text { samples }\end{array}$ & $\begin{array}{l}\text { Ovarian } \\
\text { hormones } \\
\text { measured }\end{array}$ & $\begin{array}{l}\text { Total } \\
\text { cholesterol }\end{array}$ & $\begin{array}{l}\text { Tri- } \\
\text { glyceride }\end{array}$ & VLDL & LDL & HDL & $\mathrm{HDL}_{2}$ \\
\hline $\begin{array}{l}\text { Oliver and Boyd, } \\
1953\end{array}$ & $\begin{array}{l}12 \text { women, } \\
\text { mean age } 22, \\
1 \text { cycle/woman }\end{array}$ & $\begin{array}{l}2 x / \text { week, } \\
5 \text { weeks }\end{array}$ & $\begin{array}{l}\mathrm{no} \\
\mathrm{BBT}^{\mathrm{a}}\end{array}$ & $\begin{array}{l}\downarrow \text { midcycle } \\
\downarrow \text { with menses }\end{array}$ & & & & & \\
\hline $\begin{array}{l}\text { Aldercreutz and } \\
\text { Tallquist, } \\
1959\end{array}$ & $\begin{array}{l}29 \text { women, } \\
\text { ages } 20-41, \\
1 \text { cycle/woman }\end{array}$ & 1-6x cycle & no & $\begin{array}{l}\uparrow \text { pre-ovulation } \\
\downarrow \text { post-ovulation } \\
\uparrow \text { before menses } \\
\downarrow \text { with menses }\end{array}$ & & & & & \\
\hline $\begin{array}{l}\text { Barclay et al., } \\
1965\end{array}$ & \begin{tabular}{|l|}
11 women, \\
ages $25-44$ \\
3 cycles/woman
\end{tabular} & 1x/week & no & & & & & b & $\uparrow$ day 14 \\
\hline $\begin{array}{l}\text { Low-Beer et al., } \\
1977\end{array}$ & $\begin{array}{l}11 \text { women, } \\
\text { ages } 20-43, \\
1 \text { cycle/woman }\end{array}$ & $\begin{array}{l}3 x \text { cycle (day } 5-6, \\
14 \text { days before } \\
\text { menses, } 5-6 \text { days } \\
\text { before menses) }\end{array}$ & no & $\downarrow$ luteal phase & $\downarrow$ luteal phase & & & & \\
\hline $\begin{array}{l}\text { Krauss et al., } \\
1979\end{array}$ & $\begin{array}{l}4 \text { women, } \\
\text { ages } 22-26, \\
2 \text { cycles/ woman }\end{array}$ & 1x/week & $\begin{array}{l}\text { estradiol, } \\
\text { progesterone, } \\
\text { LH }\end{array}$ & & & & & - & $\begin{array}{l}\uparrow \\
\text { ovulation } \\
\text { rapid } \downarrow \\
\text { post- } \\
\text { ovulation }\end{array}$ \\
\hline $\begin{array}{l}\text { Kim and Kalkhoff, } \\
1979\end{array}$ & \begin{tabular}{|l|}
14 women, \\
mean age 33, \\
3 cycles/woman
\end{tabular} & every $3-5$ days & $\begin{array}{l}\text { no } \\
\mathrm{BBT}^{\mathrm{a}}\end{array}$ & $\downarrow$ late luteal phase & $\begin{array}{l}\downarrow \text { late luteal } \\
\text { phase }^{c}\end{array}$ & & \begin{tabular}{|l|}
$\downarrow$ luteal \\
phase
\end{tabular} & $\begin{array}{l}\uparrow \text { late luteal } \\
\text { phase }^{c}\end{array}$ & - \\
\hline $\begin{array}{l}\text { Basdevant et al, } \\
1981\end{array}$ & $\begin{array}{l}8 \text { women, } \\
\text { ages } 25-35, \\
1 \text { cycle/woman }\end{array}$ & $\begin{array}{l}3 x / \text { cycle (days } 1,8, \\
21 \text { ) }\end{array}$ & $\begin{array}{l}\text { estradiol } \\
\text { estrone, } \\
\text { progesterone, } \\
\text { testosterone, } \\
\text { LH, FSH }\end{array}$ & - & - & & & - & \\
\hline $\begin{array}{l}\text { Demacker et al., } \\
1982\end{array}$ & $\begin{array}{l}10 \text { women, } \\
\text { ages } 24-37, \\
1 \text { cycle/woman }\end{array}$ & $2 x /$ week & no & - & - & & - & - & \\
\hline
\end{tabular}




\begin{tabular}{|c|c|c|c|c|c|c|c|c|c|}
\hline \multicolumn{10}{|c|}{ TABLE 14: Continued } \\
\hline Study & $\begin{array}{l}\text { Number of } \\
\text { women and } \\
\text { cycles }\end{array}$ & $\begin{array}{l}\text { Frequency of } \\
\text { samples }\end{array}$ & $\begin{array}{l}\text { Ovarian } \\
\text { hormones } \\
\text { measured }\end{array}$ & Total cholesterol & Tri-glyceride & VLDL & LDL & HDI & $\mathrm{HDL}_{2}$ \\
\hline $\begin{array}{l}\text { Mattsson et al., } \\
1984\end{array}$ & $\begin{array}{l}22 \text { women, } \\
\text { ages } 18-35 \\
1 \text { cycle/woman }\end{array}$ & $\begin{array}{l}\text { 4x/cycle (days 6-8, } \\
13-15,20-22,27- \\
29)\end{array}$ & \begin{tabular}{|l|} 
estradiol, \\
progesterone, \\
andiostenedrone, \\
testosterone
\end{tabular} & $\begin{array}{l}\downarrow \text { luteal (inverse } \\
\text { correlation with } E_{2} \text { ) }\end{array}$ & $\begin{array}{l}\uparrow \text { preovulatory } \\
\downarrow \text { luteal (positive } \\
\text { correlation with } E_{2}\end{array}$ & $\downarrow$ luteal & $\begin{array}{l}\text { \luteal } \\
\text { (inverse } \\
\text { correlation } \\
\text { with } \mathrm{E}_{2}\end{array}$ & $\begin{array}{l}\uparrow \text { luteal } \\
\text { (inverse } \\
\text { correlation } \\
\text { with } \mathrm{E}_{2}\end{array}$ & \\
\hline Hemer et al., 1985 & \begin{tabular}{|l|}
114 women, \\
mean age mid- \\
20s
\end{tabular} & 1 sample & \begin{tabular}{|l|} 
estradiol, \\
progesterone
\end{tabular} & $\uparrow$ late follicular & - & $\begin{array}{l}\uparrow \text { early } \\
\text { luteal }\end{array}$ & $\downarrow \downarrow$ luteal & - & \\
\hline Tikkanen et al., 1986 & \begin{tabular}{|l|}
24 women, \\
ages $21-33$, \\
2 cycles/woman
\end{tabular} & $\begin{array}{l}2 \mathrm{x} / \text { cycle (days } 7, \\
21 \text { ) }\end{array}$ & \begin{tabular}{|l|} 
estradiol, \\
progesterone, \\
LH, FSH
\end{tabular} & & $\downarrow$ luteal $^{c}$ & $\downarrow \downarrow$ luteal $^{c}$ & $\downarrow \downarrow$ luteal $^{c}$ & - & - \\
\hline Woods et al., 1987 & \begin{tabular}{|l}
15 women, \\
mean age 24.2 \\
1 cycle/woman
\end{tabular} & $\begin{array}{l}3 x / \text { cycle (days } 4-6, \\
\text { ovulation, ovulation } \\
+6-8 \text { days) }\end{array}$ & \begin{tabular}{|l|}
$\mathrm{LH}$, \\
progesterone
\end{tabular} & - & $\uparrow$ ovulatory & - & - & - & \\
\hline Jones et al., 1988 & \begin{tabular}{|l|}
31 women, \\
ages $20-40$, \\
2 cycles/woman
\end{tabular} & $\begin{array}{l}\text { 2x/cycle (follicular } \\
\text { and luteal) }\end{array}$ & \begin{tabular}{|l|} 
no \\
$\mathrm{BBT}^{\mathrm{a}}$
\end{tabular} & \begin{tabular}{|l|l|}
$\downarrow$ luteal \\
\end{tabular} & $\downarrow$ luteal & & & $\uparrow$ luteal & \\
\hline Lebech et al., 1990 & $\begin{array}{l}37 \text { women, } \\
\text { ages } 19-36, \\
1 \text { cycle/woman }\end{array}$ & $\begin{array}{l}3 x / \text { cycle (days 6-8, } \\
12-14,24-26)\end{array}$ & \begin{tabular}{|l|} 
estradiol, \\
progesterone, LH, \\
FSH
\end{tabular} & - & - & & - & - & - \\
\hline $\begin{array}{l}\text { Lussier-Cacan et } \\
\text { al., } 1991\end{array}$ & \begin{tabular}{|l|}
18 women, \\
ages $23-38$, \\
1 cycle/woman
\end{tabular} & 9x/cycle & \begin{tabular}{|l} 
estradiol, \\
progesterone, \\
$\mathrm{LH}^{\mathrm{LH}} \mathrm{FSH}$ \\
$\mathrm{BBT}^{\mathrm{a}}$
\end{tabular} & $\begin{array}{l}\downarrow \text { menses } \\
\downarrow \text { luteal }^{\mathrm{c}}\end{array}$ & $\downarrow$ menses & & & & \\
\hline Tangney et al., 1991 & \begin{tabular}{|l}
9 women, \\
ages 24-39, \\
$2-4$ months/ \\
woman
\end{tabular} & $\begin{array}{l}\text { 5x/month (days } 1- \\
5,7-10,13-17,19- \\
22,25-\text { menses) }\end{array}$ & \begin{tabular}{|l|} 
estradiol \\
\end{tabular} & $\begin{array}{l}\text { nadir menses, peak } \\
\text { ovulation }\end{array}$ & - & & & & \\
\hline
\end{tabular}

